\title{
Synthesis of axially chiral biaryl compounds by asymmetric catalytic reactions with transition metals
}

Pauline Loxq, ${ }^{\mathrm{a}, \mathrm{b}}$ Eric Manoury, ${ }^{\mathrm{a}, \mathrm{b}}$ Rinaldo Poli, ${ }^{\mathrm{a}, \mathrm{b}, \mathrm{c}}$ Eric Deydier ${ }^{\mathrm{a}, \mathrm{b}, \mathrm{d}, *}$ and Agnès Labande ${ }^{\mathrm{a}, \mathrm{b}, *}$

${ }^{a}$ CNRS, LCC (Laboratoire de Chimie de Coordination), 205 route de Narbonne, BP 44099, F-31077 Toulouse Cedex 4, France.

${ }^{b}$ Université de Toulouse, UPS, INPT, F-31077 Toulouse Cedex 4, France.

${ }^{c}$ Institut Universitaire de France, 103, bd Saint-Michel, 75005 Paris, France.

${ }^{d}$ IUT A Paul Sabatier, Departement de Chimie, Avenue Georges Pompidou, CS 20258, F81104 Castres Cedex, France

Dedicated to the memory of our colleague and friend Guy Lavigne (1947-2015).

\begin{abstract}
Axially chiral biaryl structures are unique systems encountered in various synthetic compounds such as BINAP and BINOL, polymers, but also in natural products presenting a pharmaceutical interest such as Vancomycin, Steganacin or Korupensamine. The axial chirality of these products, so-called atropisomerism, is induced by the restricted rotation around the aryl-aryl bond. This review will summarize the different strategies imagined by chemists to control such chirality, focusing on asymmetric catalytic processes with transition metals. Only transition metal complexes bearing chiral ligands will be considered and the core of this review will consist of the enantioselective coupling of two achiral substrates.
\end{abstract}

\section{Keywords}

Axial chirality - biaryls - asymmetric catalysis - transition metals - atropisomerism 


\section{Highlights}

1. A review on the synthesis of axially chiral biaryls by asymmetric catalysis

2. Exhaustive description of chiral ligands used in the palladium-catalyzed SuzukiMiyaura cross-coupling reaction

3. Emerging reactions such as asymmetric direct $\mathrm{C}-\mathrm{H}$ functionalization are presented

4. Asymmetric $[2+2+2]$ cycloadditions catalyzed by group 9 transition metals are included

\section{Contents}

\section{Introduction}

2. Kumada-Tamao-Corriu cross-coupling reaction

\section{Suzuki-Miyaura cross-coupling reaction}

3.1 Mechanism

3.2 An overview of chiral ligands

3.2.1 P,X Ligands with axial chirality

a) $P, P$ ligands with axial chirality

b) $P, N$ ligands with axial chirality

c) P,O ligands with axial chirality

3.2.2 P,X ligands with planar chirality

a) $P, P$ ligands with planar chirality:

b) $P, N$ ligands with planar chirality:

c) $P, O$ ligands with planar chirality:

d) $P$, aryl ligands with planar chirality

3.2.3 P ligands with other types of chirality

a) Monophosphorus ligands

b) Bidendate P,X ligands

3.2.4 N,N ligands

3.2.5 NHC ligands

3.2.6 Other ligands

3.3 Conclusion

4. Negishi cross-coupling reaction

5. Direct C-H functionalization

6. Oxidative couplings 
6.1 Enantioselective synthesis of 1,1'-bis-2,2'-binaphthols.

6.1.1 Copper-based reactions

6.1.2 Reactions with other metals

6.2 Enantioselective polymerization of naphthols.

6.2.1 Copper-based reactions

6.2.1 Polymerizations with other metals

6.3 Conclusion

7. $[2+2+2]$ Cycloadditions

7.1 Co catalysts

7.2 Ir catalysts

7.3 Rh catalysts

7.3.1 Axially chiral biaryls

7.3.2 Axially chiral heterobiaryls

7.4 Conclusion

\section{General conclusion}




\section{1 - Introduction}

In the world of chemical synthesis, asymmetric catalysis is probably one of the most challenging synthetic tool, one of the most demanding in terms of ligand and catalyst design, understanding of mechanism, and optimization of reaction conditions. Mainly boosted by the growing demand of pharmaceutical, agrochemical and perfume industries, asymmetric catalysis has attracted increasing interest during the last decades.

As reported in chemistry textbooks, a molecule is chiral if it is not superimposable with its mirror image. Such a property can be acquired by the presence of central chirality, planar chirality or axial chirality in molecules, the latter of which being encountered in substituted allenes, ortho-substituted biaryls or even rotationally hindered aryl amides.

The axial chirality of the biaryl products is induced by the restricted rotation around the aryl-aryl bond, so-called atropisomerism. To exhibit such chirality, there must be at least three ortho substituents about the biaryl axis. Atropisomerism is encountered in various synthetic compounds such as BINAP and BINOL, but also in natural products presenting a pharmaceutical interest such as Vancomycin, Steganacin or Korupensamine A (Figure 1.1), underlining the need to develop efficient strategies toward their synthesis in optically pure form.

The atroposelective synthesis of axially chiral biaryl compounds has been highlighted in a few recent reviews $[1,2,3]$, but contrarily to those, ours will focus exclusively on the generation of axially chiral biaryl structures by means of asymmetric catalytic reactions with transition metals. The present review is meant to give a comprehensive contribution to the field as it includes, to our knowledge, all the references that appeared in the relevant areas from the first report up to the end of 2014. Only transition metal complexes bearing chiral ligands will be considered, therefore the core of this review will consist of the enantioselective coupling of two achiral substrates. Less numerous examples of diastereoselective coupling will also be reported. 
This review will be divided into seven parts, each focusing on a different type of coupling reaction with its characteristic features and limitations, and with an emphasis on the different types of chiral ligands described in the literature. 


\section{2 - Kumada-Tamao-Corriu cross-coupling reaction}

The availability and ease of synthesis of organomagnesium halides made them attractive reagents for cross-coupling reactions with organohalides and the first transition metal-catalyzed C-C coupling reaction involving a Grignard reagent was described in 1971 by Kochi and Tamura with iron(III) salts [4], followed independently in 1972 by Kumada and Tamao and by Corriu and Masse for nickel [5,6]. Since then, both nickel and palladium catalysts have been used, however the greater reactivity and lower cost of nickel made it the metal of choice for this reaction [7]. In 1975, Tamao and Kumada used a chiral phosphine ligand with nickel to couple ortho-substituted aryl Grignard reagents with aryl halides and thus reported the first synthesis of axially chiral binaphthyls by a TM-catalyzed asymmetric cross-coupling reaction between 1-bromo-2-methylnaphthalene and 2-methyl-1-naphthylmagnesium bromide (Scheme 2.1) [8]. In the achiral version of the reaction, they already noted that chlorobenzene reacted very sluggishly compared to its bromide analogue and that yields were much better when the bulky substituents were borne by the Grignard reagent rather than the aryl halide. Finally, a triphenylphosphine ligand appeared more efficient than bidentate diphosphines. In the first asymmetric version of the reaction, $1 \mathrm{~mol} \%$ of a nickel complex bearing the optically pure bidentate diphosphine $(R, R)$-(-)-diop (1) (Figure 2.1) was used. The reaction proceeded at room temperature and allowed the synthesis of enantioenriched 2,2'-dimethyl-1,1'-binaphthyl in 32\% yield, however with very low enantioselectivity (1.9\% ee reported). The use of ferrocenyl bidentate ligand $(S)-(\mathrm{p} R)$-BPPFA (3), described by Hayashi and Kumada the previous year [9], allowed to get the product with a slightly improved enantioselectivity (4.6\% ee) [8]. In 1977, the use of axially chiral diphosphine (S)-(-)-NAPHOS-(1,1) (5) under similar conditions furnished 2,2'-dimethyl-1,1'-binaphthyl with $12.5 \%$ ee [10].

The first efficient catalytic system, however, was only reported in 1988 by Hayashi and Ito with the use of optically pure ferrocenyl ligand $(S)-(\mathrm{p} R)$-PPFOMe (4a) (Scheme 2.2) [11]. 
Thus several binaphthyls were obtained with up to $95 \%$ ee and $69 \%$ yield (for 2,2'-dimethyl1,1'-binaphthyl) using 5 mol\% of chiral nickel catalyst. Again, nickel complexes bearing monodentate phosphines revealed themselves more active than those with bidentate diphosphines (BINAP, 6) or phosphine-amines $((S)-(\mathrm{p} R)$-PPFA, 2) and more than palladium complexes. The substitution pattern on both substrates proved important since the coupling product was obtained in $84 \%$ yield and $80 \%$ ee, in $16 \mathrm{~h}$ at $-10^{\circ} \mathrm{C}$ and $2 \mathrm{~mol} \%$ catalyst, when the methyl group was situated on the Grignard reagent, whereas only $25 \%$ yield and $16 \%$ ee were reached in $98 \mathrm{~h}$ with the methyl group placed on the naphthyl bromide, under otherwise identical conditions. The authors put forward the coordination of the oxygen atom of the ferrocenyl ligand to the magnesium in the Grignard reagent at the transmetalation step to explain the high enantioselectivity levels. The production of racemic 2-methyl-1,1-binaphthyl with the use of ligand $\mathbf{4 c}$, that lacks the methoxy group on ferrocene, goes in favor of this argument.

The use of chiral bidentate ligands was further explored by Frejd et al., with the new axially chiral diphosphine BIPHEMP (7, Figure 2.1), and its efficiency was compared to that of BINAP (6) in the palladium-catalyzed cross-coupling of aryl halides with aryl Grignard reagents [12]. BIPHEMP, associated to a palladium salt (1 mol\%), proved to be more active than BINAP which gave the binaphthyl product with a maximum of $13 \%$ yield and $13 \%$ ee. However on the whole, low to moderate ees (up to 45\%) and yields (29-52\%) were obtained bearing bidentate BIPHEMP, whatever the substrate and solvent used, confirming the idea that bidentate diphosphine ligands are not the most adapted ligands for this reaction. The use of $\mathrm{NiCl}_{2}$ instead of $\mathrm{Pd}(\mathrm{acac})_{2}$ with BIPHEMP gave even worse results, with only $7 \%$ yield and $6 \%$ ee of 2,2' -dimethyl-1,1'-binaphthyl.

Very recently, Dorta et al. reported for the first time the use of a chiral, monodentate Nheterocyclic carbene ligand for the palladium-catalyzed asymmetric Kumada-Tamao-Corriu 
reaction, showing the potential of these ligands for yet another catalytic asymmetric transformation (Scheme 2.3) [13]. The palladium complex (aS,aS)-10 (2 mol\%) showed good activity with a moderate enantioselectivity (48\%) for the coupling of 1-bromonaphthalene with 2-methoxy-1-naphthalenylmagnesium bromide at room temperature in toluene, while $50^{\circ} \mathrm{C}$ were required when the methoxy substituent was placed rather on the naphthyl bromide, with a subsequent loss of activity and enantioselectivity. Aryl chlorides could be used without loss of selectivity, albeit with a lower yield for the bulkier naphthyl substrate.

Axially chiral, enantioenriched biaryl compounds are classically prepared by the coupling of two aryl substrates and thus creation of the new C-C bond along the chiral axis. An alternative method, based on the selective substitution of an enantiotopic triflate leaving group in ortho position of an achiral biaryl structure, has been developed by Hayashi et al. in the late nineties (Scheme 2.4) [14]. This procedure presents the advantage of producing functionalizable biaryls, which can be used as valuable chiral building blocks. However, it requires the synthesis of achiral biaryl ditriflates, which are obtained in three steps including a classical Suzuki-Miyaura coupling between a diortho-subsituted aryl halide and an ortho-substituted arylboronic acid. The method allowed the successful preparation of enantioenriched biaryls with up to $95 \%$ ee and excellent yields of the monophenylation product in the presence of a chiral palladium catalyst and $\mathrm{LiBr}$ or LiI as additive. Although the role of the additive is not clearly stated, its presence proved essential both for activity and enantioselectivity. The use of LiCl under similar conditions was suggested, among other things, to prevent the formation of oligomeric aggregates of the Grignard reagent [15]. Irrespective of the enantioselectivity levels, the best catalysts in terms of activity were those bearing bidentate $\mathrm{P}, \mathrm{N}$ ligands, particularly $\beta$ (dimethylamino)alkyldiphenylphosphines (13, Figure 2.1). For the latter, ligands with small alkyl groups gave the best ees. Phosphine-oxazoline $i \operatorname{Pr}-\operatorname{PHOX}(\mathbf{1 1})$ and $(S)-(\mathrm{p} R)$-PPFA (2) were active but furnished the expected product in moderate yields and respectively low to no 
ees, whereas the monophosphine $\mathrm{MeO}-\mathrm{MOP}(9)$ and, again, chelating diphosphines like DIOP (1) and BINAP (6) were almost inefficient, giving very low yields of the products.

Finally, a third type of catalytic cross-coupling involving Grignard reagents has been described by Hayashi et al. In this case, the axial chirality is generated after the cleavage of a C-S bond in a thiophene ring. In 1979, Wenkert had reported that thiophenes could participate in nickel-catalyzed cross-couplings [16]. Hayashi et al. developed an asymmetric version, and thus the reaction of a Grignard reagent on a dibenzo- or a dinaphthothiophene, in the presence of a chiral nickel catalyst, gave rise to chiral mercapto-substituted 1,1'-biaryl structures that can be further functionalized (Scheme 2.5) [17]. Palladium complexes, however, proved unable to perform the transformation. The presence of substituents at the 1- and 9- positions of dibenzothiophene is necessary to prevent the rotation around the chiral axis and thus racemization of the biaryl product. In the case of dinaphthothiophene, considered as an achiral molecule because of the rapid flipping at room temperature, the opening of the thiophene ring by reaction with a Grignard reagent is expected to generate a configurationally stable binaphthyl. The reactivity of the various substrates seemed to depend on the torsion angle of the thiophene ring: the larger it is, the more reactive the substrate. So the 1,9-dibenzothiophene was the most reactive of this series, while dinaphthothiophene needed a smaller amount of nickel catalyst and a lower temperature to undergo the cross-coupling reaction. The mechanism follows the classical steps of nickel-catalyzed cross-coupling reactions, i.e. oxidative addition, transmetalation and reductive elimination, and the enantio-determining step is believed to take place at or after the transmetalation. Several chiral ligands were evaluated in this transformation. Similarly to the cross-coupling reactions mentioned earlier, monophosphine MeO-MOP (9) and diphosphine BINAP (6) furnished the expected products in reasonable to good yields, albeit with low to very poor ees, and the ferrocenyl-based $(S)$-(pR)-PPFOMe (4a) proved no better. $(S)$-phephos $(\mathbf{1 3 b})$, one of the best ligands for the selective substitution of an 
enantiotopic triflate leaving group [14], gave in this case active catalysts but poor results in terms of enantioselectivity. Surprisingly, the choice for the best ligand was very substratedependent: whereas the $(S)$-H-MOP (8a) ligand and its derivatives gave very good yields and high levels of enantioselectivity for the transformation of dibenzothiophenes, its use for the reaction of 4-tolylmagnesium bromide with dinaphthothiophene furnished the 1,1'-binaphthyl product with only $14 \%$ ee. On the other hand, the use of phosphine-oxazolines proved futile for the reaction of 4-tolylmagnesium bromide with dibenzothiophene, while they provided the best catalysts for the transformation of dinaphthothiophene, giving the expected product with high yields and enantioselectivities. This new route is particularly interesting in the sense that it allows access to a wide range of functionalized axially chiral biaryls. However, a limitation arises with the preparation of 1,9-substituted dibenzothiophenes, which requires six synthetic steps (against two for dinaphthothiophene).

Compared to other C-C coupling reactions such as Suzuki-Miyaura, Negishi or Hiyama reactions, the (asymmetric) Kumada-Tamao-Corriu reaction has been less investigated, despite the interesting results obtained by Hayashi in the late 80 s and the low cost of nickel compared to palladium, and suffered from the low tolerance of the organomagnesium species to other functional groups. However, since the pioneering works of Knochel on functionalized Grignard reagents [18], new perspectives have emerged and the full potential of this $\mathrm{C}-\mathrm{C}$ coupling reaction remains to be exploited, especially in its asymmetric version. 


\section{3 - Suzuki-Miyaura cross-coupling reaction}

Amongst the different strategies to synthesize biaryl compounds [19,20], several palladium-catalyzed cross-coupling reactions, such as Hiyama, Kumada-Tamado-Corriu, Negishi or Suzuki-Miyaura have demonstrated good efficiency [21]. However, the SuzukiMiyaura cross-coupling of a $\mathrm{C}\left(\mathrm{sp}^{2}\right)$-halide or $\mathrm{C}\left(\mathrm{sp}^{2}\right)$-triflate with a $\mathrm{C}(\mathrm{sp} 2)$-boronic acid or boronic ester is probably the most powerful tool [22,23,24,25,26,27]. Indeed, since its discovery in 1979 [28], this reaction has attracted a lot of attention. A SciFinder search with the keywords "Suzuki-Miyaura cross coupling", conducted in April 2015, revealed more than 1500 documents dealing with the subject. The great impact of this reaction is explained by its high tolerance to a wide variety of functional groups, by its efficiency under mild conditions with aryl halides in different media (solvent free conditions [29], PEGs [30], ionic liquids [31], water [32]), by its adaptability to different processes (microwave and microtechnologies [33], continuous flow [34,35], etc.), and by the high thermal stability of the boronic acid coupling partners which are easy to synthesize (numerous structures are commercially available), stable to oxygen and water, allowing their handling without special precautions. Moreover, the recent development of new catalysts has expanded the application scope from academic areas (natural products synthesis, materials design...) to industrial large-scale synthesis [36,37]. Several classes of ligands, such as ferrocenyl phosphines, dialkylphosphines with a biaryl backbone and $\mathrm{N}$-heterocyclic carbenes have been developed to optimize the activity and efficiency of the catalysts [26-37,38,39].

Three different strategies have been reported in the literature to induce axial chirality using Suzuki-Miyaura reactions: (i) planar-to-axial induction [40,41,42], (ii) central-to-axial induction $[43,44,45,46]$ and (iii) chiral ligand induction (Scheme 3.1) [47]. However, the first two strategies (diastereoselective synthesis) require a chiral substrate (planar or central chirality) which is quite restrictive in terms of substrate availability. In the last one 
(enantioselective synthesis), the chirality is directly transferred to the product by the catalyst bearing a chiral ligand, offering then a more general pathway.

Axial chirality has also been induced using dynamic kinetic techniques and in this domain, two examples were reported to date, i.e. a Suzuki-Miyaura cross-coupling [48] and a C-P coupling [49], with interesting levels of enantioselectivity. Although the second example is not a SuzukiMiyaura reaction, the strategy employed is closely related and will therefore be reported in this section.

The first diastereoselective Suzuki-Miyaura reactions involving aryl halides bearing chiral auxiliaries were described in the mid-nineties and axially chiral biaryls were synthesized in high yields and excellent diastereoselectivities (up to 99\%) [40-46]. As an illustrative example, in 1999, Nicolaou investigated the diastereoselective synthesis of a model system as part of the total synthesis of Vancomycin via a palladium-catalyzed asymmetric Suzuki-Miyaura coupling using chiral phosphines [45].

In 2000, Cammidge [50] and Buchwald [51] published almost simultaneously the first examples of palladium-catalyzed enantioselective Suzuki-Miyaura coupling using chiral ligands. Since these pioneering works, the enantioselective version of the reaction has received an increasing attention, emphasized by the publication of several reviews [47,52], and various asymmetric ligands have been developed to this aim. This section reports the works and progress realized in this field up to the end of 2014. After a few general considerations on the proposed catalytic cycle, we will focus on the ligand structure and chirality, comparing activities and selectivities for the coupling of achiral substrates.

\subsection{Mechanism}

This reaction is commonly described in the literature by two standard catalytic cycles that differ according to the nature of the palladium intermediate, neutral or anionic [39]. Both cycles 
involving $\mathrm{Pd}(0) / \mathrm{Pd}(\mathrm{II})$ complexes are commonly accepted by the scientific community and have been widely explored in experimental [22] and computational $[53,54,55]$ studies. They can be described by three successive main steps: oxidative addition $[56,57,58,59]$, transmetalation $[60,61,62,63]$ and reductive elimination $[64,65,66]$ (the catalytic cycle involving the neutral intermediate is represented in Scheme 3.2). The starting point of both cycles is a $\operatorname{Pd}(0)$ species, suggesting that when a palladium(II) precatalyst is used, its reduction should occur first, as the oxidative addition of an aryl halide to a $\mathrm{Pd}(\mathrm{II})$ compound is not favored. Various palladium(II) reduction pathways using an excess of phosphine ligand [67] (oxidized to phosphine oxide) or alcohols (oxidized to aldehydes) [30] have been reported $[22,68,69,70]$.

The first step of the cycle is the oxidative addition of the 1-alkenyl, 1-alkynyl, allyl or aryl halide (or triflate) to the palladium(0) complex giving rise to a palladium(II) intermediate. All of these substrates present a $\mathrm{C}\left(\mathrm{sp}^{2}\right)$-X functionality with a relative reactivity decreasing in the order $\mathrm{X}=\mathrm{I}>\mathrm{OTf}>\mathrm{Br}>\mathrm{Cl}[22]$. This is mainly due to thermodynamic reasons as the exothermicity of the reaction increases along the series $\mathrm{Cl}<\mathrm{Br}<\mathrm{I}$ [56]. Considered as the limiting step of the cycle, various ligand structures have been explored in order to increase the efficiency of the catalysts. Among them, sterically hindered electron-rich ligands such as ferrocenyl monophosphines, Buchwald-type biaryldialkylphosphines [71] or carbenes, favoring monocoordination, increase the rate of this first step [52]. Maseras and coworkers confirmed by DFT computational studies on mono and diphosphine palladium systems (PdL and $\mathrm{PdL}_{2}$ ) that the oxidative addition was thermodynamically and kinetically more favorable for the monophosphine derivative [53]. Indeed, the less saturated PdL system is more prone to increase by 2 its coordination number than the $\mathrm{PdL}_{2}$ system. This is also consistent with the fact that bulky electron-rich ligands, favoring monocoordinated complexes (PdL), give more active catalysts toward the oxidative addition of challenging substrates such as aryl chlorides. 
Experimental and computational contributions have shown that the oxidative addition of aryl halides to $\mathrm{PdL}_{2}$ is a concerted process leading to cis square planar $\mathrm{PdX}(\mathrm{Ar}) \mathrm{L}_{2}$. However, transmetalation is usually considered to take place from the trans square planar complex, suggesting that an isomerization should take place before the transmetalation step. Computational studies on a $\mathrm{PdX}(\mathrm{Ar}) \mathrm{L}_{2}$ model $\left(\mathrm{Ar}=\mathrm{C}_{2} \mathrm{H}_{3}\right.$ and $\left.\mathrm{L}=\mathrm{PH}_{3}\right)$ have shown that even if the direct isomerization (through an unstable tetrahedral $\mathrm{d}^{8}$ complex) is energetically consistent (around $20 \mathrm{kcal} / \mathrm{mol}$ ), there is an alternative, less energetically demanding pathway (<6 kcal/mol) involving phosphine dissociation or other ligand coordination (such as $\mathrm{OH}-$ ) $[53,60]$. These results indicate that the isomerization step should not be a critical barrier for the overall process. Moreover it was also shown that with this simple model, transmetalation could occur both from cis or trans complexes. Similar computational observations were reported by Goossen, Thiel and co-workers starting from cis- $\left(\mathrm{CH}_{3} \mathrm{CO}\right) \mathrm{Pd}(\mathrm{OAc})\left(\mathrm{PMe}_{3}\right)_{2}[54,57]$.

Ligand hemilability is another important point to consider in ligand design strategies as it has been demonstrated that it presents a strong positive action on Suzuki-Miyaura reactions. Indeed, the presence in the same ligand of a strongly coordinating atom, such as phosphorus, and a weakly basic ether functional group, for example, promotes a facile switchable protection and deprotection of the metal center (coordination flexibility) whatever the mechanism involved. For example, working on ferrocenyl dicyclohexyphosphines, Hor et al. observed that the 1,1 '-ferrocenyl phosphine/ether was much more active in the Suzuki-Miyaura coupling of aryl chlorides than the corresponding 1,1'-ferrocenyldiphosphine or the monoferrocenylphosphine $[72,73]$. This is why ligands presenting both a phosphorus and an oxygen atom, with a geometry allowing a bidendate $\mathrm{P}, \mathrm{O}$ coordination, will be considered here as $\mathrm{P}, \mathrm{O}$ ligands instead of monophosphine ligands.

A remarkable ligand effect in the palladium-catalyzed coupling of chloroaryl triflates with ortho-methylphenyl boronic acid was reported Fu et al. (Scheme 3.3) [74]. The nature of the 
phosphine $\left(\mathrm{P} \mathrm{Bu}_{3}\right.$ or $\left.\mathrm{PCy}_{3}\right)$ allows controlling the reaction regioselectivity (oxidative addition across the C-Cl or C-triflate bond). In 2010, DFT calculations made by Schoenebeck et al. showed that $\mathrm{P} t \mathrm{Bu}_{3}$ favors a monoligated $\mathrm{PdL}$ intermediate whereas $\mathrm{PC} \mathrm{y}_{3}$ favors a bis-ligated $\mathrm{PdL}_{2}$ intermediate. Regioselectivity is controlled by the distortion energy for monoligated PdL which reacts with the weakest bond $(\mathrm{C}-\mathrm{Cl})$. On the contrary, the selectivity is controlled by the strongest interaction (Pd-chloroaryltriflate) in the transition state with $\mathrm{PdL}_{2}$ [75]. One year later they highlighted the role of the solvent on the selectivity of this reaction, observing that polar solvents stabilized monoligated PdL intermediates, and so oxidative addition across the C-Cl bond [76].

Contrary to the other steps of the catalytic cycle, the transmetalation reaction is specific to cross-coupling reactions. Although oxidative addition and reductive elimination are well understood, transmetalation still needs to be explored as this reaction is highly dependent on numerous factors such as the reaction conditions, ligand nature, base nature, etc. At this step, the aryl substituent of the boronic compound is transferred onto palladium, however this transfer cannot occur spontaneously due to the low nucleophilicity of the organic group on the boron atom (experimental observations showed that the reaction is favored when the aryl substituent bound to the boron atom possesses electron donating groups) [22,39]. Two different hypothetical pathways were proposed and studied by computational methods (Scheme 3.4), both of them requiring the action of a $\mathrm{RO}^{-}$base $(\mathrm{R}=\mathrm{H}$, alkyl). The first one is the substitution by $\mathrm{RO}^{-}$of the halogen on the $\mathrm{L}_{\mathrm{n}} \mathrm{Pd}(\mathrm{X}) \mathrm{Ar}$ palladium intermediate, formed after the oxidative addition of the aryl halide, giving rise to $\mathrm{L}_{n} \mathrm{Pd}(\mathrm{OR}) \mathrm{Ar}$ (Scheme 3.4 - pathway $\left.\mathrm{A}\right)$. In this case, the transfer is favored by the high boron oxophilicity (Figure 3.1). This is supported by experimental evidence of aryl transfer from the organoboron compound to the palladium complex bearing alkoxy ligands without any base [39]. The second hypothesis is the addition of the base $\left(\mathrm{RO}^{-}\right)$to the $\left.\mathrm{Ar}{ }^{\prime} \mathrm{B}(\mathrm{OR})_{2}\right)_{2}$ boron compound, inducing its quaternization (Scheme 3.4 
- pathway B). The boronate $\left[\mathrm{Ar}{ }^{\prime} \mathrm{B}(\mathrm{OR})\left(\mathrm{OR}^{\prime}\right)_{2}\right]^{-}$, bearing a negative charge, may be more inclined to transfer the Ar' group to the palladium intermediate as experimentally observed with trialkylboranes. Computational studies carried out by Maseras et al. indicated that the transmetalation reaction is a multistep mechanism where the organoboronic acid, initially activated by the base, attacks the palladium as an organoboronate anion (Scheme 3.4 - pathway B is favored) $[60,61,77]$.

However, Amatore and Jutand, studying the Suzuki-Miyaura mechanism by electrochemistry, demonstrated that the role of the base was much more subtle (Scheme 3.5) $[78,79,80]$. Based on kinetic experiments they observed that the base $\left(\mathrm{OH}^{-}\right)$is essential and may play at least three roles. Two of them present a positive action on the reaction, promoting the transmetalation and reductive elimination steps whereas the last one, i.e. the formation of a boronate anion $\left[\mathrm{Ar}{ }^{\prime} \mathrm{B}(\mathrm{OH})_{3}\right]^{-}$, shows a negative effect. The reaction rate increases with the base concentration, as the addition of $\mathrm{OH}^{-}$to $\mathrm{L}_{2} \mathrm{Pd}(\mathrm{X}) \mathrm{Ar}$ gives rise to $\mathrm{L}_{2} \mathrm{Pd}(\mathrm{OH}) \mathrm{Ar}$, a more reactive compound for the transmetalation step (pathway A - Scheme 3.4). However, at high concentrations, the reaction slows down because of the low $\operatorname{ArB}(\mathrm{OH})_{2}$ concentration, consumed by the formation of the poorly active $\mathrm{Ar}^{\prime} \mathrm{B}(\mathrm{OH})_{3}{ }^{-}$species. The base concentration may be adjusted to find a compromise between the two base-dependent ratios $\mathrm{L}_{2} \mathrm{Pd}(\mathrm{X}) \mathrm{Ar} / \mathrm{L}_{2} \mathrm{Pd}(\mathrm{OH}) \mathrm{Ar}$ and $\mathrm{Ar}^{\prime} \mathrm{B}(\mathrm{OH})_{3}{ }^{-} / \mathrm{Ar}{ }^{\prime} \mathrm{B}(\mathrm{OH})_{2}$. Various bases such as sodium carbonate, potassium carbonate or $\mathrm{CsF}$ are reported in the literature and in a recent paper, Amatore, Jutand et al. observed a similar behavior with fluoride anions. Thus the addition of $\mathrm{F}^{-}$favors the reductive elimination and increases the reaction rate. However, fluoride ions also have a negative impact, as their addition to boronic acids produce less reactive $\operatorname{Ar}^{\prime} \mathrm{BF}_{\mathrm{n}}(\mathrm{OH})_{(3-\mathrm{n})^{-}}$compounds. But interestingly, the reaction is less sensitive to high fluoride concentrations than to high hydroxide concentrations, probably because of the high boron oxophilicity. Finally, the base $\left(\mathrm{Z}^{-}=\mathrm{OH}^{-} \mathrm{F}^{-}\right)$promotes the reductive elimination step, as its coordination to neutral $\mathrm{Pd}(\mathrm{Ar})\left(\mathrm{Ar}^{\prime}\right) \mathrm{L}_{2}$ produces an anionic 
palladium intermediate, $\left[\mathrm{Pd}(\mathrm{Z})(\mathrm{Ar})\left(\mathrm{Ar}^{\prime}\right) \mathrm{L}_{2}\right]^{-}$, more prone to liberate the biaryl product by reductive elimination.

Despite the numerous papers published on the mechanism of the Suzuki-Miyaura reaction, its full understanding remains a challenge as many experimental results point out unanswered questions and new directions to explore [63]. Indeed, the activity and selectivity of this reaction are very sensitive to the reaction conditions (metal precursor, solvent, base, ligand structure) and the complexity is even higher when chirality transfer is taken into account. If it is commonly accepted that the chirality transfer occurs at the transmetalation and reductive elimination steps, the intimate mechanism remains obscure. However some progress in understanding has been made in the last ten years and the results will be discussed in the following parts of this review.

\subsection{An overview of chiral ligands}

We present here an historical overview of the different ligands used in the asymmetric Suzuki-Miyaura reaction. In order to facilitate the comparison between the various studies on the subject, we will categorize ligands on the basis of their chemical nature (most of them are phosphine ligands) and of the type of chirality (axial, planar, and central).

\subsubsection{P,X Ligands with axial chirality}

Since the pioneering work of Cammidge and Buchwald on the enantioselective SuzukiMiyaura coupling [50,51], various ligands presenting an axial chirality have been reported in the literature. Most of them are P,P (Figures 3.2), P,N (Figures 3.3) or P,O (Figures 3.4) bidendate ligands and present a binaphthyl backbone.

a) P,P ligands with axial chirality 
Cammidge et al. reported in 2000 the first use of a diphosphine in the synthesis of chiral binaphthalenes (Scheme 3.6) [50,81]. A maximum of $25 \%$ ee (55\% yield) was reached after 17 h with BINAP (6), $\mathrm{Ba}(\mathrm{OH})_{2}$ as base and 3 mol.\% of $\mathrm{PdCl}_{2}$ in $\mathrm{DME}-\mathrm{H}_{2} \mathrm{O}$. As observed with other reactions involving hindered partners, the reaction competes with deboronation. Interestingly, they observed opposite enantiomers depending on the nature of the boronate (pinacol- versus ethylene glycol boronate esters), concluded that the reaction is operating under kinetic control and that the transmetalation reaction may be an important step for controlling the products symmetry.

A few months later Buchwald et al. reported a similar ee (22\%) using the $\operatorname{Pd}_{2}(\mathrm{dba})_{3}$ precursor (2 mol\%) with BINAP (6) $(2.4 \mathrm{~mol} \%)$ and $\mathrm{K}_{3} \mathrm{PO}_{4}$ (2 equiv.), in toluene at $70^{\circ} \mathrm{C}$, for the coupling of the $o$-nitrophenyl bromide with 1.5 equivalents of naphthylboronic acid bearing a phenyl at the 2-position [51].

Studying the coupling of 2-methoxy-1-naphthylboronic acid and 1-iodo-2methoxynaphthalene (Scheme 3.7) in DME or dioxane with CsF as a base and BINAP (6), Colobert et al. reported slightly higher ees (14 - 30\%) and yields (up to 94\%) in only 3-6 hours, albeit with 10-20 mol\% of palladium [82]. The use of CsF in an anhydrous solvent neutralized the deboronation reaction. In addition, using $\mathrm{Pd}(\mathrm{OAc})_{2},\left[\left(\eta^{3}-\text { allyl }\right) \mathrm{PdCl}\right]_{2}$ and $\mathrm{Pd}_{2}(\mathrm{dba})_{3}$ they observed that the ligand/metal ratio had a significant impact on the ee. Similar reactions were run with BINAP analogs such as $\mathrm{BINAP}(\mathrm{O})$ (bearing one phosphine oxide moiety, 14) and tolBINAP (15), but both presented a lower activity than BINAP. Regarding selectivity in almost identical conditions, similar ees were obtained in the cases of BINAP and tol-BINAP, whereas the use of BINAP(O) resulted in much lower enantioselectivities.

Using a cationic palladium precursor, $\left[(\mathrm{MeCN})_{4} \mathrm{Pd}\right]\left[\mathrm{BF}_{4}\right]_{2}$ with $(S)$-BINAP $(6)\left(1: 2 \mathrm{Pd} / \mathrm{L}^{*}\right.$ ratio), Mikami et al. managed to reach $47 \%$ ee and $97 \%$ yield in only $1 \mathrm{~h}$ for the coupling of 2 methoxy-1-naphthylboronic acid with 1-bromo-2-methoxynaphthalene at $80^{\circ} \mathrm{C}$ in DME (Table 
3.1) [83]. They also observed that the use of a combination of the preformed cationic complex $\left[\mathrm{PdL}^{*}\right]\left[\mathrm{SbF}_{6}\right]_{2}$ and the corresponding ligand $\mathrm{L}^{*}(1: 1$ ratio) allowed to increase the enantioselectivity from $47 \%$ to $56 \%$ ee in only 30 minutes. However, the potential role of the counter-anion on enantioselectivity was not discussed and cannot be completely excluded. This reaction is similar to the one reported by the group of Colobert but with a much lower amount of catalyst ( $3 \mathrm{~mol} \%$ ). Mikami et al. also investigated the influence of the phosphine substituents of BINAP ligand analogues (Figure 3.2). Aryl phosphines bearing a methyl group in position 4 (Tol-BINAP, 15) or two methyl groups in positions 3 and 5 (17) present a lower selectivity than BINAP. The best results were obtained with cyclohexyl substituents (Cy-BINAP, 16) giving rise to $70 \%$ ee and $92 \%$ yield in 1 hour at $80^{\circ} \mathrm{C}$ in DME (Table 3.1, entry 1 ). The ee rose up to $84 \%$ at $\mathrm{rt}$ but in this case, the kinetics was much slower and the yield dropped to $17 \%$ after $6 \mathrm{~h}$. The influence on both activity and selectivity of the ortho substituent on 1-bromonaphthalene was also studied (Table 3.1, entries 3-6). The amino group has a negative impact on the reaction kinetics (more important in the case of Cy-BINAP than that of BINAP) compared to alkoxy groups, probably due to its electron donating effect which does not favor the oxidative addition step. One can also notice that the ees obtained with these substrates in the presence of BINAP are slightly higher than the ees reported in previous works using 1-bromonaphthalene or 1bromo-2-methylnaphthalene, suggesting that polar alkoxy groups on the bromo halide could play a positive role on the control of enantioselectivity.

In 2013, Donohoe et al. investigated the efficiency of BINAP-type $(\mathbf{6}, \mathbf{1 5}, \mathbf{1 7})$ and SEGPHOS-type $(\mathbf{1 8}, \mathbf{1 9 a}, \mathbf{1 9 b})$ ligands in one step of the total synthesis of antitumor, antibiotic $( \pm)$-Streptonigrin involving an asymmetric Suzuki-Miyaura coupling reaction, but the results showed moderate yields (15-65\%) and low ees (13-36\%) [84].

Interestingly, the best activities and selectivities obtained with BINAP (6) were reported in 2008 by Fujihara et al. who used various bisphosphine ligands as Pd nanoparticle (Pd NPs) 
stabilizers [85]. When the asymmetric coupling of 1-bromo-2-methoxynaphthalene with naphthylboronic acid was carried out at room temperature in a DME/water (9/1) mixture, the reaction was remarkably influenced by the nature of the protective ligand, even though the chiral Pd NPs had similar diameters $(1.2-1.7 \mathrm{~nm})$. Using $(S)$-BINAP-Pd NPs, the most effective system, a dramatic effect of the base (Table 3.2) on both yields (42-96\%) and enantioselectivities $(18-74 \%)$ was observed. These results underline the question of the real nature of the active species in enantioselective Suzuki-Miyaura coupling: molecular compound or nanoparticles [39].

One year later Yamashita et al. reported the synthesis of magnetic FePd NPs and their application in the synthesis of binaphthyl compounds by the asymmetric Suzuki-Miyaura reaction, using the BINAP ligand (6) in a DME/ $\mathrm{H}_{2} \mathrm{O}(9 / 1)$ mixture at $80^{\circ} \mathrm{C}$ for 24 hours [86]. Despite the moderate selectivities obtained (ees $<48 \%$ and yields $>99 \%$ ), the interest of this NP architecture is to combine both a chiral surface to promote asymmetric catalysis and magnetic properties to allow an easy catalyst recycling.

\section{b) $P, N$ ligands with axial chirality}

The first P,N ligands used in the asymmetric Suzuki-Miyaura coupling have been reported by Buchwald et al. in 2000 [51]. When screening the influence of the architecture of different ligands (Table 3.3), they observed that BINAP (22\% ee - reaction B) was less efficient than the analogous P,N ligand (20 - Figure 3.3) which gave $75 \%$ and $38 \%$ ee, respectively, in reactions A and B (entry 1 and 2). The best selectivity (87\% ee) was obtained with KenPhos ligand (21) in reaction A (entry 3- Table 3.3). Interestingly, the ee reached $92 \%$ using a slightly different boronic acid (2-ethylphenylboronic acid). The substitution of cyclohexyl by isopropyl groups on the phosphine had a slightly negative effect on the reaction, however poorer results were obtained with the tert-butyl phosphine analogue as none of the expected coupling product 
was observed in reaction B. Replacing the dimethylamino group by $n$-butyl (39a) or trimethoxysilyl groups (39b) (Figure 3.11, entries 6-7) resulted in a significant decrease in enantioselectivity, which remained however higher than the ee values obtained with BINAP. Toluene was a better solvent than THF, as higher ees and smaller amounts of dehalogenated compounds were observed in the former. Finally, they noted the influence of the amount of base on the activity since the use of 3 equivalents of $\mathrm{K}_{3} \mathrm{PO}_{4}$ instead of 2 allowed to complete the reactions within $24 \mathrm{~h}$ and to use very small amounts of catalyst (down to $0.2 \mathrm{~mol} \%$ against 4-10 mol\% with 2 eq. of base) without loss of enantioselectivity.

In order to get some insight into the source of enantioselectivity in this reaction, Buchwald et al. carried out in 2010 a series of stoichiometric, catalytic and computational experiments [87]. As aryl halides bearing an ortho phosphonate group allowed to reach the best ees in the presence of the $\operatorname{Pd}($ KenPhos) complex (Table 3.3, entry 3, reaction A), they were used for the synthesis of intermediates in the catalytic cycle. The complex resulting from oxidative addition of the aryl halide was isolated and characterized by X-ray diffraction (Figure 3.5). The structure analysis reveals a putative $\mathrm{Pd}-\mathrm{O}$ interaction $(\mathrm{Pd}-\mathrm{O}$ bond distance $=2.77 \mathrm{~A})$ which was speculated to be responsible for the stereoselectivity control of the reaction. Then they explored the effect of aryl halides bearing functional groups that could interact with $\mathrm{Pd}$ to induce stereocontrol of the reaction (Scheme 3.8). With an ester substituent in ortho position, the reaction presented a good activity (90\% yield at rt) but a low enantioselectivity (40\% ee). By contrast, reactions involving phosphonates or phosphine oxides afforded the expected products with higher ees (84-85\%). Computational studies carried out on the reaction of dimethyl 1bromo-2-naphthylphosphonate with $o$-tolylboronic acid in the presence of the $\mathrm{Pd}(\mathrm{KenPhos})$ complex identified 14 possible transition states for the selectivity-determining reductive elimination step. According to this study, the enantioselectivity control arises from a combination of weak hydrogen bonding interactions between the phosphonate and hydrogen 
atoms from the tolyl moiety and the ligand backbone and steric interactions between the tolyl and naphthylphosphonate groups.

Encouraged by these results, the same authors explored the synthesis of axially chiral biaryl amides starting from aryl bromides possessing an ortho amide group [87]. Excellent yields and ees in the $75-82 \%$ and $75-93 \%$ ranges, respectively, were obtained (Table 3.4) with $\mathrm{Pd}(\mathrm{OAc})_{2} / \mathrm{KenPhos}$, in $\mathrm{THF}$ at low temperature ( $\mathrm{rt}$ to $50^{\circ} \mathrm{C}$ ). The selectivity increased with the steric hindrance of the amide substituents, the best results being obtained with a cumyl substituent $\left(\mathrm{CMe}_{2} \mathrm{Ph}\right)$. Screening the influence of the cumyl amide structure, they observed that both electron-rich and electron-poor phenyl amides were well tolerated in reactions with naphthylboronic acid, with yields between 80 and 92\% and ees between 88 and 94\% (Scheme 3.9). However, the introduction of a methyl group at the 6-position $\left(\mathrm{R}^{\prime}=6-\mathrm{Me}\right)$ induced a significant drop in selectivity ( $48 \%$ ee). As the cumyl protecting group can be readily removed (TFA at rt) to produce the corresponding primary amine, this strategy offers an easy access to various axially chiral amide compounds. Notably, axially chiral heterocyclic biaryl compounds could also be prepared for the first time with this methodology, with the synthesis of a pyridine derivative (Scheme 3.10).

Baudoin et al. compared the efficiency of KenPhos (21) to that of analogous ligands (22ad) for the synthesis of intermediates of biologically relevant molecules (Scheme 3.11) [88]. In this reaction, the KenPhos ligand (21) offered the best activity/selectivity compromise (56\% yield and $40 \%$ ee). Higher ees were obtained with ligands $\mathbf{2 2 b}$ and $\mathbf{2 2 c}$ in the coupling of diethyl 1-bromo-2-naphthylphosphonate with 2-methyl-1-phenylboronic acid, underlying the influence of the reagent structure on the selectivity (Scheme 3.12). However, their activity (5$37 \%$ yield) and selectivity (77-81\% ee) still remained lower than those obtained with KenPhos (21) $(93 \%$ yield, $87 \%$ ee). 
In 2012, Qiu et al. reported the synthesis of new atropisomeric P,N ligands (23a-c - Figure 3.3) presenting an axial chirality induced by a chiral bridge [89]. A screening of the solvent, the base and the nature of the ligand for the coupling of 4-methoxy-1-naphthylboronic acid with diethyl 1-bromo-2-naphthylphosphonate was first realized (Table 3.5). Ligand 23a (Cy) presented the best activity whereas $\mathbf{2 3 b}(\mathrm{Ph})$ allowed to reach the higher selectivity (up to $82 \%$ ee). However, ligand 23c, with bulkier $t$ Bu phosphine substituents, led to both low activities and selectivities (entries 1-3). Among the different solvents, THF appeared superior to toluene, dioxane or DME (entries 3-6). Encouraged by these results, they studied the influence of differently substituted phenyl- or naphthylboronic acids and different 1-bromo-2naphthylphosphonates in THF. With ligands $\mathbf{2 3 a - b}$, activities in the 55-98\% range and good selectivities (48-82\% ee) were obtained.

\section{c) $P, O$ ligands with axial chirality}

The commercial MOP ligand (9) was one of the first P,O ligands applied in the atroposelective Suzuki-Miyaura synthesis of biaryl intermediates of biologically relevant molecules by Baudoin et al. in 2003 (Scheme 3.11), but the selectivity remained lower (51\% yield and 7\% ee) than with the P,N KenPhos ligand (21) (56\% yield and $40 \%$ ee).

More recently (2011) Dai et al. prepared a series of original atropisomeric naphthylamidederived phosphines which possess a hemilabile character (24a-d, Figure 3.4) [90]. The structure and absolute configuration of ligand $(\mathrm{a} R)$-24d were determined by X-Ray diffraction analysis. 24c and 24d allowed reaching chiral biaryl compounds with good yields (> 95\%) and enantioselectivities (72-84\% ee) under mild conditions (Scheme 3.13).

In 2012 Qiu et al. synthesized a series of P,O chiral-bridged atropisomeric phosphines (25a-g - Figure 3.4) which gave good results in the synthesis of diethylphosphonate-substituted binaphthyls [91]. Under optimized conditions (Scheme 3.14), very good selectivities were 
obtained (71-88\% ee), higher than with MOP (9) (46\% ee) or KenPhos (21) (57\%). 25d was the most efficient ligand of this family and its use allowed reaching excellent yields (92-98\%) and ees (78-97\%) with several boronic reagents at only $20^{\circ} \mathrm{C}$ in toluene $(120 \mathrm{~h})$. Various catalysts proved efficient in the asymmetric Suzuki-Miyaura synthesis of substituted biaryl compounds. However, the process efficiency strongly depends on the nature of the aryl group substituents and most of them involve phosphonate, nitro, alkoxy or alkyl groups which limits the possibilities of further transformations. In order to enlarge the scope of accessible chiral biaryls products, Qiu et al. investigated the synthesis of multifunctionalized axially chiral biaryls having either a phosphonate or nitro group and a formyl group (versatile functional group in organic synthesis) or alkoxy group at the C2/C2' positions (Schemes 3.15 and 3.16) [92]. The ligands (25-27) and reagents were first screened to determine the best conditions in order to explore the influence of aryl halide and aryl boronic acid substituents on both activity and enantioselectivity. The best results were obtained in toluene at $50^{\circ} \mathrm{C}$ using ligand $25 \mathrm{~h}$ or electron-rich phosphines (26 and 27) analogous to the MOP ligand (9). Ligand 26 (CyMOP) gave the best results with $93 \%$ yield and $96 \%$ ee for the coupling of diethyl 1-bromo-2naphthylphosphonate with 2-formylphenylboronic acid (Scheme 3.15). Its use allowed accessing multifunctionalized axially chiral biaryls bearing phosphonate and formyl groups in good yields (34-97\%) and excellent ees (86-96\%) (Scheme 3.16). As the best selectivities were obtained with formyl-substituted aryl halides, DFT calculations were carried out on this type of substrates in order to determine the origin of the enantioselectivity during the reductive elimination step [92b]. According to these, both palladium-hydrogen bond (from the formyl group) and palladium-oxygen bond (from the phosphoryl group) are involved in the transition state and should control the enantioselectivity of the coupling product (Figure 3.6).

\subsubsection{P,X ligands with planar chirality}


Since the pioneering work of Cammidge on the enantioselective Suzuki-Miyaura coupling, various ligands presenting planar chirality have been reported in the literature. Most of them are P,P (Figure 3.7), P,N (Figure 3.8), P,O (Figure 3.9) and P,aryl (Figure 3.10) bifunctional ligands and possess a ferrocenyl backbone.

\section{a) P,P ligands with planar chirality}

Between 2000 and 2004, Cammidge et al. reported the use in asymmetric Suzuki-Miyaura of two different diphosphines presenting planar chirality (Scheme 3.17) [50,81]. The ferrocenyl bidentate ligand $(S)$-(pR)-BPPFA (3), which did not yield 2,2'-dimethyl-1,1'-binaphthyl with high levels of enantioselectivity in the Kumada-Tamao-Corriu coupling, was not successful either when used in the Suzuki-Miyaura reaction $\left(3 \mathrm{~mol} \% \mathrm{PdCl}_{2} / 3 \mathrm{~mol} \%(3)\right.$ and $\mathrm{Ba}(\mathrm{OH})_{2}$ in refluxing DME) as only 4\% ee of 2-methyl-1,1'-binaphthyl were reached. A slightly better ee was obtained in the presence of $\mathrm{CsF}(17 \%)$ but to the detriment of yield (13\%). The marked difference with the P,N ligand PPFA (2), which showed great efficiency (see 3.2.2.b), could come from the fact that ligand $\mathbf{3}$, despite the presence of a nitrogen atom, is a P,P ligand and probably coordinates more strongly via the two P donor atoms. Similarly, the Josiphos ligand 28a (Figure 3.7) [93], which is very efficient in several asymmetric catalytic reactions $[94,95,96]$, was inefficient for the asymmetric Suzuki-Miyaura coupling [81] as a very poor yield $(6 \%)$ of the racemic binaphthyl was reached.

Using a strategy closely related to that of the dynamic kinetic Suzuki-Miyaura crosscoupling, Stolz, Virgil et al. reported a palladium-catalyzed atroposelective C-P coupling toward the synthesis of QUINAP [49]. Several chiral diphosphines were tested in the dynamic kinetic resolution of an atropoisomeric bromo substrate (Scheme 3.18). The ferrocene-based ligand 29 (Figure 3.7) was particularly efficient with a selectivity factor $\left(\mathrm{k}_{\mathrm{f}} / \mathrm{k}_{\mathrm{s}}\right)$ up to 154 . The kinetic resolution of a similar triflate substrate was also tested (Scheme 3.19). With Josiphos- 
type ligands, a dynamic kinetic asymmetric transformation occurred : the ee of the product was different from $0 \%$ at full conversion. The best ee was obtained with ligand $\mathbf{2 8 b}$ (Figure 3.7). Using an enantiomerically pure substrate, the ee of the product could be increased to $99 \%$ for the matched enantiomer and the recovered substrate was still enantiomerically pure, showing that no racemization of the substrate happens during the reaction. The dynamic phenomenon observed can be explained by a racemization of the arylpalladium intermediate.

\section{b) $P, N$ ligands with planar chirality}

Cammidge et al. were also the first to use P,N ligands with planar chirality in the asymmetric Suzuki-Miyaura coupling (Figure 3.8) [50,81]. It was shown in section 3.2.2.a that the P,P ligand 3 gave good yields (up to 73\%) but low enantioselectivities (4-17\% ee) of 2methyl-1,1'-binaphthyl. The P,N PPFA ligand 2, possessing planar and central chirality, gave better results, in terms of enantioselectivity (up to 85\%), than 3 or BINAP 6 (Scheme 3.17). To explain these results, a possible coordination of the $\mathrm{N}$ atom of the ligand on the boron atom of the boronic derivative before the transmetalation step was proposed.

With the intention of studying the impact of backbone modifications on the PPFA ligand 2, Baudoin et al. [88] reported in 2003 the synthesis and use of ligand $\mathbf{3 0}$ for the asymmetric Suzuki-Miyaura synthesis of biologically relevant intermediates (see Scheme 3.11 for reaction conditions). The substitution of the phenyl groups on the phosphine moiety by cyclohexyl groups did not dramatically change the yield (28\% versus $38 \%)$ nor the enantioselectivity ( $8 \%$ versus 5\%). Interestingly, both ligands gave much lower ees than atropisomer ligands 21 (KenPhos) and 22a (around 40\% ee). As with KenPhos-type ligands, the coupling of diethyl 1bromo-2-naphthylphosphonate with 2-methyl-1-phenylboronic acid (see Scheme 3.12 for reaction conditions) gave higher enantioselectivities, underlying the strong influence of the 
substrate structure on the selectivity. In this reaction, ligand 2 (60\% yield, $44 \%$ ee) appeared to be slightly more efficient than ligand $\mathbf{3 0}$ (79\% yield, $24 \%$ ee).

The PPFA ligand 2 allowed reaching good enantioselectivities, however the reaction times required to obtain total conversion of the naphthyl halide were important (up to 6 days). Espinet et al. tried to address this issue by proposing a micro-wave irradiation as an alternative to the traditional oil bath heating (Table 3.6) [97]. With this method, reaction times were dramatically improved (from 6 days to a few hours), but unfortunately where the yields were preserved, enantioselectivities were lowered.

Espinet et al. also studied a parameter that Cammidge et al. had considered as problematic: the use of a naphthylboronic acid with a sterically hindered naphthyl halide. Indeed, the latter observed a non-negligible amount of deboronation product during the coupling of such naphthyl halides and explained their choice to use boronic esters. In order to provide an alternative to the rather sensitive boronic esters, they reported a purification procedure of naphthylboronic acids [98] that improved dramatically the efficiency of the catalytic reactions (from traces of coupling products before purification to up to $95 \%$ yield) under the same conditions than those reported by Cammidge et al [50]. During this study, they also investigated the modifications of the PPFA ligand (2) backbone on the catalytic efficiency. Thus analogues of the PPFA ligand possessing different steric or electronic properties, ligands $\mathbf{3 1}$ and $\mathbf{3 2}$ (Figure 3.8), were evaluated in the asymmetric coupling of naphthyl bromides with several boronic acids (Scheme 3.20). The nature of the palladium precursor was also looked into. The tuning of the stereoelectronic properties of the phosphine substituents or of the substituent at the $\alpha$ position to the amino group did not allow reaching higher yields or enantioslectivities. However, the nature of the palladium precursor had a non-negligible effect on the reactions. In general, whereas cationic palladium complexes provided higher enantioselectivities, neutral palladium complexes led to better 
yields. Nevertheless, a large amount of palladium precursor (up to 10 mol\%) was always necessary to achieve these couplings in good yields and enantioselectivities.

\section{c) $P, O$ ligands with planar chirality}

The utility of hemilabile ligands for the (asymmetric) Suzuki-Miyaura reaction has been demonstrated by several authors, for example Hor [72,73], Dai [90] and Qiu [91,92], although planar chiral P,O ligands have been less exploited than the corresponding P,N ligands for the asymmetric version.

In 2000, Cammidge et al. studied the catalytic efficiency of ligand 4a (Figure 3.9) for the first time in asymmetric Suzuki-Miyaura reactions [50]. Ligand 4a, first developed by Hayashi [99], presents planar and central chirality, and gave high yields and enantioselectivities in the asymmetric Kumada-Tamao-Corriu coupling reaction [100]. However, the use of 4a in asymmetric Suzuki-Miyaura reactions gave poor ees (up to 17\%) despite good activities (up to $82 \%)$. In order to explain the differences between the two catalytic reactions, a possible interaction between the methoxy group of the ligand (4a) and the magnesium atom of the Grignard reagent was suggested, allowing a good stereocontrol in the Kumada-Tamao-Corriu coupling, interaction that was not present with the boronic derivative in the Suzuki-Miyaura coupling.

Driven by Buchwald's observations about the unique reactivity of dialkylbiarylphosphines, Johannsen et al. evaluated the catalytic efficiency of a series of electron-rich aryl-ferrocenyl (pseudo-biarylic) dialkylphosphines with planar chirality (Figures 3.9 and 3.10) [101]. Amongst these ligands, 33 (Figure 3.9) presents an oxygen atom in a position that may allow its coordination to the metal center. Its use in the asymmetric Suzuki-Miyaura coupling of 1bromo-2-methylnaphthalene with 2-methyl-1-naphthylboronic acid in toluene at $70^{\circ} \mathrm{C}$ for $24 \mathrm{~h}$ gave moderate results ( $30 \%$ yield and $46 \%$ ee). 
Shortly thereafter, Baudoin et al. [88] reported the use of the same ligand $(S)$-33 as an $\mathrm{HBF}_{4}$ adduct (phosphonium salt) for the coupling of diethyl 1-bromo-2-naphthylphosphonate and 2-methyl-1-phenylboronic acid (see Scheme 3.12 for the reaction conditions). After $44 \mathrm{~h}$ at $70^{\circ} \mathrm{C}$ in toluene, the coupling product was obtained in $52 \%$ yield and only $3 \%$ ee, which is much lower than that obtained with KenPhos-type ligands $(\mathbf{2 1}, \mathbf{2 2})$ or $\mathrm{P}, \mathrm{N}$ ligands with planar chirality (2 and 30).

In 2010, Schaarschmidt and Lang prepared a series of planar chiral ferrocenyl aryl ethers that should allow the formation of 5-membered palladacycles and evaluated these ligands for the coupling of various aryl halides with substituted phenylboronic acids [102]. They were presented as hemilabile bidentate $\mathrm{P}, \mathrm{O}$ ligands, however they used 2 equivalents of ligand per palladium, restricting the possibility of bidentate coordination due to the stronger coordination ability of the phosphorus atom. The ligands proved particularly active for the coupling of chloroarenes and sterically hindered substrates. However when an enantioenriched version of ligand 34 (37-40\% ee) was engaged in the coupling of 1-bromo-2-methylnaphthalene with 2methoxyphenylboronic acid in the presence of $\mathrm{Pd}_{2}(\mathrm{dba})_{3}\left(0.5 \mathrm{~mol} \%\right.$ in $\left.\mathrm{Pd}, \mathrm{Pd} / \mathrm{L}^{*}=1 / 2\right)$, reasonable yields of the biaryls were obtained $\left(54 \%\right.$ at $50^{\circ} \mathrm{C}$ and $91 \%$ at $\left.100^{\circ} \mathrm{C}\right)$ but ees were very poor $(1-4 \%)$. One obvious explanation would be the low ee of the chiral ligand, but the enantiopure version of the latter was not described.

Recently, Deydier, Manoury et al. [103] reported a kinetic study using P,O ligands bearing planar or planar and central chirality, 35 and 36 (Figure 3.9), with a different steric hindrance on the oxygen atom, for the asymmetric Suzuki-Miyaura coupling of 1-bromo-2methylnaphthalene with naphthylboronic acid (Scheme 3.21). These preliminary results showed that the most crowded ligand 36 (slower kinetics), presenting both planar and central chirality, afforded the best results with $60 \%$ conversion and $37 \%$ ee at $40{ }^{\circ} \mathrm{C}$ in toluene after 2 $\mathrm{h}(75 \%$ conversion after $24 \mathrm{~h}$ with a total selectivity in the expected product). 


\section{d) $P$, aryl ligands with planar chirality}

In 2003, Johannsen et al. reported the synthesis and application in the Suzuki-Miyaura coupling of a series of electron-rich aryl-ferrocenyl dicyclohexylphosphines [101] (37, Figure 3.10, Scheme 3.22) considered as pseudo-dialkylbiarylphosphines such as those developed by the group of Buchwald. A preliminary study on the non-enantioselective version of the SuzukiMiyaura coupling of several activated or non-activated chlorobenzenes with phenylboronic acids gave high yields (up to $96 \%$ ) with a moderate catalyst loading ( 2 to 5 mol\%). This study also showed the influence of the L/Pd ratio on the catalytic activity and put forward a possible interaction between the aryl group of the ligand and the palladium center that could stabilize and activate $\operatorname{Pd}(0)$ intermediates during the catalytic cycle. Those ligands were used in the asymmetric Suzuki-Miyaura coupling of 1-bromo-2-methylnaphthalene and 2-methyl-1naphthylboronic acid in toluene at $70^{\circ} \mathrm{C}$ during $24 \mathrm{~h}$ (Scheme 3.22). The best results of $65 \%$ yield and 54\% ee were obtained when ligand $\mathbf{3 7 b}$ was involved.

A new sterically bulky ferrocenyl phosphine $(S)$-38 has been recently designed by Lang et al. (Figure 3.10, Scheme 3.23) [104]. This ligand presents a phosphorus atom and an alkene functionality that could both coordinate to the metal, thus giving it a hemilabile character. However the addition of two equivalents of ligand on $\mathrm{PdCl}_{2}$ gave a complex presenting only $\mathrm{P}$ coordination, as confirmed by NMR and X-ray diffraction analysis. A similar coordination mode should occur during the catalytic reaction as the same metal/ligand ratio (1:2) is maintained. The use of ligand $(S)$-38 in the synthesis of various congested biaryls allowed reaching good yields $(52-99 \%)$ under relatively mild conditions $\left(50-70^{\circ} \mathrm{C}\right)$ with low catalyst loadings (0.1-0.5 mol\% in Pd) albeit with poor to moderate ees (0-36\%) (Scheme 3.23). When the reaction was carried out in the presence of mercury as test reagent for the presence of nanoparticles, the yield dropped from quantitative to $60 \%$ after $1 \mathrm{~h}$. As no change was observed 
in the presence of poly(4-vinylpyridine), the reaction could be solely made by the molecular complex. However, the presence of nanoparticles cannot be completely excluded since $\operatorname{Pd}_{2}(\mathrm{dba})_{3}$ was used as precursor and Ananikov et al. showed that this compound always presents a mixture of molecular complex and nanoparticles [105].

\subsubsection{P ligands with other types of chirality}

a) Monophosphorus ligands

Even if polydendate ligands are most frequently used in asymmetric synthesis, some efficient monophosphine ligands, presenting good to excellent enantioselectivities, have been reported in the literature.

In their first paper dealing with the asymmetric Suzuki-Miyaura reaction [51], Buchwald et al. studied the activity and selectivity of two axially chiral monophophorus ligands (39, Figure 3.11). Both ligands presented higher activities but lower selectivities (23-62\% ee) than analogous P,N bidendate ligands (Table 3.3 entries 6-7).

Baudoin et al. reported the synthesis of new aryldialkylphosphine ligands (phosphetane ligands) presenting two chiral centers (40, Figure 3.11) [88]. Their use in the synthesis of biologically relevant molecule intermediates (Scheme 3.11) or in the coupling of diethyl-(1bromo-2-naphthyl)phosphonate with 2-methyl-1-phenylboronic acid gave again low selectivities (0-40\% ee) compared to KenPhos (21) or analogous P,N ligands (22).

A few months later, Cammidge et al. explored the efficiency of a series of new monophosphine ligands (49 - Figure 3.12), presenting both a biaryl substituent and chirality at phosphorus, for the coupling of 1-iodonaphthalene with 2-methyl-1-naphthylboronic acid in the presence of $3 \mathrm{~mol} \% \mathrm{PdCl}_{2}$ and $6 \mathrm{~mol} \%$ ligand in a refluxing DME/ $\mathrm{H}_{2} \mathrm{O}$ mixture [81]. After 17 $\mathrm{h}$, good yields (40-83\%) and poor enantioselectivities were obtained (4-24\%). As the selectivity remained lower than with ferrocenyl P,N ligand 2 (Figure 3.8), with which $43 \%$ 
yield and $63 \%$ ee were obtained under the same conditions (Scheme 3.17), the authors speculated that the amine nitrogen could serve to deliver the boronate via a N-B interaction and that transmetalation may be the key step of the reaction.

In 2009 Uozumi et al. published the synthesis and catalytic applications of new imidazoindole-phosphine ligands (41, Figure 3.11, Scheme 3.24) [106]. They gave excellent stereoselectivities (72-94\% ee) in the coupling of 1-iodo-2-methylnaphthalene or 1-chloro-2methylnaphthalene with 2-methyl-1-naphthaleneboronic acid in toluene at $100^{\circ} \mathrm{C}$ with $10 \mathrm{~mol} \%$ $\mathrm{Pd}(\mathrm{OAc})_{2}$ and a 1:1 $\mathrm{Pd} / \mathrm{L}^{*}$ ratio after $5 \mathrm{~h}$. Interestingly, the immobilization of ligand 41c on a polystyrene-poly(ethyleneglycol) copolymer (PS-PEG) resin allowed performing the reaction in water with excellent enantioselectivities (88-94\% ee) and to recycle the catalyst four times without loss of selectivity.

The highly enantioselective synthesis of axially chiral biarylphosphonates by Suginome et al., using helically chiral polyquinoxaline-based phosphines (PQXphos), showed the potential of macromolecular ligands for this catalysis (Scheme 3.25) [107]. They prepared 20 mer-based block copolymers by living block copolymerization of a chiral spacer monomer and a phosphorus-containing monomer in a presence of a chiral initiator (42). 1000 mer-based high molecular weight block copolymers $(\mathbf{4 3})$ were also prepared by living random copolymeristation of the chiral and the phosphorus-containing monomers in a 950/50 ratio using an achiral organonickel initiator. Their use in asymmetric Suzuki-Miyaura coupling showed a $10 \%$ ee increase when the reaction temperature decreased from $80^{\circ} \mathrm{C}$ to $40^{\circ} \mathrm{C}$, and macroligands $\mathbf{4 3}$ gave excellent enantioselectivities, slightly higher than analogues $\mathbf{4 2}$ (around $+5 \%)$. All ligands possessed a pure right-handed $(P)$ helical structure with an $(R)$ phosphine. However, the helical direction of the high molecular weight PQXphos $(P)-(R)-\mathbf{4 3}$ ligand is easily switchable to the left-handed $(M)$ helical structure giving rise to the PQXphos $(M)-(R)$ 43 ligand by heating a solution of PQXphos $(P)-(R)-\mathbf{4 3}$ ligand in 1,1,2-trichloroethane/THF. 
Interestingly the use of these two ligands, $(P)-(R)-\mathbf{4 3}$ and $(M)-(R)-\mathbf{4 3}$, produced the opposite $(S)$ - and $(R)$-biaryl products with similar ees (98 and 90\% ee).

In 2011, Iuliano et al. reported the application of some biaryl phosphites derived from deoxycholic acid (44) in asymmetric Suzuki-Miyaura cross-coupling [108]. The ees observed were moderate $(<55 \%)$ but they observed, like in previously reported studies, that the choice of the base and its amount, among the different reaction parameters, were crucial as variations up to $19 \%$ ee were measured for the synthesis of 2-methyl-2'-methoxy-1,1'-binaphthyl in a given solvent.

Iwasawa et al. also investigated sterically very hindered phosphonites possessing axially chiral substituents (45, Figure 3.11, Scheme 3.26) [109]. Remarkably, very good yields (average yield $>85 \%$ after 3-7 hours) and ees up to $78 \%$ were observed in the coupling of less reactive aryl chlorides with various boronic acids at rather low temperatures $\left(<90^{\circ} \mathrm{C}\right)$ with only $0.25 \mathrm{~mol} \%$ of palladium.

More recently (2013), Claver et al. described the synthesis of a series of new chiral monodentate phosphorus ligands (46-48 - Figure 3.11). However, their application in asymmetric Suzuki-Miyaura gave only moderate ees $(<35 \%)[110]$.

Interestingly, new monophosphine ligands bearing a chiral phosphorus atom and presenting very good activities and excellent selectivities (up to 99\% ee) were reported recently by Tang et al. (50-51 - Figure 3.12, Scheme 3.27) [111,112]. Enantioselectivity (72\% to 94\%) increased sharply upon varying the $\mathrm{R}$ substituent of the aryl bromide from $\mathrm{R}=\mathrm{P}(\mathrm{O}) \mathrm{Ph}_{2}$ to $\mathrm{R}=\mathrm{BOP}$, and this suggested a significant polar- $\pi$ interaction between the highly polarized BOP group and the extended $\pi$ system of the boronic acid partner during the reductive elimination step.

Lassaletta, Fernandez et al. used phosphoramidate $\mathbf{5 2}$ in an interesting example of dynamic kinetic Suzuki cross-coupling reaction (Figure 3.12, Scheme 3.28) [48]. The triflate used for 
the reaction is configurationally stable and was used as racemic mixture. The substrate could be fully converted into the expected product with up to $92 \%$ enantiomeric excess. The ee's of the product were far from $0 \%$, value which should be obtained if each enantiomer of the substrate was transformed independently, showing some equilibration during the reaction, probably between the two arylpalladium intermediates.

\section{b) Bidendate P,X ligands}

In 2004, Cammidge et al. investigated the use of diphosphine ligands (53a-b - Figure 3.13) bearing two chiral phosphorus atoms for the coupling of 1-iodonaphthalene with 2-methyl-1naphthylboronic acid with $3 \mathrm{~mol} \% \mathrm{PdCl}_{2}$ and $6 \mathrm{~mol} \%$ ligand in a refluxing DME/ $\mathrm{H}_{2} \mathrm{O}$ mixture [81]. However they gave poor yields $(7-10 \%)$ and optical purities (4-11\%) compared to monophosphines 49a-c (Figure 3.12) and P,N ferrocenyl ligand 2 (Figure 3.8) also assessed in this study under the same conditions.

Lassaletta et al. synthesized a series of phosphino-hydrazone ligands derived from a $C_{2}$ symmetric hydrazine (54a-h, Figure 3.13) that exhibit excellent activities and good enantioselectivities at room temperature in toluene (Scheme 3.29) [113]. A similar ligand presenting an oxazoline group (55) was also prepared but no ee was observed. Ligands $\mathbf{5 4 a}$ and 54c afforded the best enantioselectivities (up to $80 \%$ ee) and were assessed in the coupling of various aryl halides and aryl boronic acids. 54a was also used by Donohoe et al. for the synthesis of a tetracyclic streptonigrin intermediate by asymmetric Suzuki-Miyaura coupling [84]. Moderate enantioselectivities were obtained, $42 \%$ and $29 \%$ ee at $40^{\circ} \mathrm{C}$ and $60^{\circ} \mathrm{C}$, respectively, but these values were slightly higher than the selectivities obtained with BINAP and KenPhostype ligands. Phosphino-hydrazone ligand 54a was also used in a dynamic kinetic Suzuki crosscoupling reaction (see Scheme 3.28) [48]. After 3h of reaction, the substrate was fully converted 
into the expected product but with a moderate ee (34\%), much lower than those reported with phosphoramidate ligand $\mathbf{5 2}$.

More recently, Claver et al. compared the efficiency of various new bidendate P,P ligands based on a carbohydrate structure (56-58) to that of known ligands $\mathbf{1}$ and $\mathbf{5 9}$ for the coupling of iodonaphtalene with an ortho-substituted naphthylboronic acid [110]. The use of the iodide reagent allowed reaching excellent activities, however enantioselectivities remained moderate (less than $37 \%$ ee).

The DIOP ligand 1 was also evaluated by Fujihara et al. using palladium nanoparticles (Pd NPs) but this system gave lower activities and enantioselectivities than BINAP-type or SEGPHOS ligands used under the same conditions (10\% ee compared to $58 \%$ and $32 \%$ ee, respectively) [85].

\subsubsection{N,N ligands}

Phosphorus-based ligands are undoubtedly privileged ligands for the asymmetric SuzukiMiyaura reaction, thanks to their rich coordination chemistry with palladium and the important number of chiral representatives. The use of phosphorus-free ligands in the palladium-catalyzed asymmetric Suzuki-Miyaura reaction is still relatively uncommon and few papers report highly enantioselective processes. In this category, N,N ligands were among the first to be evaluated in the asymmetric version of the Suzuki-Miyaura reaction.

Axially chiral diamine ligand (R)-(+)-BINAM 60 (Figure 3.14) was used as early as 2000 by Cammidge et al. (3 mol\% $\left.60 / \mathrm{PdCl}_{2}\right)$ in the presence of $\mathrm{Ba}(\mathrm{OH})_{2}$ in $\mathrm{DME} / \mathrm{H}_{2} \mathrm{O}$ at reflux, but proved inefficient as the expected 2-methyl-1,1'-binaphthyl was obtained as a racemic mixture in a very low $9 \%$ yield, while $C_{2}$-symmetric $(1 R, 2 R)$-DIAMCY $\mathbf{6 1}$ did not furnish the product at all in the same conditions $[50,81]$. 
$C_{2}$-symmetric Phebox ligands had been used successfully by Nishiyama in a wide variety of catalytic reactions such as allylation [114], hetero Diels-Alder [115], Michael reactions [116], etc, therefore Iwasa et al. decided to evaluate the $(S S, S S)-(s \mathrm{Bu}-\mathrm{phebox})$ ligand (Figure 3.14) in the asymmetric Suzuki-Miyaura reaction [117]. Various naphthyl iodides and two naphthylboronic acids were used in the presence of 5 mol\% catalyst 62 and $\mathrm{K}_{2} \mathrm{CO}_{3}$ in 1,2dichloroethane. Moderate to good yields were generally obtained and a better yield was reached when the substituent was borne by the naphtyl iodide rather than the boronic acid. Lowering the temperature from 80 to $50^{\circ} \mathrm{C}$ did not bring any real improvement to enantioselectivity and the best ee obtained was $49 \%$. With this pincer ligand the mechanism is suspected to proceed via a $\mathrm{Pd}(\mathrm{II})-\mathrm{Pd}(\mathrm{IV})$ cycle rather than the usual $\mathrm{Pd}(0)-\mathrm{Pd}(\mathrm{II})$ cycle.

An important improvement was brought by Lassaletta et al. in 2008 with the synthesis of a series of $C_{2}$-symmetric bis-hydrazones (Scheme 3.30) [118]. The reaction conditions (5 mol\% catalyst 63-65, $\mathrm{Cs}_{2} \mathrm{CO}_{3}$ in toluene) were applied to a variety of substrates and allowed reaching very high enantioselectivies, particularly with complex 64. The reactions could even be carried out at room temperature to improve the ees, albeit with extended times and generally lower yields. The choice of the reagent in excess also proved important since better yields were obtained with an excess of aryl halide, while higher enantioselectivities were observed with an excess of arylboronic acid. The high efficiency of these systems was attributed to the intrinsic features of the ligands, i.e. $C_{2}$ symmetry, a limited flexibility about the $\mathrm{N}-\mathrm{N}$ bonds, an important steric crowding that helps stabilize the intermediate $\operatorname{Pd}(0)$ species and finally a high electron density that is usually beneficial to the oxidative addition step. Interestingly, due to the high stability of the complexes, the presence of water and oxygen was not detrimental to the catalysis in most cases.

Finally, a series of non- $C_{2}$-symmetric N-heterocyclic pyridylmethylamines was described by Prim et al. in 2011 and the corresponding palladium complexes were evaluated in the 
asymmetric Suzuki-Miyaura reaction (Scheme 3.31) [119]. Only chiral complexes bearing two stereocenters were used. Classical reaction conditions were applied (5 mol\% catalyst 66a-e, $\mathrm{Cs}_{2} \mathrm{CO}_{3}, 80^{\circ} \mathrm{C}$ in a ternary mixture of solvents) and conversions were good to excellent. However, a non-negligible amount of dehydrohalogenation product was observed whatever the catalyst used, even becoming the major product in the case of complex 66e. In the latter case, the presence of the dangling $-\mathrm{OH}$ functionality on the ligand was put forward to explain the poor results. Low to moderate ees were obtained (8-40\%) and a match-mismatch effect was observed with most pairs of diastereomeric complexes. This effect was attributed to the pseudobenzylic stereocenter the configuration of which seems to play a role in the enantiodiscriminating step.

\subsubsection{NHC ligands}

Considering the growing importance of N-heterocyclic carbene (NHC) ligands in catalysis in the last fifteen years and their extreme efficiency in the Suzuki-Miyaura reaction [120], it was only logical to see the emergence of chiral NHCs for its asymmetric version [121].

Less common than NHCs, partly due to a more challenging synthesis, acyclic diaminocarbenes (ADCs) have interested several groups as they are generally more strongly donating and sterically demanding ligands [122]. Hong et al. took advantage of these specific properties and prepared a series of ADC-Pd complexes for the Suzuki-Miyaura reaction, which usually benefits from catalysts bearing bulky, strongly donating monodentate ligands (Scheme 3.32) [123]. Unfortunately, the catalysts were not as active as expected, requiring $3 \mathrm{~mol} \%$ at $65^{\circ} \mathrm{C}$ to efficiently couple hindered substrates in $20 \mathrm{~h}$. Chiral representatives 67-69 were evaluated in the model reaction of 1-bromo-2-methoxynaphthalene with napthylboronic acid but none gave more than $4 \%$ e.e. 
The first example of a chiral NHC used in asymmetric Suzuki-Miyaura was reported in 2010 by Labande et al., followed by an extended study in 2014, and consisted of planar chiral, bidentate NHC-phosphine ligands where the chirality was brought by ferrocene (Figure 3.15) [124]. Either neutral or cationic palladium complexes 70-72 were evaluated in the asymmetric Suzuki-Miyaura reaction and the substituents around the NHC were changed in order to measure the effect of stereoelectronic parameters on activity and enantioselectivity. Among the advantages of these complexes are their stability toward air and moisture and the low catalyst loadings (0.1-0.5 mol\%) that allowed getting the expected binaphthyls with good to excellent yields at moderate temperatures $\left(40-70^{\circ} \mathrm{C}\right)$. The enantioselectivities, however, did not exceed $46 \%$ whatever the structure of the ligand and the complexes were not active with naphthyl chlorides. The naphthyl bromide bearing a phosphonate substituent at the 2-position, widely used in asymmetric Suzuki-Miyaura reactions, did not lead to the expected product but gave instead a non-negligible amount of the dehalogenated product. This side-reaction has already been observed under the conditions of the Suzuki-Miyaura coupling with BINAP (6) and could indicate that the oxidative addition takes place but the subsequent transmetalation step does not occur [51]. Qiu et al. also observed that BINAP was totally ineffective for the coupling of diethyl 1-bromo-2-naphthylphosphonate with 2-formyl phenylboronic acid, although they did not specify whether the naphthyl bromide was consumed or simply did not react under these conditions [92].

Other examples were described shortly after this first report. In 2012, Zhang et al. prepared a palladium complex bearing a chiral bis-NHC based on the $C_{2}$-symmetrical 1,2cyclohexanediamine structure (Figure 3.15) [125]. Moderate to excellent yields of 2-methyl- or 2-methoxy-1,1'-bipnaphthyl were obtained with 2 mol\% palladium complex 73a in the presence of $\mathrm{Cs}_{2} \mathrm{CO}_{3}$ in DMA and reasonable levels of enantioselectivities (up to 61\%) were reached at $80^{\circ} \mathrm{C}$. Lowering the temperature to $25^{\circ} \mathrm{C}$ increased the selectivity (70\% ee), albeit 
with a very long reaction time (7 days) and low yield (19\%). In 2014, a series of similar ligands 73-75 were synthesized and the influence of sterics on the enantioselectivity was evaluated for the reaction of 1-bromo-2-methoxynaphthalene with naphthylboronic acid [126]. Both neutral and cationic palladium complexes were used but the nature of the co-ligand had little influence on the yields (conditions: $\mathrm{Cs}_{2} \mathrm{CO}_{3}$, THF, $65^{\circ} \mathrm{C}$ ), except with $\mathbf{7 5 b}$ which afforded the expected binaphthyl with a lower yield. Catalyst 73i did not furnish any binaphthyl: this was explained by the presence of two free hydroxyl groups on the ligand, which can be deprotonated in the presence of $\mathrm{Cs}_{2} \mathrm{CO}_{3}$ to give a tetracoordinated palladium complex bearing a $\mathrm{L}_{2} \mathrm{X}_{2}$ ligand, probably inactive in the Suzuki-Miyaura reaction. Finally, CsF/THF was chosen as the base/solvent couple yielding the best compromise between activity and enantioselectivity for most catalysts, although carbonate bases gave the bipnaphthyl with often better ees. Depending on the R substituent on the dangling oxygen atom of the ligand, ees varied from 11 to $45 \%$ : the existence of noncovalent interactions between aromatic rings in the ligand could be responsible of the different levels of enantioselectivity observed. These conditions were then applied to other substrates with catalyst 73e. As observed in other reports, increasing the steric bulk on the boronic acid partner became problematic since the reaction of 1-bromo-2methoxynaphthalene with a naphthylboronic acid bearing a methyl substituent failed to produce the expected binaphthyl. It is interesting to note that this catalyst proved active for the coupling of less activated 1-chloro-2-methoxynaphthalene, giving the binaphthyl with the highest enantioselectivity (64\%) in a moderate yield (55\%).

The first chiral monodentate NHC ligands used in asymmetric Suzuki-Miyaura crosscoupling were reported in 2012 by Cao, Shi et al (Figure 3.16) [127]. Their structure is based on that of commercially available L-phenylalanine and the chiral center is situated on the skeleton of the heterocycle. Palladium complex 76 was thus evaluated for the coupling of 1bromonaphthalene with naphthaleneboronic acid. Complex $\mathbf{7 6}$ showed a very good activity for 
this reaction since the expected binaphthyl was obtained in quasi-quantitative yield with a low catalytic charge $\left(0.5 \mathrm{~mol} \%\right.$, in the presence of $3 \mathrm{eq} . \mathrm{KOH}$ in dioxane at $\left.100^{\circ} \mathrm{C}\right)$, however a disappointing $5 \%$ ee was observed. One reason for this low enantioselectivity may be the remote position of the chiral center from the palladium.

In 2013, Dorta et al. used monodentate chiral NHCs bearing bulky naphthyl wingtips substituted with cyclooctyl or 4-heptyl groups (Figure 3.17) [13]. The former had previously given interesting results in palladium-catalyzed asymmetric intramolecular $\alpha$-arylation reactions [128]. All the palladium complexes evaluated in the asymmetric Suzuki-Miyaura reaction were diastereomerically pure. Among the four complexes tested in the model reaction between 1-bromo-2-methoxynaphthalene and naphthylboronic acid, only one of the three diastereomers $((\mathrm{a} S, \mathrm{a} S)-10)$ showed a promising $60 \%$ ee. After optimization of the reaction conditions with 1-bromo-2-methylnaphthalene, the use of other substrates did not improve this value and raising the catalytic charge from 2 to $5 \mathrm{~mol} \%$ had a negative effect on the selectivity. Complex (aS,aS)-10, however, showed good activities with naphthyl chlorides and substituted naphthylboronic acids.

Sterically bulky monodentate chiral NHCs have also been designed recently by Kündig et al. and the catalytic activity of the resulting air and moisture-stable chiral PEPPSI complexes 78-80 (Figure 3.17) was studied in asymmetric Suzuki-Miyaura (Scheme 3.33) [129]. Compared to the systems developed by Dorta et al., the introduction of a methylene bridge on the wingtip substituents may give some flexibility while keeping the steric bulk and the chiral centers are positioned closer to palladium. Both unsaturated and more synthetically challenging saturated Pd-NHC complexes were developed. After optimization of the reaction conditions, the best results were obtained with 5 mol\% complex 80i in the presence of $\mathrm{KOH}$ in 1:1 dioxane/water. Surprisingly, the saturated analogue of $\mathbf{8 0 i}, \mathbf{8 0 s}$, was completely inactive under the same conditions. A screening of substrates was then performed with 80i. It is noteworthy 
that most substrates - even less reactive naphthyl chlorides and 3-bromo-4-methylthiophene could be coupled in good yields at room temperature, while the amount of excess boronic acid had some influence on activity but not on selectivity. Unfortunately, the use of substituted naphthylboronic acids did not furnish any of the expected product (substituted phenylboronic acids were more reactive). Moderate to good enantioselectivities were achieved, with up to $80 \%$ ee for 2-methyl-1,1'-binaphthyl, which represents the best enantioselectivity so far with a palladium catalyst bearing a chiral NHC.

\subsubsection{Other ligands}

The use of chiral dienes has been so far limited in asymmetric catalysis with palladium due to the relatively weak coordination of olefins to palladium compared to rhodium or iridium. Nonetheless in 2010, Lin et al. managed to synthesize a series of air-stable palladium(II) complexes bearing chiral diene ligands (81a-h) and evaluated their activity for the asymmetric Suzuki-Miyaura reaction (Scheme 3.34) [130]. After an optimization study with model substrates, i.e. 1-bromo-2-methylnaphthalene and naphthylboronic acid, the best results were obtained with $5 \mathrm{~mol} \%$ palladium catalyst $81 \mathrm{~d}$ in the presence of $\mathrm{Cs}_{2} \mathrm{CO}_{3}$ at $80^{\circ} \mathrm{C}$ in toluene. Reaction times were very short, since $0.5 \mathrm{~h}$ were generally necessary to obtain the expected product in reasonable yields whereas most systems require $24 \mathrm{~h}$. A fast ligand exchange was observed on palladium and therefore the addition of 5 to $25 \%$ free ligand allowed reaching higher yields and enantioselectivities. Finally, the reaction could be carried out at room temperature with extended reaction times and allowed reaching a high enantioselectivity with catalyst 81d (90\% ee, 78\% yield). The substrate scope was also studied with functionalizable aryl bromides or even aryl triflate and relatively bulky boronic acids. Therefore moderate to high ees were obtained at room temperature and in relatively short reaction times compared to most systems, additionally with good to excellent yields. The presence of an ortho formyl group 
on the halide may be beneficial to the reaction and the justification is the existence of a weak interaction between the palladium center and the oxygen atom, supported by spectroscopic studies and similar observations by Buchwald [51] and Qiu [92b].

\subsection{Conclusion}

Since the pioneering work of Cammidge and Buchwald on the enantioselective SuzukiMiyaura coupling, many studies on the design of chiral ligands have been reported. In spite of some successful examples reported here, a good stereocontrol in the asymmetric SuzukiMiyaura coupling remains difficult because of the high sensitivity of the reaction to the medium (nature of the base, base concentration, metal precursor, solvent, temperature) and to the nature of the substrates (steric crowding, polarity of substituents). Furthermore, no ligand really emerges as universal and the catalytic charge is, more often than not, elevated (1-5 mol \%). A better understanding of the parameters that rule enantioselection is necessary and coupled experimental, structural and theoretical studies would bring valuable information to address the remaining challenges.

Despite the high steric hindrance of both substrates and reagents, the use of sterically hindered ligands, mainly phosphines such as binaphthyl phosphines, ferrocenyl phosphines... or more recently NHCs have increased the catalytic activity, allowing running reactions under relatively mild conditions. However the use of less expensive and more available aryl chlorides remains limited to a few examples. Hence, the design of new ligands remains a major challenge. Compared to other ligands, the few recently used N-heterocyclic carbenes (NHC) have given promising results and offer a wide synthetic space to explore.

As previously mentioned, the best ees are generally obtained with reagents and substrates bearing polar moieties such as phosphonates, amides or aldehydes in the ortho position to the reactive groups (halide or boronic acid). This limitation restricts the possible application field 
of the reaction. However, the problem can be partially overcome if we are able to synthesize enantioenriched biaryl atropisomers presenting three different ortho substituents allowing further selective modification via specific reactions to reach the expected compounds. However, this strategy is highly time consuming as it increases the number of synthetic steps. The role of the substituents in the enantioselectivity control remains difficult to anticipate and theoretical studies tend to demonstrate that weak interactions involving those substituents are important for controlling the correct orientation.

For industrial applications, the possibility to confine the catalyst in liquid (biphasic synthesis) or solid phases (heterogeneized homogeneous reaction), allowing an easy catalyst recovery and recycling, would be extremely valuable. To our knowledge, only two heterogeneous reactions have been reported to date. Uozumi et al. supported a chiral monophosphine on an amphiphilic resin (PS-PEG) and reported good ee (88\%) with a slight decrease of the yield from 90 to $86 \%$ after four recycling runs. Fujihara et al. used various diphosphine ligands with Pd nanoparticles (Pd NPs). The best results obtained with BINAP (42 - $96 \%$ yield and $18-72 \%$ ee) were even higher than with palladium complexes with BINAP. These results also underline the question of the real nature of the active species in enantioselective Suzuki-Miyaura coupling: molecular compound or nanoparticles. Some systematic kinetics studies and catalyst leaching measurements would be valuable for potential batch or continuous flow industrial applications.

Finally, the emergence in the last ten years of the $\mathrm{C}-\mathrm{H}$ activation (or $\mathrm{C}-\mathrm{H}$ functionalization) of substituted aryls (instead of aryl halides) enlarges the scope of potential substrates, opening interesting routes for the synthesis of chiral biaryl compounds. If the comments above highlighted the complexity of the reaction they also underline the remaining challenges for the near future. 


\section{4 - Negishi cross-coupling reaction}

The nickel- or palladium-catalyzed cross-coupling of alkyl electrophiles using organozinc reagents has been well studied, particularly by $\mathrm{Fu}$ who developed the first asymmetric version in 2005 [131]. However, the asymmetric coupling of sterically hindered aryl partners using organozinc species has seldom been explored with only two examples reported by Espinet et al. (Scheme 4.1) [97,132]. They presented the Negishi coupling of naphthyl derivatives as an interesting alternative to the more common Stille and Suzuki cross coupling reactions, arguing that, in the latter, side-reactions such as deboronation were important in the case of very hindered substrates. Thus various 1-bromonaphthalenes and functionalized naphthylzinc reagents were coupled in the presence of a palladium precursor and planar chiral ligand 2 [132].

Other chiral ligands were tested but none proved as efficient as $\mathbf{2}$. The reactions were conducted at moderate temperatures with relatively high catalyst loadings $(5 \mathrm{~mol} \% \mathrm{Pd}, 20$ mol\% ligand). On the whole, very good yields and moderate to high enantioselectivities were obtained in reasonable reaction times. In terms of yields, these results compared favorably with those obtained with analogous compounds under Suzuki-Miyaura conditions, which shows that the Suzuki-Miyaura cross-coupling reaction may be more sensitive to sterics. However, no improvement of enantioselectivities was observed in most cases.

In a subsequent paper, Espinet et al. showed that the use of microwave allowed to reduce drastically the reaction times from several days to 45 min while maintaining the yields [97]. On the other hand, enantioselectivities were somewhat lower, maybe due to the use of higher temperatures $\left(100^{\circ} \mathrm{C}\right.$ against $50-60^{\circ} \mathrm{C}$ under "classical" conditions).

The limited number of reports may come from the fact that the asymmetric Negishi coupling requires anhydrous conditions and the naphthylzinc species needs to be prepared in 
two steps from the corresponding substituted naphthalene through a lithiated species, which could hamper the applicability of this reaction to other functionalized substrates.

\section{5 - Direct C-H functionalization}

In parallel to the development of ever more efficient catalytic systems for the traditional cross-coupling reactions, the direct $\mathrm{C}-\mathrm{H}$ functionalization of aryl compounds has emerged in the last decade as a powerful new synthetic strategy [133]. Indeed, this step-economic reaction circumvents the need for functionalized aryl halides and thus broadens the substrate scope. Mostly palladium and rhodium complexes have been used to this aim and their efficiency has been highlighted in several reviews [134]. Among the main drawbacks are the low reactivity of the $\mathrm{C}-\mathrm{H}$ bond and the lack of selectivity between competing $\mathrm{C}-\mathrm{H}$ bonds. The presence of a directing heteroatom on the substrate is therefore often required to allow the reaction to proceed. Even more challenging is the direct coupling of two hindered aryl substrates and to date, only three groups have investigated the generation of optically enriched biaryl structures by direct C-H functionalization [135,136,137].

The first example was reported in 2000 by the group of Murai [135]. He proposed to increase the rotational restriction between two rapidly interconverting atropisomers by metalcatalyzed $\mathrm{C}-\mathrm{H}$ bond activation of the achiral biaryl substrate and subsequent alkylation. Thus the reaction of naphthyl pyridines and naphthyl quinolines with olefins was investigated in the presence of a rhodium complex (Scheme 5.1). After optimization of the reaction conditions with achiral complexes, $\left[\mathrm{RhCl}(\mathrm{coe})_{2}\right]_{2}$ was associated to the planar chiral ligand $(S)-(\mathrm{p} R)-$ PPFOMe (4a), developed by Hayashi and already successfully applied in other asymmetric CC coupling reactions, for the asymmetric version. The reaction of 2-(1-naphthyl)-3methylpyridine with ethylene, in the presence of $5 \mathrm{~mol} \%\left[\mathrm{RhCl}(\mathrm{coe})_{2}\right]_{2}$ and $30 \mathrm{~mol} \% \mathbf{4 a}$ in toluene at $120^{\circ} \mathrm{C}$, gave the expected coupling product in $37 \%$ yield after $20 \mathrm{~h}$, with $49 \%$ ee. 
Lowering the temperature to $60^{\circ} \mathrm{C}$ was not successful since only traces of the product were observed, and the use of ruthenium salt $\mathrm{Ru}(\operatorname{cod})(\cot )$ instead of rhodium gave disappointing results $\left(15 \%\right.$ yield, $15 \%$ ee). The use of diphosphine $(R)$-BINAP $(6)$ with $\left[\mathrm{RhCl}(\mathrm{coe})_{2}\right]_{2}$ was ineffective, whereas the mixed P,O ligand (R)-MeO-MOP (9) gave a moderate yield of 49\%, although with no asymmetric induction. The use of 1-(1-naphthyl)isoquinoline did not improve the selectivity since only $33 \%$ yield and $22 \%$ ee were reached with ligand $\mathbf{4 a}$.

Yamaguchi, Itami et al, disclosed the next report only in 2012. They screened several ligands in the presence of $\mathrm{Pd}(\mathrm{OAc})_{2}$ and found that bisoxazolines were suitable for the coupling of hindered substrates, namely 2,3-dimethyl thiophene and 2-methyl-1-naphthylboronic acid (Scheme 5.2) [136a]. After optimization of the reaction conditions, they showed that the use of $10 \mathrm{~mol} \% \mathrm{Pd}(\mathrm{OAc})_{2}$ and chiral ligand $\mathbf{8 2}$ in the presence of 4 equivalents of TEMPO, in $n \mathrm{PrOH}$ at $70^{\circ} \mathrm{C}$ in air, furnished the expected coupling product with $41 \%$ ee and $63 \%$ yield and an excellent regioselectivity, thus reporting the first example of enantioselective $\mathrm{C}-\mathrm{H}$ functionalization to generate biaryls. The ee was raised to $72 \%$ using a bulkier substituent on the boronic acid partner, to the detriment of yield. The reaction was optimized a year later as the authors found that the use of iron phthalocyanine as co-catalyst (5 mol\%) allowed avoiding the use of stoichiometric TEMPO or any other chemical oxidant (Scheme 5.2) [136b]. The influence of the chiral ligand was also further investigated and a mixed sulfoxide-oxazoline palladium complex $\mathbf{8 3}$ proved to be the best choice, giving the expected coupling product in $61 \%$ yield and $61 \%$ ee, in DMAc at $70^{\circ} \mathrm{C}$ in air, although with a lower regioselectivity.

The strategy previously developed by Murai was investigated again in 2014 by the group of You [137]. The reaction was catalyzed by a chiral Rh(III) complex, successfully developed by Cramer for $\mathrm{C}-\mathrm{H}$ allylations of benzamides [138]. The coupling of 1-(naphthalene-1yl)benzo[h]isoquinoline with 2-vinylnaphthalene was chosen as model reaction, in the presence of $84 \mathbf{a}-\mathbf{f} /(\mathrm{BzO})_{2}(5 \mathrm{~mol} \%)$ and $\mathrm{Cu}(\mathrm{OAc})_{2}$ (2eq.) as oxidant, in $\mathrm{MeOH}$ at $80^{\circ} \mathrm{C}$ (Scheme 5.3). 
Complexes 84a and $\mathbf{8 4 c}$ gave the best results (99\% yield and $72 \%$ ee) and the use of $20 \mathrm{~mol} \%$ $\mathrm{Cu}(\mathrm{OAc})_{2}$ and 1 eq. $\mathrm{Ag}_{2} \mathrm{CO}_{3}$ allowed increasing the enantiomeric excess to $80 \%$ with $84 a$. The substrate scope was then investigated under the optimized reaction conditions. The ees reached $86 \%$, while using very hindered substituents on the naphthalene ring of the benzo[h]isoquinoline or on the olefin decreased the yield (24\% and $45 \%$, respectively). A few of the enantioenriched biaryls thus generated were successfully used as ligands for the rhodiumcatalyzed conjugate addition of phenylboronic acid to cyclohexenone.

The asymmetric $\mathrm{C}-\mathrm{H}$ functionalization reaction to produce enantioenriched axially chiral compounds is still in its infancy and one of the main challenges associated with it is the development of adapted chiral ligands.

\section{6 - Oxidative couplings}

The oxidative coupling of phenols is a direct method to obtain biphenols but selectivity issues do not make it very attractive except for 2-naphthols, which are almost completely selectively coupled at the 1 position [139]. For instance, phenols can yield coupling products at the ortho but also para position, as well as peroxides and ethers. Even para-substituted phenols could yield Pummerer ketones as by-products [136]. For this reason, the enantioselective version of this coupling reaction is almost exclusively realized with 2naphthols to yield 1,1'-bis-2,2'-binaphthols [140] or polymers [141] according to the nature of the substrate. The first part of this section will be devoted to the coupling reactions yielding 1,1'-bis-2,2'-binaphthols and the second part will concern polymerization reactions. Each part will be divided in two parts according to the metal used as catalyst.

\subsection{Enantioselective synthesis of 1,1'-bis-2,2'-binaphthols.}

6.1.1 Copper-based reactions 
The first asymmetric oxidative coupling of 2-naphthol was described by Feringa and Wynberg using a stoichiometric amount of $\mathrm{Cu}\left(\mathrm{NO}_{3}\right)_{2} .3 \mathrm{H}_{2} \mathrm{O} /(S)$-1-phenyl-ethylamine [142]. Binaphthol could be obtained with a $63 \%$ yield and an enantiomeric excess of $2.5 \%$. Using other chiral amines and substituted 2-naphthols, a maximum ee of $16 \%$ could be obtained with amine 85 (Figure 6.1, Scheme 6.1).

After continuous efforts to improve stoichiometric reactions, yielding in some cases high enantiomeric excesses because the coupling step was followed by selective precipitation of the chiral copper(II) amine-binaphthol complex with simultaneous racemization of the binaphthol $[143,144,145,146]$, the first catalytic oxidative coupling was described by Smrcina, Kocovsky et al. [146]. Using (-)-sparteine $\mathbf{8 6}$ and silver chloride to reoxidize $\mathrm{Cu}^{\mathrm{I}}$ to $\mathrm{Cu}^{\mathrm{II}}$, they were able to obtain good yields of binaphthols by coupling sodium salts of naphthol (Figure 6.1, Scheme 6.2).

Further improvements involved the use of dioxygen as oxidant by Nakajima et al. (Figure 6.1, Scheme 6.3) [147,148]. They first used (-)-sparteine 86 as chiral ligand for copper and could obtain ees in the 10-47\% range depending on the binaphthol substituents. The best results were obtained using chiral diamines $\mathbf{8 7}$ derived from proline. The enantioselectivity of the reaction was very low when $R^{1} \neq H$ but could reach interesting levels for $R^{1}=H$ especially with aniline-based ligands (85\% yield, $78 \%$ ee with $\mathbf{8 7} \mathbf{j}$ and $\left.\mathrm{X}=\mathrm{CO}_{2} \mathrm{Me}\right)$. More recently, Breuning et al. extended this study to 29 additional ligands 87 (Figure 6.1, Scheme 6.4) [149]. In particular, they were able to synthesize enantiomerically pure ligands $\mathbf{8 7}$ bearing substituents at the 5 position of the pyrrolidine ring. The substituent at the 5-position has a strong influence on the enantioselectivity, the best results being obtained with a phenyl group. A methyl substituent on the pyrrolidine nitrogen was optimal and any other substituent (H or bigger alkyl group) led to lower enantioselectivity. The best enantioselectivities were obtained for ligand 
$\mathbf{8 7 t}$ with ees up to $75 \%\left(87 \%\right.$ if the reaction was carried out at $0^{\circ} \mathrm{C}$ ) when the substrate bearing $\mathrm{R}=t \mathrm{Bu}$ was used.

A new breakthrough was achieved when Kozlowski et al. introduced chiral 1,5-diaza-cisdecalins 88 as ligands for copper in the aerobic coupling of naphthols (Figure 6.1, Scheme 6.5) $[150,151]$. High yields of binaphthols and high enantioselectivities could be obtained in the coupling of naphthols bearing a substituent at the 3 position such as an ester, a ketone, a phosphine oxide, a phosphonate, a phosphoramide, etc. $(\mathrm{X}=\mathrm{COOR}, \mathrm{C}(\mathrm{O}) \mathrm{R}, \mathrm{P}(\mathrm{O}) \mathrm{R})$, which could also possibly bind the copper atom. The amount of copper could be limited to $2.5 \mathrm{~mol} \%$ using $\mathrm{CuI}$ as metal source, however the chiral ligand/metal ratio should be limited to 1 . Greater ligand amounts decreased the catalytic activities without increasing the enantioselectivity. Catalysis could even be completely inhibited with more than 2 equivalents of chiral ligand per copper atom: copper(II) complexes bearing two 1,5-diaza-cis-decalins ligands $\left(\mathrm{Cu}^{\mathrm{II}} \mathrm{L}_{2}^{2+}\right)$ were isolated and proved stable but completely inactive, suggesting that the catalytically active species bears only one L per copper $[152,153]$. Various ligands with different R substituents on the nitrogen atoms were tested but the best enantioselectivities were obtained for ligand $\mathbf{8 8 a}$ (Scheme 6.5). The catalytic activities could be further increased by using molecular sieves in order to trap the water produced during the reaction $[150,154]$.

The chiral 1,5-diaza-cis-decalin-based catalytic system was tested for more functionalized substrates in order to open new synthetic pathways for more complex molecules. In particular, when Kozlowski et al. carried out the oxidative coupling of naphthol $\mathbf{B}$ under the same conditions as naphthol $\mathbf{A}$, the corresponding binaphthol was obtained with good yields but very low ees (Figure 6.2). The presence of three methoxy groups on $\mathbf{B}$ may explain the drop in enantioselectivity, which reduces the naphthalene oxidation potential and strongly stabilizes the intermediate radical. The reaction is therefore much faster for $\mathbf{B}$ but with a lower 
enantioselectivity. By decreasing the substrate electron density, good enantioselectivities resulted for highly substituted naphthols, like C-E.

Kozlowski et al. applied their chiral 1,5-diaza-cis-decalin-based catalytic systems to the total synthesis of various chiral natural products like nigerone $[155,156]$, perylenequinones $[152,157]$ such as hypocrellin A [158,159], cercosporin [160], pleichrome [161,162] or $(S)$ bisoranjidol [163,164] (Figure 6.3).

Palmisano, Sisti et al. used a new chiral diamine (89, Figure 6.1) obtained from camphor for the aerobic oxidative coupling under conditions close to those optimized by Kozlowski et al. (Scheme 6.6) [165]. Once again, the best yields and enantioselectivities were obtained with binaphthols bearing an ester group at the 3 position (for $\mathrm{R}=\mathrm{H}$ : $65 \%$ yield, $6 \%$ ee; for $\mathrm{R}=\mathrm{COOMe}: 90 \%$ yield, $65 \%$ ee).

In 2003, Gao and coworkers used a family of dicopper complexes (90 and 91, Figure 6.4) as catalysts for the oxidative coupling of naphthols (Scheme 6.7) [166]. These complexes were synthesized from macrocyles containing two adjacent salen moieties obtained from $(1 R, 2 R)$ 1,2-diaminocyclohexane or $(1 R, 2 R)$-1,2-diphenylethylenediamine and diformylphenol, or derivatives of the corresponding bis-salan ligands obtained by reduction of the salen imine function. The dicopper complexes 90 and 91 were tested in the aerobic oxidation of 2-naphthol. Good yields of binaphthol and good enantioselectivities were obtained with both complexes 90 and 91, although complexes 91 were always slightly more efficient and more enantioselective than 90 with the same $\mathrm{R}, \mathrm{R}^{1}$ and $\mathrm{R}^{2}$ substituents. The enantiomeric excesses of binaphthol obtained by using dicopper complexes $\mathbf{9 0}$ and 91 in the oxidative coupling of unsubstituted 2naphthol were the highest described so far (up to $88 \%$ ee with 91d).

Derivatives of 1,1'-binaphtyl-2,2'-diamine or BINAM (92, Figure 6.4) were tested as ligands for copper in the oxidative coupling of 3-hydroxy-2-naphthoate methyl ester (Scheme 6.8) [167]. Low yields and enantioselectivities were obtained with disubstituted BINAM but 
better results were obtained with monosubstituted BINAM (up to 94\% ee with $\mathbf{9 2 h}$ ). Using BINAM ligand 92a (Figure 6.4), Sekar et al. could obtain excellent enantioselectivities in the aerobic coupling of methyl 3-hydroxy-2-naphthanoate in the presence of $\mathrm{CuCl}$ in toluene at $90^{\circ} \mathrm{C}$ but the reaction was very slow (Scheme 6.9) [168]. The reaction could be largely sped up by adding a catalytic amount of TEMPO to the reaction mixture but the enantioselectivities in these conditions were significantly lower. However, by a careful optimization of solvent, temperature, copper/ligand ratio, they could reach high yields and enantiomeric excesses. The optimized conditions were successfully applied to the asymmetric aerobic cross-coupling of various esters of 3-hydroxy-2-naphthanoic acid.

Habaue et al. studied the cross-coupling between 2-naphthol and 3-hydroxy-2-naphthoate esters or amide (Scheme 6.10) [169,170,171]. Indeed, for cross-coupling reactions, the first issue is the selectivity towards cross-coupling compounds versus the two possible homocoupling products. Various diamines were evaluated as ligands for copper in this reaction, like 1-(2-pyrrolidinyl)pyrrolidine, sparteine or bis(oxazolines). In particular, good yields and good enantioselectivities were obtained using (S)-Phbox 93 (Figure 6.5) or (-)-sparteine 86 $[170,171]$.

Recently, a family of copper complexes bearing O,N,O tridentate ligands (94, Figure 6.5) obtained from aminoacids were tested in the oxidative coupling of 2-naphthol [172]. The main issue with these ligands was the selectivity in binaphthol which was often lower than $50 \%$. The best yields were found for ligands $94 \mathbf{a}$ (up to $33 \%$ yield and $42 \%$ ee), $\mathbf{9 4 b}$ (up to $34 \%$ yield and $30 \%$ ee) or $\mathbf{9 4 c}$ (up to $32 \%$ yield and $43 \%$ ee).

\subsubsection{Reactions with other metals}

After the early attempts of naphthol enantioselective oxidative coupling with $\mathrm{Co}(\mathrm{acac})_{3}$ in the presence of chiral $\mathrm{Ru}(\mathrm{II})$ complexes as photosensitizers [173] or by electrocatalytic coupling 
on a TEMPO-modified graphite felt electrode [174], the first successful use of complexes with metals other than copper in this reaction was described by Katsuki and coworkers using a chiral ruthenium salen complex (95) (Scheme 6.11) [175]. Good yields (up to 93\%) and enantioselectivities (up to $69 \%$ ee) of various disubstituted 1,1'-bis-2,2'-binaphthols were obtained.

Vanadium complexes bearing chiral tridentate Schiff bases were also evaluated. These tridentate ligands were obtained from different salicylaldehydes and various aminoacids (96104, Figure 6.6) [176]. Thanks to the high tunability of the ligands, the structure of the complex was optimized for the oxidative coupling of 2-naphthol (Scheme 6.12). Good yields and enantioselectivities were obtained with the optimized vanadium complex 103d (84\% yield and $62 \%$ ee). However, the product ees were usually lower for substituted 2-naphthols, except when $\mathrm{R}^{2}=\mathrm{R}^{3}=\mathrm{H}$ and $\mathrm{R}^{1}=\mathrm{OBn}(68 \%$ ee $)$. Using the same family of ligands, the oxidative coupling of 2-naphthols could be carried out at room temperature with only $2 \mathrm{~mol} \%$ of complex in the presence of $2 \mathrm{~mol} \%$ of trimethylsilylchloride as promoter, leading to good yields and moderate enantioselectivities ( $82 \%$ yield and $51 \%$ ee for 2-naphthol; $91 \%$ yield and $51 \%$ ee for 7 methoxy-2-naphthol) [177].

Uang et al. developed a new family of ligands based on the same structure by introducing a naphthol substituent and therefore an additional (axial) element of chirality (105-106, Figure 6.6, Scheme 6.13) [178]. All ligands were synthesized from (S)-formyl-1,1'-bi-2-naphthol and various aminoacids with different $\mathrm{R}$ groups or absolute configuration of the carbon bearing the $\mathrm{R}$ group. The relative configuration of the two chirality elements has a strong influence on enantioselectivities: for $\mathrm{R}=\mathrm{Bn}$, the oxidative coupling of 2-naphthol yielded binaphthol with $52 \%$ ee for the matched diasteroisomer (105a) but only $8 \%$ ee for the mismatched diastereoisomer (106) under the same conditions [178]. The best enantioselectivities were 
obtained with the complex possessing $\mathrm{R}=\mathrm{Bn}(\mathbf{1 0 5 a})$ or $t \mathrm{Bu}(\mathbf{1 0 5 b})$ and $(R)$ configuration on the carbon.

A series of vanadium complexes obtained from other O,N,O ligands derived from aminoacids and ketopinic acid (107, Figure 6.6, Scheme 6.14) were investigated [179]. The best results were obtained with ligand $107 \mathrm{e}$. Working at $45^{\circ} \mathrm{C}$, the amount of vanadium complex could be limited to 3 mol\% while excellent yields and very high ees were obtained (for $\mathrm{R}=\mathrm{R}^{2}$ $=\mathrm{R}^{3}=\mathrm{H}: 99 \%$ yield, $84 \%$ ee; for $\mathrm{R}^{2}=\mathrm{R}^{3}=\mathrm{H}$ and $\mathrm{R}^{1}=\mathrm{OMe}, 99 \%$ yield and $88 \%$ ee).

Ligands bearing both axial and central chiralities were reported by Gong et al. [180]. These ligands were obtained from $(R)$ or $(S)$-3,3'-diformyl-2,2-dihydroxy-1,1'-bi-2-naphthol and various chiral aminoacids with different R groups (Figure 6.7, Scheme 6.15). Using 10 mol\% of vanadium dimers 108-109, excellent yields (up to 99\%) and enantioselectivities were obtained (up to $98 \%$ ee with $109 \mathrm{c}$ and $\mathrm{R}^{1}=\mathrm{R}^{3}=\mathrm{H}, \mathrm{R}^{2}=\mathrm{Br}$ ). They also synthesized complexes 110, analogues of complexes 109 made from achiral 3,3'-diformyl-2,2-dihydroxy-1,1'biphenol instead of enantiomerically pure 3,3'-diformyl-2,2-dihydroxy-1,1'-bi-2-naphthol [181,182], which is tedious to synthesize, or analogue 111 synthesized from partially hydrogenated 3,3'-diformyl-2,2-dihydroxy-1,1'-bi-2-naphthol (Figure 6.7) [182]. Up to 98\% ee were reached using ligands $\mathbf{1 1 0}$ and up to 97\% ee using ligand $\mathbf{1 1 1}$ [181,182]. Using ligand $110 f$ with $\mathrm{R}=\sec -\mathrm{Bu}$, a few chiral binaphthol syntheses could be optimized with great efficiency, leading to the expected compounds with greater than $98 \%$ ee and excellent yields (Scheme 6.16) [182,183].

With the same ligands, Sasai et al. synthesized the vanadium complexes 112-115 (Figure 6.7), which proved efficient in the aerobic oxidation of 2-naphthols (up to 97\% ee for 115) but gave binaphthols with the opposite axial chirality [184,185,186,187]. Finally, they compared the catalytic activities of complex 112 and of the corresponding mononuclear version 116 (Figure 6.7). For instance, for $\mathrm{R}=t \mathrm{Bu}$, under the same experimental conditions, the 2-naphthol 
coupling was 43 times faster with 5 mol\% 112a than with 10 mol\% 116, proving the synergic role of the two vanadium centers in complex 112a [184]. Complex 114 was used in the total synthesis of $(S)-2,2^{\prime}-1,1^{\prime}$-binaphtyl-5,5',6,6'-tetraol [188], the structure of which had been wrongly proposed for a metabolite isolated from a Indonesian sponge (Scheme 6.17) [189].

The first heterogeneous catalysts for the asymmetric coupling of naphthols were described by Iwasawa et al. These catalysts were obtained by grafting of chiral vanadium complexes of O,N,O ligands, derived from aminoacids (117, Scheme 6.18), on a silica surface [190,191,192]. The vanadium complexes grafted on silica self-dimerize, probably by H-bonding between the free hydroxyl groups and the carbonyl oxygen atoms of the neighboring complex, with a distance between two vanadium atoms of $0.4 \mathrm{~nm}$. These catalysts were successfully used in the aerobic oxidative coupling of 2-naphthol with good yields (up to 99\%), excellent chemioselectivities (up to 100\%) and excellent enantioselectivities (up to 91\% ee) for all tested $\mathrm{R}$ groups, except for $t \mathrm{Bu}$, which is probably too bulky. If the enantioselectivities did not change much as a function of the $\mathrm{R}$ group, they were however very sensitive to the vanadium loading on silica, the best results being obtained with the highest loadings corresponding to a full coverage of the silica surface. For instance, with complexes obtained from L-leucine, the ee of binaphthol was $32 \%$ at $0.3 \%$ loading and $90 \%$ at $3.4 \%$ loading. Finally, the heterogeneous complexes could be reused several times without loss of catalytic performances.

Chiral salan iron dimer 118 was successfully used in the aerobic oxidative coupling of substituted 2-naphthols [193], as good yields and enantioselectivities were reached, in particular for 3-substituted 2-naphthols (up to 97\% ee, Scheme 6.19). A large range of electron-rich 2naphthols and electron-poor 2-naphthols were also coupled in the presence of dimer 118. If the difference in electronic richness of the two cross-coupling partners was important enough, the homocoupling of the less electron-rich 2-naphthols could be completely suppressed and the 
cross-coupling product obtained with high selectivity and enantioselectivity, as exemplified in Scheme 6.20 [194].

\subsection{Enantioselective polymerization of naphthols}

\subsubsection{Copper-based reactions}

The first synthesis of chiral binaphtyl polymers [195] by asymmetric oxidative coupling of 2-naphthol substrates was performed using 1,5-diaza-cis-decalin (88a)-copper complexes $[\mathrm{Cu}(\mathbf{8 8 a})(\mathrm{OH})] \mathrm{X}$ (Scheme 6.21) [196,197]. The best catalysts in terms of activities and enantioselectivities were those with iodide or tetrafuoroborate anions but the tetrafluoroborate salt was preferred because iodine-containing by-products were observed when the iodide salt was used. In order to determine the stereoselectivity of each biaryl coupling, the polymerization was stopped at low conversion. Dimers and trimers were isolated and their analysis showed that each coupling proceeded independently with a 92.5/7.5 conformation ratio. In the same papers, Kozlowski et al. also described the synthesis of chiral binaphtyl polymers via a tandem reaction (oxidative coupling / Glaser reaction) (Scheme 6.22). The Glaser reaction can be carried out first using an achiral catalyst $(\mathrm{CuCl}(\mathrm{OH})(\mathrm{TMEDA}))$ followed by the asymmetric oxidative coupling of the dimer with the chiral catalyst $[\mathrm{Cu}(\mathbf{8 8 a})(\mathrm{OH})] \mathrm{BF}_{4}$, but both reactions can be carried out "one-pot" using the monomeric alkyne-naphthol in the presence of $[\mathrm{Cu}(\mathbf{8 8 a})(\mathrm{OH})] \mathrm{BF}_{4}$. Both ways led to the same polymer and no cross-coupling reaction products were observed. The conformation ratio of each asymmetric oxidative coupling was determined as $86.5 / 13.5$.

In 2003, bis(oxazoline) ligands $\mathbf{9 3}$ or $\mathbf{1 1 9}$ (Scheme 6.23) were used in an efficient copperbased asymmetric oxidative polymerization of 2,3-dihydroxynaphthalene [198]. If high yields of polymers of high molecular weights could be obtained, the control of axial chiralities was low (the $R / S$ ratio was estimated to be $44 / 56$ at best). In order to obtain polymers with higher 
specific rotations, chiral enantiomerically pure binaphthols had to be oxidatively coupled (Scheme 6.24) using chiral or achiral catalysts $[199,200,201]$. The specific rotations obtained with achiral catalysts could only be slightly increased in some cases with chiral catalysts.

Bis(oxazoline) 93-119a/CuCl complexes were also successfully used in the asymmetric oxidative coupling of an achiral binaphthol bearing an amide functional group (Scheme 6.25) [171]. Although the rotatory power of the polymers was high, the stereoselectivities were not reported.

\subsubsection{Polymerizations with other metals}

After testing several chiral vanadium complexes, Habaue and coworkers found that the vanadium complexes of bis(oxazolines) $\mathbf{9 3}$ or $\mathbf{1 1 9}$ were efficient catalysts for the asymmetric oxidative polymerization of 2,3-dihydroxynaphthalene (Scheme 6.26) [202]. The best results in terms of specific rotations and polydispersities of the polymers were obtained with ligand 93. By limiting the reaction time to $24 \mathrm{~h}$ at $\mathrm{rt}, 58 \%$ yield of polymer could be obtained with $M_{w}=2700$ g. $\mathrm{mol}^{-1}$ and a polydispersity index $M_{w} / M_{n}$ of 2.3 . The specific rotation $[\alpha]_{D}$ of this polymer was $-147^{\circ}$ (in $\mathrm{CHCl}_{3}$ ), higher than that obtained using copper complexes with bis(oxazoline) ligands [198]. The enantioselectivity of the first coupling reaction was estimated to be $90 / 10$ in favor of the $(S)$ conformation.

Polymers with even higher specific rotations $\left([\alpha]_{\mathrm{D}}=+172^{\circ}\right.$ in $\left.\mathrm{CHCl}_{3}\right)$ could be obtained using a cobalt salen complex 120 (Scheme 6.27) at low conversion [203]. For higher conversions, the polymer yield increased significantly but the specific rotation decreased dramatically (from +172 after $0.5 \mathrm{~h}$ to +9 after $24 \mathrm{~h}$ ) and the polydispersity index increased (up to 3.1 after $24 \mathrm{~h})$.

A mixture of $\mathrm{VO}(\text { stearate })_{2}$ and a tartaric acid salt $\mathbf{1 2 1}$ also proved an efficient catalyst to obtain polymers with high specific rotations (Scheme 6.28). The Li salt 121a was slightly more 
selective but less active. For the first coupling reaction, the enantiomeric excess of the product was determined as $88 \%$ with the sodium salt $\mathbf{1 2 1 b}$ and $89 \%$ for the lithium salt 121a [204].

\subsection{Conclusion}

If asymmetric oxidative coupling reactions of arenes to obtain enantiomerically enriched chiral biaryl compounds is essentially limited to the homocoupling of 2-naphthols, it is certainly the method of choice to obtain scalemic 1,1'-bis-2,2'-binaphthols with various substituents. In particular, asymmetric oxidative coupling reactions provided the necessary chiral intermediates for the synthesis of complex structures, especially natural products (Figure 6.3).

In addition, asymmetric oxidative coupling is an efficient way to obtain enantiomerically enriched polymers based on 1,1'-bis-2,2'-binaphthol units.

\section{7 - $[2+2+2]$ Cycloadditions}

The rapid construction of polycyclic compounds bearing functional groups has been elegantly developed by the means of transition metal-catalyzed $[2+2+2]$ cycloadditions and related in an important number of reviews [205], and stands as a sound alternative to classical C-C coupling reactions such as the Suzuki-Miyaura cross-coupling for the generation of biaryl structures. According to the generally accepted catalytic cycle (represented in Figure 7.1 for the rhodium-catalyzed version) [206], one of the limitations of this reaction is the chemoselectivity control during the first metallacycle formation and the regioselectivity during the insertion of the third alkyne. The most employed strategy to overcome this problem has been the use of tethered 1,6-dialkynes, and fewer totally intermolecular reactions were thus developed [207]. The pioneering work of Mori [208] and Stará and Starý [209] allowed the development of an asymmetric version using a nickel complex bearing the chiral ligand (S)-MeO-MOP 9 for the construction of, respectively, central and helical chirality. The first reports for the creation of axial chirality were only disclosed in 2004, almost simultaneously and independently, by three 
groups: Heller et al. used a chiral cobalt(I) complex [210], Shibata et al. developed a system based on iridium(I) associated to a chiral diphosphine ligand [211], and Tanaka et al. worked on a rhodium(I) complex bearing a chiral diphosphine ligand [212]. [2+2+2] cycloaddition reactions based on these three metals have then been developed and are described in the following subparts.

\subsection{Co catalysts}

When studying the $\mathrm{Co}^{\mathrm{I}}$-catalyzed $[2+2+2]$ cycloaddition of alkynes and nitriles to give pyridines, Heller and Gutnov discovered that irradiation allowed the reaction to proceed under mild conditions (room temperature, in water with a substrate/catalyst ratio of up to $10000 / 1$ ). In 2004, they took advantage of these results to develop the first asymmetric version of transition metal-catalyzed $[2+2+2]$ cycloaddition to generate axially chiral biaryls (Scheme 7.1), using chiral $\mathrm{Co}^{\mathrm{I}}$ complexes under mild conditions (THF, $20^{\circ} \mathrm{C}$, visible light irradiation) (Figure 7.2) [210]. Moderate yields (traces to 81\%) and ees (19-71\%) were obtained, and they observed that the enantioselectivity is solvent independent (THF, hexane, dioxane or toluene). In the authors' opinion, using bulkier substrates (in the presence of catalyst 125, Figure 7.2, Scheme 7.2) led to improved enantioselectivity, with $74-88 \%$ ee and $>98 \%$ ee after recrystallization [210]. As expected, ees increased from 82 to $93 \%$ when lowering the temperature from 20 to $-20^{\circ} \mathrm{C}(\mathrm{R}=\mathrm{Ph})$. The origin of the enantioselectivity was attributed to the formation of a diastereomeric cobaltacyclopentadiene intermediate 127 (Figure 7.3). In 2007, they extended the range of accessible products to axially chiral biaryls bearing phosphorus functionalities (Scheme 7.3) [213]. Moderate to good yields and ees (12-83\%: $>99 \%$ after recrystallization for those products with ee $>72 \%$ ) were reported under mild conditions $\left(25-45^{\circ} \mathrm{C}\right)$ using the most efficient catalyst 125. Finally, in 2010 they investigated the co-cyclotrimerization of a range of diynes and functional nitriles in order to gather 
information on the scope of the reaction [214]. Interestingly, heterocyclic nitriles bearing a sulfur or a nitrogen atom (ortho to the nitrile group) inhibited the catalyst activity, probably because of their chelating ability.

\subsection{Ir catalysts}

Shibata et al. reported in 2004 a highly enantio- and diastereoselective [2+2+2] cycloaddition catalyzed by iridium(I) complexes (Scheme 7.4) [211]. Various substrates and chiral ligands were used but the best ees (>99\%) were obtained with DuPhos ligands (128 Figure 7.4), whereas BINAP (6) and BDPP (59) (Figure 7.4) gave only 6\% and 51\% ee, respectively. One year later, they applied the same strategy for the enantioselective synthesis of helical polyaryls using polyalkyne substrates (Scheme 7.5) [215]. One can notice that these compounds present several consecutive axial chiralities (up to 8), in an almost enantiomerically pure form. In order to better understand the enantiomeric $[2+2+2]$ cycloaddition of diynes with monoalkynes (reactions similar to those described in Scheme 7.4), they screened the influence of various parameters [216]. They observed that in most cases the temperature ( $\mathrm{rt}$ to $100^{\circ} \mathrm{C}$ ) and the nature of $\mathrm{Z}$, Ar or R did not dramatically affect the ee value, underlying the robustness of the reaction. In the case of the reaction of unsymmetrical diynes with symmetrical monoalkynes, BINAP (6) and Tol-BINAP (15) ligands complexed to iridium appeared to give higher enantioselectivities than Me-DuPhos (128a), BDPP (59) or DIOP (1). Interestingly, they reported in 2006 and 2008 a highly enantioselective intramolecular [2+2+2] version of the reaction starting from triyne [217] (Scheme 7.6) and hexayne [218] substrates (Scheme 7.7), giving rise to complex chiral polycyclic molecules. If ligand $\mathbf{1 2 8 a}$ allowed reaching the best enantioselectivities for the $[2+2+2]$ cycloaddition of triynes, BINAP-type ligands appeared to be much more efficient than ligands $\mathbf{1 2 8}, \mathbf{5 9}$ or $(S, S)$-ChiraPhos 130 for the intramolecular cycloaddition of hexaynes. The same authors also reported in 2008 an interesting way to reach 
axially chiral anthracenes via a [4+2] cycloaddition of binaphthalene with monoalkynes presenting an ortho-substituted phenyl substituent via a proposed three-step mechanism (Scheme 7.8) [219]. Among the different ligands studied (BINAP (6), Me-DuPhos (128a) or Ph-BPE (129b) and Me-BPE (129a), Figure 7.4) the latter one gave the best enantioselectivity, higher than $65 \%$ ee. The presence of an electron-withdrawing group on one side of the alkyne and an electron-donating on the other side is also important to reach high enantioselectivities.

More recently, Takeuchi et al demonstrated that $[\operatorname{IrCl}(\mathrm{COD})]_{2} / \mathrm{BINAP}(\mathbf{6})$ was an efficient catalyst for the $[2+2+2]$ cycloaddition of 1,6-diynes with isocyanates under mild conditions, giving rise to a series of 2-pyrrolidones presenting axial chirality (Scheme 7.9) with moderate to good enantioselectivities [220]. The reaction also appeared to be regioselective with unsymmetrical diynes and the authors highlighted both steric and electronic effects.

\subsection{Rh catalysts}

\subsubsection{Axially chiral biaryls}

Rhodium is the privileged metal for asymmetric $[2+2+2]$ cycloadditions in that it produces more efficient and more easily tunable catalysts. Most examples make use of cationic rhodium(I) complexes associated to a chiral diphosphine bearing a biaryl or binaphthyl backbone. The first example of asymmetric, rhodium-catalyzed construction of axially chiral biaryls was disclosed by Tanaka et al. in 2004, shortly after the first reports dealing with cobalt and iridium catalysts. In this work, they described the synthesis of axially chiral phthalides by cross alkyne cyclotrimerization of electron-deficient 1,6 diynes and terminal monoynes (Scheme 7.10) [212]. The reactions were efficient and highly enantioselective, with up to $87 \%$ ee and $79 \%$ yield. The best results were obtained in the presence of $\left[\mathrm{Rh}(\operatorname{cod})_{2}\right]\left[\mathrm{BF}_{4}\right]$ associated to the partially hydrogenated ligand $(S)-\mathrm{H}_{8}-\mathrm{BINAP}(\mathbf{1 3 5})$. Using this catalytic system, they were able in 2005 to produce highly substituted biaryls via a completely intermolecular pathway 
(Scheme 7.11). Differently substituted internal alkynes were used in association with dialkyl acetylenedicarboxylates and the products were obtained with high enantioselectivities, ranging from $84 \%$ to $96 \%$ ee, and reasonable to good yields [221]. The same rhodium salt/chiral ligand combination allowed them to obtain synthetically challenging axially chiral, tetra-orthosubstituted biaryl phosphorus compounds that could be of great interest as ligands in other types of asymmetric catalyses (Scheme 7.12) [222]. Such structures could not be synthesized via asymmetric Suzuki-Miyaura cross-coupling, the latter being limited to less sterically challenging tri-ortho-substituted biaryl phosphonates [51]. Thus the coupling of alkynes bearing either phosphonate or phosphine oxide substituents with symmetrical 1,6-diynes furnished the expected sterically encumbered biaryls with very high yields (usually above 90\%) and excellent enantioselectivities (91-98\%). Similar structures, bearing an alkoxycarbonyl group in place of a phosphonate, were also synthesized in very high yields, albeit with lower enantioselectivities, and other chiral diphosphines proved more efficient than $(S)-\mathrm{H}_{8}$-BINAP in this case [223].

The use of $(S)$ - or $(R)$-SegPhos 18 was also more efficient than $(S)$ - $\mathrm{H}_{8}$-BINAP 135 or other BINAP derivatives for the synthesis of biaryl diphosphonates and dicarboxylates (Scheme 7.13) [224]. Thus the reaction of 1,6-diynes with a 1,3-diyne bearing two electron-withdrawing diethylphosphonate substituents in the presence of $5 \mathrm{~mol} \%\left[\mathrm{Rh}(\operatorname{cod})_{2}\right]\left[\mathrm{BF}_{4}\right] /(R)-\mathrm{SegPhos}$, at room temperature in dichloromethane, led to axially chiral biaryl diphosphonates in moderate to good yields (59-81\%) and excellent enantioselectivities (>99\%), even when lowering the catalytic charge to $1 \mathrm{~mol} \%$ and could be scaled up to an $18 \mathrm{~g}$ batch. The synthesis of dicarboxylates under the same conditions was also successful [224], whereas axially chiral biaryls bearing diphosphine oxide substituents, precursors of axially chiral biaryl diphosphines, were obtained with higher enantioselectivities when $(S)$-Tol-BINAP 15 was used [225]. SegPhos 18 proved its usefulness again for the preparation of $C_{2}$-symmetric, tetra-ortho- 
substituted axially chiral biaryls, either from electron-deficient 1,6-diynes and 1,3-diynes (type 1) or from ether-linked tetraynes and electron-deficient monoynes (type 2) (Scheme 7.14) [226]. Axially chiral biaryls were obtained in excellent enantioselectivities (>98\%) and moderate yields via type 1 coupling, whereas type 2 coupling led to moderate yields and more modest enantioselectivities (52 to $98 \%$ ee) under the same conditions. The cycloaddition of chiral tetraynes with monoynes was then examined, in the presence of achiral and chiral ligands, and the results showed that the axial chirality was solely controlled by the nature of the monoyne and not by the chirality of the ligand (Scheme 7.15) [227]. Finally, 1,4-teraryls bearing an anthraquinone backbone were successfully obtained from 1,2-bis(arylpropiolyl)benzenes and monoynes, using $\left[\mathrm{Rh}(\operatorname{cod})_{2}\right]\left[\mathrm{BF}_{4}\right]$ and $(S)-$ SegPhos $18(10 \mathrm{~mol} \%)$ (Scheme 7.16) [228]. Other diphosphine ligands or metal precursors $\left([\mathrm{Rh}(\operatorname{cod}) \mathrm{Cl}]_{2},\left[\operatorname{Ir}(\operatorname{cod})_{2}\right]\left[\mathrm{BF}_{4}\right]\right)$ were also evaluated but gave poorer results in terms of activity. Thus axially chiral 1,4-teraryls were generated, with the simultaneous creation of two chiral axes. Good yields and excellent enantioselectivities of the major diastereomers (85-98\% ee) were obtained, although the levels of diastereoselectivity were not always satisfactory (from 8:1 to 2:1).

Finally, synthetically useful axially chiral hydroxyl carboxylic acid derivatives, accessible via other methods (for example asymmetric Suzuki-Miyaura cross-coupling [87]), were investigated by the group of Tanaka [223]. They found that the reaction of a 2methoxynaphthalene-derived alkynylester with an ether-linked 1,6-diyne proceeded smoothly in the presence of $5 \mathrm{~mol} \%$ of $\left[\mathrm{Rh}(\operatorname{cod})_{2}\right]\left[\mathrm{BF}_{4}\right]$ and a chiral diphosphine (Scheme 7.17). In this case, the BINAP ligand 6 was selected, although other BINAP derivatives also proved very efficient. Various 1,6-diynes, as well as one 1,7-diyne, were coupled to the alkynylester and gave the axially chiral hydroxyl carboxylic acid derivatives in very good yields (>90\%, except $71 \%$ for the 1,7-diyne) and enantioselectivities (89-97\% ee). The presence of the 2methoxynaphthalene moiety proved essential for a high enantioselection, since the absence of 
either the naphthyl backbone or the methoxy group furnished the products with, respectively, $<5 \%$ and $26 \%$ ee.

The group of Shibata investigated the formation of chiral tetraphenylene structures by rhodium-catalyzed $[2+2+2]$ cycloadditions [229]. These molecules, constituted of four orthoannulated benzene rings, are usually achiral and possess a $D_{2 \mathrm{~d}}$ point symmetry. However, the introduction of substituents on the benzene rings may break this symmetry to give chiral $\pi$ conjugated systems that possess very high inversion barriers. Before the work of Shibata et al., the synthesis of optically active chiral tetraphenylenes were based on the resolution of racemic compounds [230] or on enantioselective syntheses with the sparteine-mediate lithiation of 2,2'dibromobiphenyl derivatives followed by oxidative homocoupling in the presence of an excess of $\mathrm{CuBr}_{2}$ [231]. Therefore, the rhodium-catalyzed dimerization of triynes was investigated as a more efficient way to get access to chiral tetraphenylene derivatives (Table 7.1) [229]. Several chiral diphosphine ligands were evaluated in association with $\left[\mathrm{Rh}(\operatorname{cod})_{2}\right]\left[\mathrm{BF}_{4}\right](5 \mathrm{~mol} \%)$ for the dimerization of a triyne in 1,2-dichloroethane and both Cy-BINAP 16 and QuinoxP* 138 proved the most efficient, giving the expected tetraphenylene with $84 \%$ yield and $79 \%$ ee or $65 \%$ yield and $88 \%$ ee, respectively. The substrate scope was also investigated and differently substituted tetraphenylene derivatives were thus prepared in good yields and high enantioselectivities (75 to $>99 \%$ ee).

Similarly to Tanaka, Doherty et al. investigated the formation of axially chiral biaryl diphosphines via rhodium-catalyzed $[2+2+2]$ cycloaddition (Scheme 7.18) [232]. The reaction of a 1,6-diyne with the diphosphine oxide-substituted diyne, in the presence of $[\operatorname{Rh}\{(R)$ BINAP $\}]\left[\mathrm{PF}_{6}\right](10 \mathrm{~mol} \%)$ in 1,2-dichloroethane at $80^{\circ} \mathrm{C}$, selectively furnished the monocycloaddition product in very good yields with no trace of the expected axially chiral biaryl product. The former then reacted with less sterically challenging terminal 1,6-diynes, again in the presence of $[\operatorname{Rh}\{(R)-\mathrm{BINAP}\}]\left[\mathrm{PF}_{6}\right](10 \mathrm{~mol} \%)$ in 1,2 -dichloroethane at $80^{\circ} \mathrm{C}$, to 
give the axially chiral biaryl diphosphine oxides in very good yields (79-84\%) and excellent enantioselectivities $(96-97 \%$ ee). Further reduction of the phosphine oxides furnished the axially chiral biaryl phosphines in excellent yields with no loss of enantioselectivity.

More recently, Caminade, Pla-Quintana et al. investigated the use of dendritic ligands for the rhodium-catalyzed $[2+2+2]$ cycloaddition of a N-tosyl-1,6-diyne with 2methoxynaphthalene alkynyl derivatives (Table 7.2) [233]. The chiral ligand chosen for this study was a monodentate phosphoramidite, which had never been used before as ligand in $[2+2+2]$ cycloaddition reactions. A monomeric (141-M) and a branched (141-B) ligand were synthesized for comparison purposes and generation 1 (141-G1, 12 phosphoramidites), generation 2 (141-G2, 24 phosphoramidites) and generation 3 (141-G3, 48 phosphoramidites) dendritic ligands were prepared (Figure 7.6). The cycloaddition reactions were carried out in the presence of $2.5 \mathrm{~mol} \%\left[\mathrm{Rh}\left(\mathrm{C}_{2} \mathrm{H}_{4}\right)_{2} \mathrm{Cl}\right]_{2}$ and chiral ligand, in toluene at room temperature. Although the monomeric and branched ligands were poorly efficient, the use of dendritic ligands 141-G1 to 141-G3 proved very rewarding, giving the expected axially chiral biaryls in good to excellent yields and high enantioselectivities. The reaction was more efficient in the case of phosphonate-based substrates ( $>97 \%$ yield, $>96 \%$ ee) compared to carboxylate-based substrates (70-77\% yield, 81-90\% ee). These results showed an unprecedented enhancement of stereoselectivity thanks to a positive dendritic effect.

\subsubsection{Axially chiral heterobiaryls}

Rhodium catalysts are most often employed for the generation of axially chiral heterobiaryls by asymmetric [2+2+2] cycloadditions and the use of cationic rhodium(I) precursors seems necessary to achieve good activities. Tanaka et al. thus investigated the formation of several axially chiral heterobiaryls with the help of a catalytic system that proved highly efficient for the synthesis of axially chiral biaryls, i.e. $\left[\mathrm{Rh}(\operatorname{cod})_{2}\right]\left[\mathrm{BF}_{4}\right]$ associated to a 
BINAP derivative. In 2005, they described the synthesis of 2-pyridones via the $[2+2+2]$ cycloaddition of unsymmetrical 1,6-diynes, bearing one ortho-substituted phenyl group, with alkyl isocyanates (Scheme 7.19) [234]. The sterically bulky $(R)$-DTBM-SegPhos ligand 19b was chosen for the reaction and the expected axially chiral 2-pyridones were obtained in moderate to good yields $(58-89 \%)$ and high enantioselectivities $\left(85-92 \%\right.$ ee), at $-20^{\circ} \mathrm{C}$ in dichloromethane. The presence of a halogen substituent in ortho position of the phenyl group proved essential for the outcome of the reaction. The use of 2-substituted phenyl isocyanates as substrates was also a valuable option for the synthesis of $\mathrm{N}$-aryl-2-pyridones [235]. The cycloaddition of the former with symmetrical 1,6-diynes in the presence of $\left[\mathrm{Rh}(\operatorname{cod})_{2}\right]\left[\mathrm{BF}_{4}\right](5$ mol\%) led to the expected products and the ligand that gave the best enantioselectivities was in this case $(R)$-BINAP 6. The ees obtained were however lower than that usually obtained for this type of reaction (30-87\%). In parallel to their work on the synthesis of axially chiral biaryl phosphorus compounds, Tanaka et al. also reported the first synthesis of axially chiral diphenylphosphinoyl-substituted 1-arylisoquinolines by asymmetric catalysis (Scheme 7.20) [236]. These compounds could prove very useful as chiral ligands. To this aim, several BINAP derivatives were screened as chiral ligands and most showed good activity at high catalyst loading (20 mol\%), but $(R)-\mathrm{H}_{8}$-BINAP 135 proved the best choice when the catalytic charge was lowered to $5 \mathrm{~mol} \%$. Very high enantioselectivities were obtained when a methyl substituent was introduced at the 8 position of the isoquinoline substrate ( $>90 \%$ ee). Very recently, the same authors reported efficient $[2+2+2]$ cycloadditions with carbodiimides, using either $(S)$ $\mathrm{H}_{8}$-BINAP 135 or DTBM-SegPhos $19 \mathrm{~b}$ as ligands, with enantioselectivities ranging from 70 to $91 \%[237]$.

The group of Hsung related the rhodium-catalyzed synthesis of chiral N,O-biaryls, with the control of both $\mathrm{C}-\mathrm{C}$ and $\mathrm{C}-\mathrm{N}$ axial chirality, as chiral auxiliary-based approaches failed to give satisfactory results in terms of diastereoselectivity [238]. The [2+2+2] cycloaddition of 
asymmetric ynamides and symmetrical 1,6-diynes was carried out in the presence of $\left[\mathrm{Rh}(\operatorname{cod})_{2}\right]\left[\mathrm{BF}_{4}\right]$ and $(S)$-xylyl-BINAP $17(10 \mathrm{~mol} \%)$, at $85^{\circ} \mathrm{C}$ in 1,2-dichloroethane (Table 7.3$)$. In the case of ynamides containing 5-membered 2-oxazolidinones, the chiral N,O-biaryls were obtained in good yields (>78\%) and high enantioselectivities (82 to $99 \%$ ee), although the diastereoisomeric ratios varied from 1:1 to 1:6.

An original approach, based on the use of chiral counteranions, was recently applied to rhodium-catalyzed $[2+2+2]$ cycloadditions by Aubert, Fensterbank and Ollivier for the synthesis of axially chiral pyridones and represents the first example of atroposelective transformation using asymmetric counteranion-directed catalysis (Table 7.4) [239]. Based on the screening of various diphosphines and chiral silver phosphate salts 142a-e, the best combination for the catalyzed [2+2+2] cycloaddition of a symmetrical 1,6-diyne and a 2substituted phenyl isocyanate was $[\mathrm{Rh}(\operatorname{cod}) \mathrm{Cl}]_{2}$ with dppb (5 mol\%) and $7.5 \mathrm{~mol} \%$ of the chiral silver salt 142a. Ees ranging from 4 to $82 \%$ were obtained according to the substrates used and in some cases (with alkoxylated isocyanates) were better than those obtained via the more “classical” approach with chiral BINAP derivatives.

\subsection{Conclusion}

The $[2+2+2]$ cycloaddition reaction is an interesting strategy to assemble chiral biaryl, heterobiaryl or polyaryl structures and allows the synthesis of challenging tetra-orthosubstituted biaryls, which is more difficult via other reactions such as Suzuki-Miyaura crosscoupling. However, this powerful method necessitates the design and synthesis of the alkyne substrates beforehand. In addition, few totally intermolecular reactions have been developed so far due to chemoselectivity and regioselectivity problems during the catalytic cycle and research efforts will undoubtedly continue to overcome this limitation. 


\section{8 - General conclusion}

Interest in the development of efficient synthetic methods to obtain chiral enantiomerically enriched biaryl compounds has remained strong over the last decades because of the numerous applications in the total synthesis of biologically relevant molecules, in the development of chiral ligands for asymmetric catalysis, in materials chemistry, etc. Among the various strategies imagined by chemists, asymmetric catalytic reactions with transition metals have probably opened the most promising pathways. We have presented here an overview of this rapidly expanding area through six major reactions: the Kumada-Tamao-Corriu cross-coupling reaction, the Suzuki-Miyaura cross-coupling reaction, the Negishi cross-coupling reaction, the direct $\mathrm{C}-\mathrm{H}$ functionalization, the oxidative coupling of functionalized arenes and the $[2+2+2]$ cycloaddition reactions.

The Kumada-Tamao-Corriu cross-coupling reaction suffers from the low tolerance of organomagnesium compounds to other functional groups and water. The development of more stable functionalized Grignard reagents in the last decade opens new perspectives for this reaction, which remains however one of the most delicate reactions together with Negishi-type cross-couplings, both requiring anhydrous conditions. The Suzuki-Miyaura cross-coupling reaction, on the other hand, is very tolerant to numerous functional groups and to various reaction conditions. Even though high activities and enantioselectivities were reported, no ligand really emerges so far as universal and the enantioselectivity control appears to be strongly medium- and functional group-dependent. Interestingly, the emergence of $\mathrm{C}-\mathrm{H}$ activation (or $\mathrm{C}-\mathrm{H}$ functionalization) in the last ten years enlarges the scope of potential substrates (substituted arenes instead of substituted aryl halides), opening an alternative way to chiral biaryl products. Oxidative coupling is the method of choice to obtain enantiomerically enriched 1,1'-2,2'-binaphthols bearing a large variety of substituents but it appears to be essentially limited to the homocoupling or polymerization of 2-naphthols. Finally, the $[2+2+2]$ 
cycloaddition reaction is another interesting strategy to assemble chiral biaryl or chiral polyaryl structures and allows the synthesis of challenging tetra-ortho-substituted biaryls. However, this powerful method necessitates the careful design and synthesis of the alkyne substrates before running the cycloaddition step.

By a careful choice of the asymmetric catalytic reaction, many chiral biaryl compounds are now available in high enantiomeric purity but there is still room for improvement. We can therefore predict that research efforts to improve the catalytic access to scalemic biaryl compounds will continue for all reactions and especially in emerging and largely unexplored fields, such as direct $\mathrm{C}-\mathrm{H}$ functionalization.

\section{Acknowledgements}

We thank the Ministère de l'Enseignement Supérieur et de la Recherche (doctoral grant to P. L.) for financial support of this work. 


\section{Schemes}

\section{2 - Kumada-Corriu}

Scheme 2.1 - First asymmetric aryl-aryl Kumada-Tamao-Corriu cross-coupling reactions by Kumada et al. $[8,10]$.

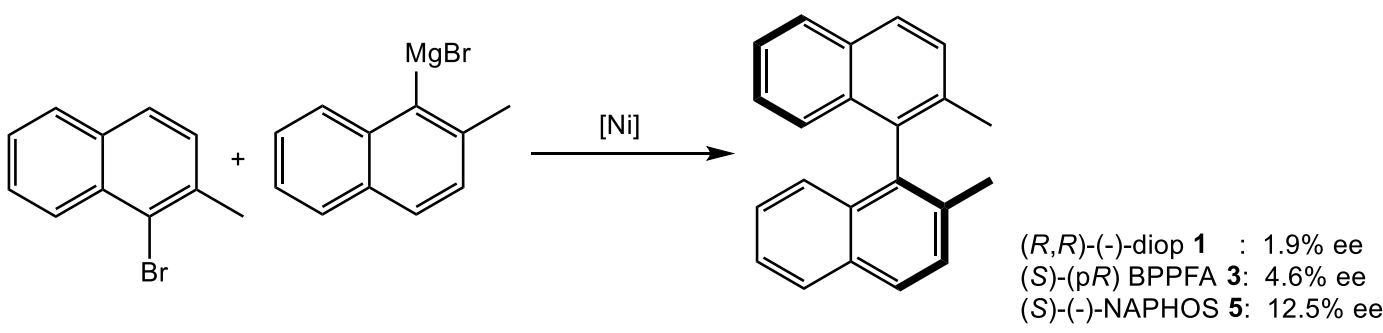

Scheme 2.2 - First efficient asymmetric aryl-aryl cross-coupling by Hayashi et al. [11].<smiles>[R]c1ccc2ccccc2c1[N+]Br</smiles>

$\mathrm{R}^{1}=\mathrm{H}, \mathrm{Me}, \mathrm{Et}$

$\mathrm{R}^{2}=\mathrm{H}, \mathrm{Me}$
[Ni] / $\mathbf{4 a}, \mathbf{4 b}$ or $\mathbf{4 c}$<smiles>[R]c1ccc2ccccc2c1-c1c([R])ccc2ccccc12</smiles>

$69 \%$ yield, $95 \%$ ee $\left(R^{1}, R^{2}=M e ; L^{*}=4 a\right)$

Scheme 2.3 - KTC with a chiral palladium-NHC complex by Dorta et al. [13].<smiles>[R]c1ccc2ccccc2c1[N+](=O)Br</smiles><smiles>[R]c1ccc2ccccc2c1[X]</smiles>

$\mathrm{X}=\mathrm{Cl}, \mathrm{Br}$

$\mathrm{R}^{1}, \mathrm{R}^{2}=\mathrm{H}, \mathrm{Me}, \mathrm{OMe}$
(aS, aS)-10 (2 $\mathrm{mol} \%)$

\section{toluene}

rt or $50^{\circ} \mathrm{C}$

$16 \mathrm{~h}$<smiles>[R]c1ccc([C])c(-c2c([R])ccc3ccccc23)c1C=C</smiles>

$\mathrm{R}^{1}=$ OMe, 1-bromonaphthalene:

$81 \%$ yield, $48 \%$ ee 
Scheme 2.4 - Substitution of an enantiotopic triflate by Hayashi et al. [14].

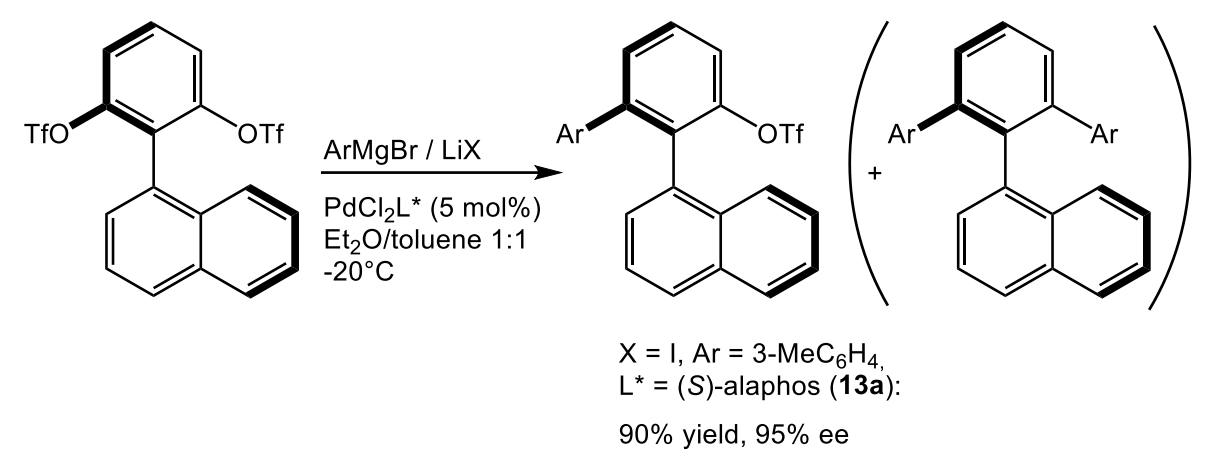

Scheme 2.5 - Reaction of a Grignard reagent on a dibenzo- or a dinaphthothiophene by Hayashi et al. [17].<smiles>[R]c1cccc2sc3cccc([R])c3c12</smiles>

$\mathrm{R}^{1}=\mathrm{Me}, \mathrm{Bu}, \mathrm{Ph}$

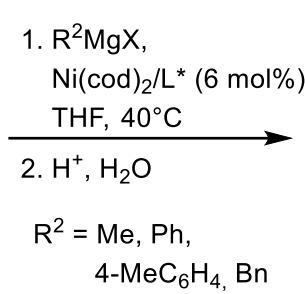<smiles>[R]c1cccc([R])c1-c1c([R])cccc1S</smiles>

$\mathrm{R}^{1}=\mathrm{Me}, \mathrm{R}^{2}=4-\mathrm{MeC}_{6} \mathrm{H}_{4}$ : $85 \%$ yield, $82 \%$ ee<smiles>c1ccc2c(c1)ccc1sc3ccc4ccccc4c3c12</smiles>

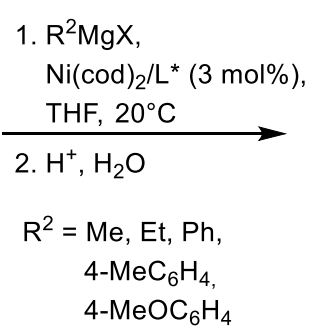
$L^{*}=(S)-i \operatorname{Pr}$-phox 11

$\mathrm{R}^{2}=4-\mathrm{MeC}_{6} \mathrm{H}_{4}:$ $97 \%$ yield, $95 \%$ ee 


\section{3 - Suzuki-Miyaura}

Scheme 3.1 - Axial chirality induction via (i) planar, (ii) central or (iii) ligand chirality in asymmetric Suzuki-Miyaura coupling.
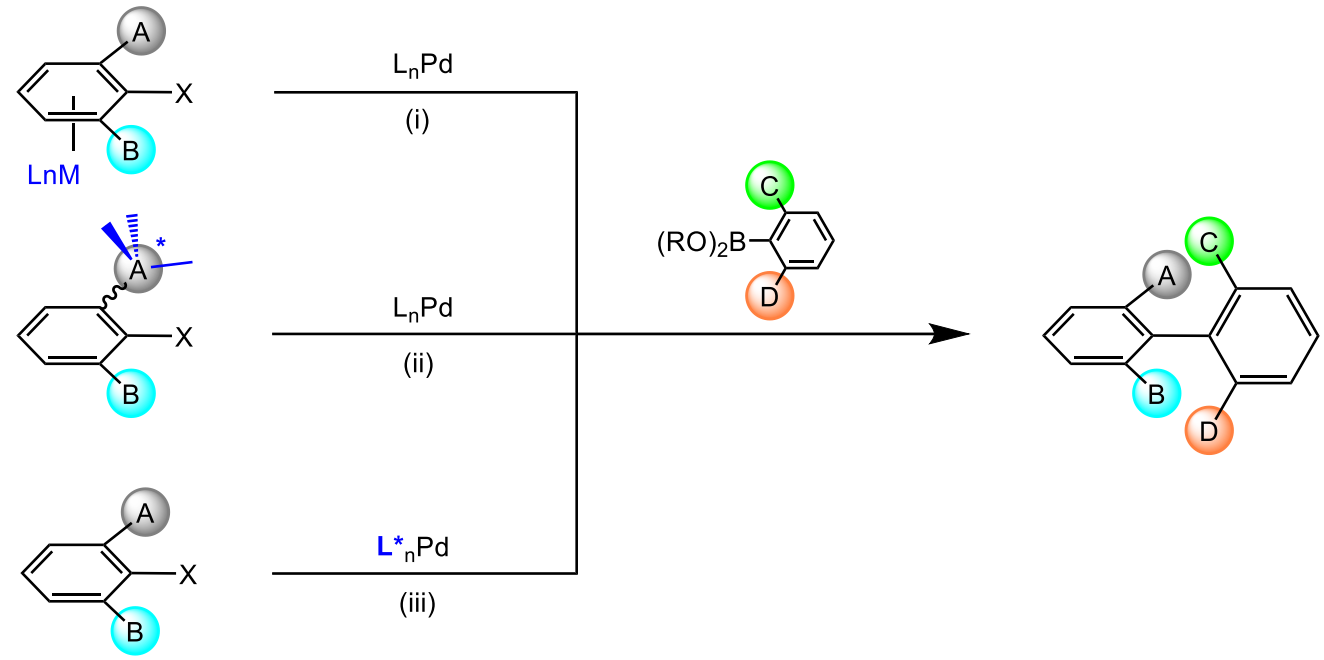

Scheme 3.2 - Simplified Suzuki-Miyaura catalytic cycle.

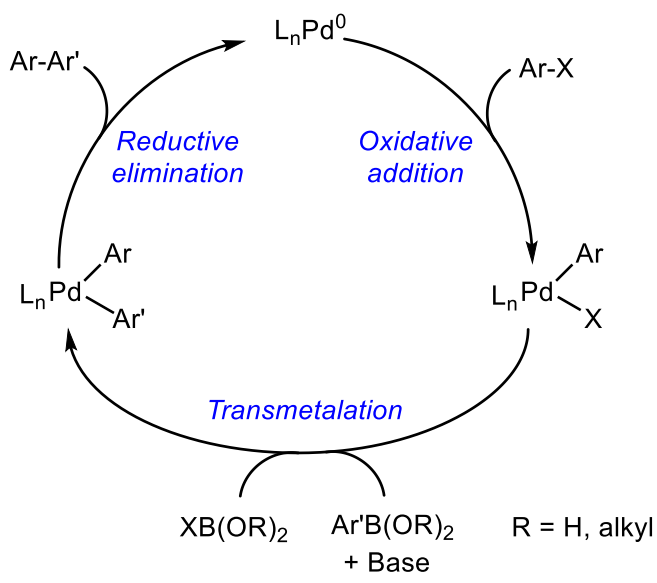


Scheme 3.3 - Ligand-dependent chemioselectivity.<smiles>Oc1ccccc1Oc1cccc(Cl)c1</smiles><smiles>COc1ccccc1C</smiles>

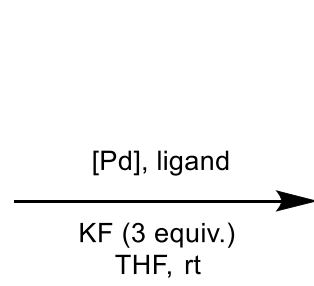

Cl)<smiles>Cc1ccccc1-c1ccc(O)cc1</smiles>

Yield: $95 \%$

$\mathrm{Pd}_{2}(\mathrm{dba})_{3} 1.5 \mathrm{~mol} \%$ $\mathrm{P}\left({ }^{\mathrm{t}} \mathrm{Bu}\right)_{3} \quad 3.0 \mathrm{~mol} \%$

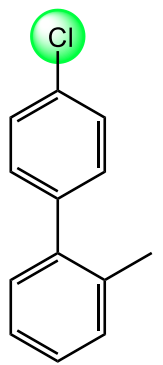

Yield: $87 \%$

$\mathrm{Pd}(\mathrm{OAc})_{2} 1.5 \mathrm{~mol} \%$ $\mathrm{P}(\mathrm{Cy})_{3} \quad 3.0 \mathrm{~mol} \%$

Scheme 3.4 - Proposed transmetalation pathways.

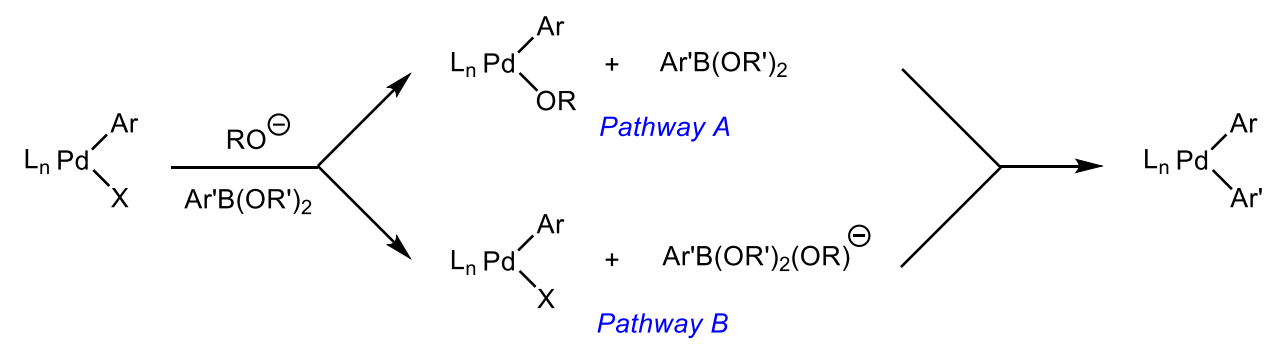

Scheme 3.5 - Suzuki-Miyaura catalytic cycle proposed by Amatore and Jutand [78-80].

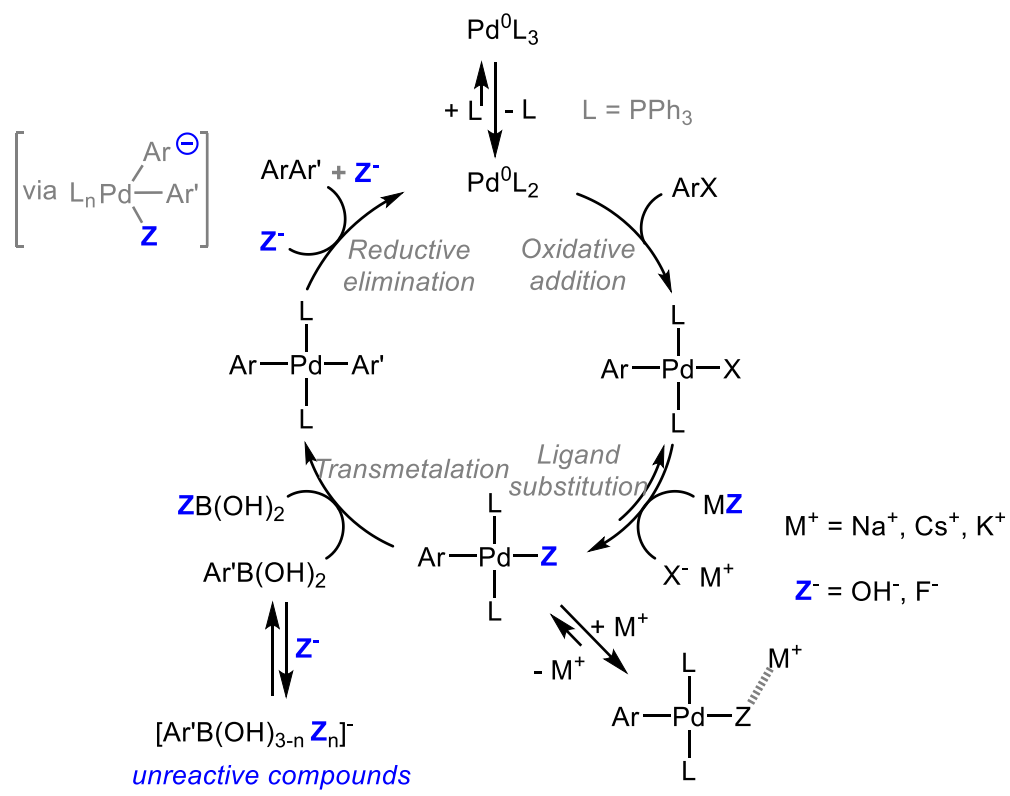


Scheme 3.6 - Asymmetric Suzuki-Miyaura coupling of naphthyl halides with naphthylboronic acids [50,81].<smiles>[R]c1ccc2ccccc2c1I</smiles>

$\mathrm{R}=\mathrm{H}, \mathrm{Me}$<smiles>CO[R10](=O)c1c(C)ccc2ccccc12</smiles>

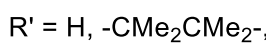
$-\mathrm{CH}_{2} \mathrm{CH}_{2-}$
$\mathrm{PdCl}_{2}(3 \mathrm{~mol} \%)$

BINAP (6) (3 mol \%)

Base (1.5-2 eq)

Solvent, reflux

$19 \mathrm{~h}-6$ days

Solvent $=\mathrm{DME}$

DME- $\mathrm{H}_{2} \mathrm{O}$, toluene<smiles>[R]c1ccc2ccccc2c1-c1c(C)ccc2ccccc12</smiles>

Yield: $17-55 \%$ ee: $8-25 \%$

Scheme 3.7 - Asymmetric Suzuki-Miyaura coupling of ortho-methoxy naphthyl halides with ortho-methoxy naphthylboronic acids varying the Pd/BINAP ratio from 0.53 to 3 [82].<smiles>[X]c1c(OC)ccc2ccccc12</smiles>

$\mathrm{X}=\mathrm{I}, \mathrm{Br}$<smiles>COc1ccc2ccccc2c1Br</smiles>

$\mathrm{Pd}(10-20 \mathrm{~mol} \%)$ Pd/BINAP (6) (0.53-3.1) CsF $(6$ eq) DME or Dioxane $70^{\circ} \mathrm{C}$ $6-12 \mathrm{~h}$

$\mathrm{Pd}_{2}(\mathrm{dba})_{3} \quad(10 \mathrm{~mol} \%)$ $\mathrm{Pd}(\mathrm{OAc})_{2} \quad(10 \mathrm{~mol} \%)$ $\left(\eta^{3} \text {-allylPdCl }\right)_{2} \quad(20 \mathrm{~mol} \%)$<smiles>COc1ccc2ccccc2c1-c1c(OC)ccc2ccccc12</smiles>

Yeld: $19-94 \%$ ee: $14-30 \%$

Scheme 3.8 - Synthesis of chiral biaryl compounds containing esters, phosphonates and phosphine oxides [87].<smiles>COC(=O)c1ccc2ccccc2c1Br</smiles><smiles>Cc1ccccc1OCCO</smiles>

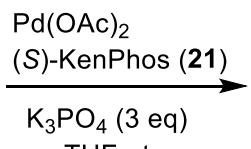
THF, rt<smiles>[R12]NC(=O)c1ccc2ccccc2c1-c1ccccc1C</smiles><smiles>O=P(O)(O)c1ccc2ccccc2c1Br</smiles><smiles>Cc1ccccc1Br</smiles>

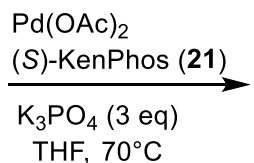
$\mathrm{K}_{3} \mathrm{PO}_{4}(3 \mathrm{eq})$
$\mathrm{THF}, 70^{\circ} \mathrm{C}$<smiles>Cc1ccccc1-c1c(P(=O)(O)OCc2ccccc2)ccc2ccccc12</smiles><smiles>O=[PH](=O)(O)c1ccc2ccccc2c1Cl</smiles><smiles>COc1ccccc1C</smiles>

$\mathrm{Pd}(\mathrm{OAc})_{2}$ $\underset{\mathrm{K}_{3} \mathrm{PO}_{4} \text { (3 eq) }}{\stackrel{(S)-K e n P h o s ~(21)}{\longrightarrow}}$ THF, $100^{\circ} \mathrm{C}$<smiles>Cc1ccccc1-c1c(P(=O)(O)[Na])ccc2ccccc12</smiles> 
Scheme 3.9 - Synthesis of axially chiral biaryl amides [87].

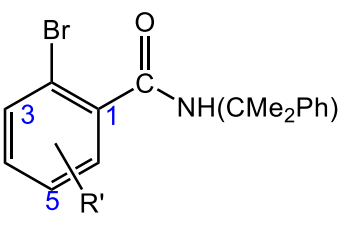

$\mathrm{R}^{\prime}=\mathrm{H}, 4-\mathrm{F}, 4-\mathrm{Me}, 4-\mathrm{NO}_{2}$, $5-\mathrm{OMe}, 5-\mathrm{CF}_{3}, 5-\mathrm{F}$

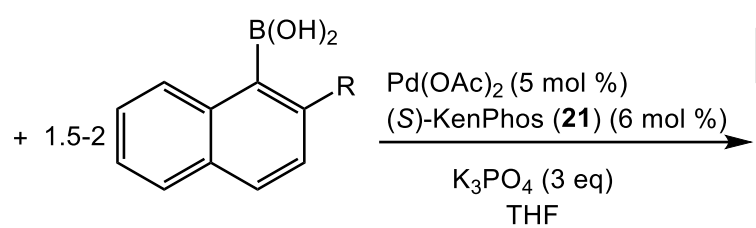

$\mathrm{R}=\mathrm{Me}, \mathrm{OEt}$

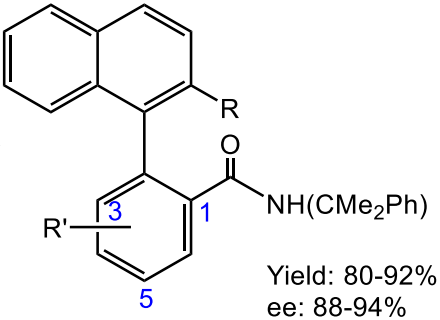

Scheme 3.10 - Synthesis of an axially chiral biaryl pyridine derivative [87].<smiles>CC(NC(=O)c1ccncc1Br)c1ccccc1</smiles><smiles>Cc1ccc2ccccc2c1Br</smiles>

$\mathrm{Pd}(\mathrm{OAc})_{2}(5 \mathrm{~mol} \%)$ (S)-KenPhos (21) (6 mol \%) $\mathrm{K}_{3} \mathrm{PO}_{4}(3 \mathrm{eq})$ $\mathrm{THF}, 80^{\circ} \mathrm{C}$<smiles>Cc1ccc2ccccc2c1-c1cnccc1C(=O)NCc1ccccc1</smiles>

ee: $70 \%$

Scheme 3.11 - Ligand screening for the synthesis of an axially chiral biaryl as intermediate of a biologically relevant molecule [88].<smiles>[R]OCC(CC)(CC)c1ccccc1I</smiles>

$\mathrm{R}=\mathrm{MOM}$<smiles>[Y]c1ccccc1N</smiles>

$\mathrm{Y}=\mathrm{B}(\mathrm{pin}), \mathrm{B}(\mathrm{OH})_{2}$
$\mathrm{Pd}_{2}(\mathrm{dba})_{3} \cdot \mathrm{CHCl}_{3}(2.5 \mathrm{~mol} \%)$ 21, 22a or 22b $(6 \mathrm{~mol} \%)$

$\mathrm{Ba}(\mathrm{OH})_{2}(2 \mathrm{eq})$ dioxane/water $(9 / 1)$ $80^{\circ} \mathrm{C}, 1 \mathrm{~h}$

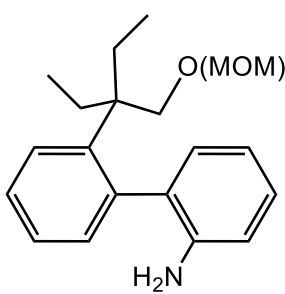

Yield: $8-56 \%$ ee: $3-41 \%$

Scheme 3.12 - Application of ligands 22b-c for the synthesis of an axially chiral biaryl [88]. 


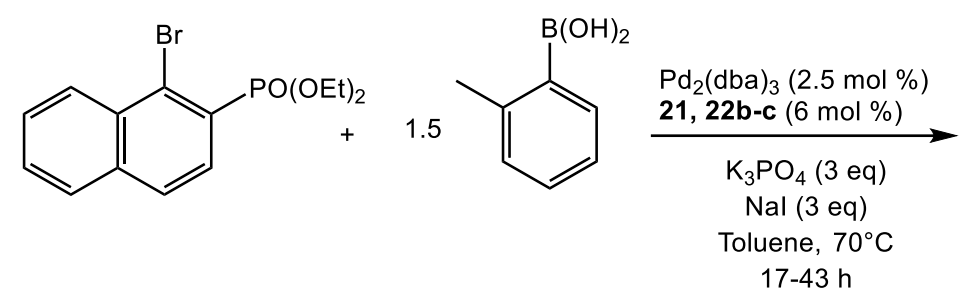<smiles>CCOc1ccc2ccccc2c1-c1ccccc1C</smiles>

Yield: $5-93 \%$ ee: $77-87 \%$

Scheme 3.13 - Application of ligands $\mathbf{2 4 c - d}$ for the synthesis of axially chiral biaryls [90].<smiles>CCO[SnH3]</smiles><smiles>Cc1ccc2ccccc2c1Br</smiles>

$\mathrm{Pd}_{2}(\mathrm{dba})_{3}(2 \mathrm{~mol} \%)$ 24c (8 $\mathrm{mol} \%)$

CsF (3 eq) toluene, $40^{\circ} \mathrm{C}$ $144 \mathrm{~h}$<smiles>Cc1ccc2ccccc2c1-c1ccccc1COC(C)(C)C</smiles><smiles></smiles>

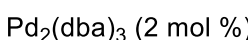
24d (8 $\mathrm{mol} \%)$ $\mathrm{CsF}$ (3 eq) toluene, $40^{\circ} \mathrm{C}$ $120 \mathrm{~h}$<smiles>Cc1ccccc1-c1c(CO[Na])ccc2ccccc12</smiles>

Scheme 3.14 - Application of ligands 25a-g for the synthesis of an axially chiral biaryl [91].<smiles>CCOc1ccc2ccccc2c1Br</smiles><smiles>Oc1cccc2ccccc12</smiles>

\section{$\mathrm{Pd}_{2}(\mathrm{dba})_{3}(2 \mathrm{~mol} \%)$ 25a-g $(4.8 \mathrm{~mol} \%)$ \\ $\mathrm{K}_{3} \mathrm{PO}_{4}(3 \mathrm{eq})$ toluene, $40^{\circ} \mathrm{C}$} $40 \mathrm{~h}$<smiles>CCOc1ccc2ccccc2c1-c1cccc2ccccc12</smiles>

Conversion: $62-90 \%$ ee: $71-88 \%$

Scheme 3.15 - MOP-type ligands screening [92]. 
<smiles>CCOP(=O)(OCC)c1ccc2ccccc2c1Br</smiles><smiles>COc1ccccc1C=O</smiles>
toluene, $50^{\circ} \mathrm{C}$<smiles>CCOc1ccc2ccccc2c1-c1ccccc1C=O</smiles>

26, 27b, 27c: Yield $=65-93 \%$ ee $=93-96 \%$

9, 27d, 27e: Yield $=30-70 \%$ ee $=68-81 \%$

Scheme 3.16 - Synthesis of multifunctionalized axially chiral biaryls with ligand 26 [92].<smiles></smiles>

$\mathrm{R}=\mathrm{OMe}, \mathrm{OEt}$, $\mathrm{OPh}, \mathrm{OiPr}$ $\mathrm{Ph}, 4$-tolyl, 3,5-xylyl

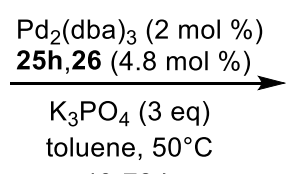
48-72 h<smiles>[R]c1cccc(C=O)c1-c1c([R20])ccc2ccccc12</smiles>

Scheme 3.17 - Asymmetric Suzuki-Miyaura coupling of naphthyl halides with naphthylboronic acids with ligands $\mathbf{2}$ and $\mathbf{3}[50,81]$<smiles>[R]c1ccc2ccccc2c1I</smiles>

$\mathrm{R}=\mathrm{H}, \mathrm{Me}$<smiles></smiles>

$\mathrm{R}^{\prime}=\mathrm{H},-\mathrm{CH}_{2} \mathrm{CH}_{2}-$
$\mathrm{PdCl}_{2}(3 \mathrm{~mol} \%)$

$\mathrm{L}^{*}(3 \mathrm{~mol} \%)$

Base (1.5-2 eq.)

Solvent, reflux

$19 \mathrm{~h}-6$ days

Base: $\mathrm{Ba}(\mathrm{OH})_{2}$ or $\mathrm{CsF}$

Solvent: DME or

DME- $\mathrm{H}_{2} \mathrm{O}$ or

toluene/EtOH/ $\mathrm{H}_{2} \mathrm{O}$

$L^{*}=3:$ yield: $13-73 \%$

ee: $4-17 \%$

28a: yield: $6 \%$, ee: $0 \%$

$L^{*}=2$ : yield: $44-60 \%$ ee: $52-85 \%$

Scheme 3.18 - Kinetic resolution by C-P coupling using ligand 29 [49]. 
<smiles>Brc1ccc2ccccc2c1-c1nccc2ccccc12</smiles>

racemic

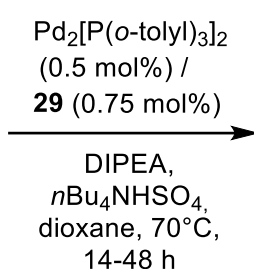

$14-48 \mathrm{~h}$<smiles>CCCCc1ccc2ccccc2c1-c1nccc2ccccc12</smiles>

recovered substrate<smiles>Brc1ccc2ccccc2c1-c1nccc2ccccc12</smiles>

Ar=Ph: $k_{f} / k_{s}=154$, yield: $45 \%$, ee: $95 \%$,

yield (recovered substrate): $47 \%$, ee: $96 \%$

Ar $=p$-tolyl: $\mathrm{k}_{\mathrm{f}} / \mathrm{k}_{\mathrm{s}}=94$, yield: $46 \%$, ee: $92 \%$, yield (recovered substrate): $44 \%$, ee: $96 \%$

Scheme 3.19 - Dynamic kinetic asymmetric transformation by C-P coupling using ligand 28b [49].<smiles>c1ccc([OH+]c2ccc3ccccc3c2-c2nccc3ccccc23)cc1</smiles>

racemic

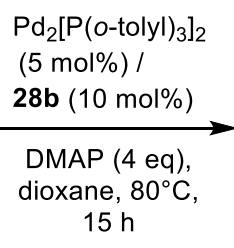

$15 \mathrm{~h}$<smiles>CCCCc1ccc2ccccc2c1-c1nccc2ccccc12</smiles>

Yield: $45 \%$, ee: $60 \%$ 
Scheme 3.20 - Asymmetric biaryl coupling with ligands 2, 31 and 32 [98].

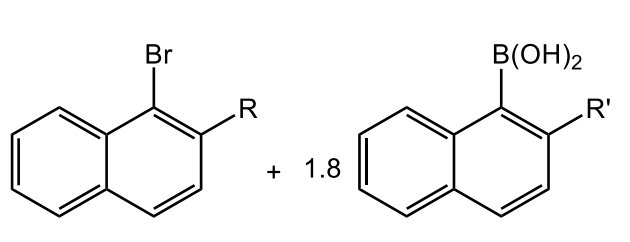

$$
\begin{gathered}
{\left[\mathrm{Pd}_{2}(\mathrm{dba})_{3}\right] . \mathrm{CHCl}_{3}} \\
(2.5-5 \mathrm{~mol} \%)
\end{gathered}
$$

$\left[\mathrm{Pd}(\mathrm{MeCN})_{4}\right] \cdot\left(\mathrm{BF}_{4}\right)_{2}$ or $\mathrm{Pd}(\mathrm{OAc})_{2}$ (3-10 $\mathrm{mol} \%)$

2, 31-32 (12-20 mol\%) $\mathrm{CsF}(3 \mathrm{eq})$

THF or DME $\left(50-65^{\circ} \mathrm{C}\right)$ 48-96 $\mathrm{h}$<smiles>Cc1ccc2ccccc2c1-c1c(C)ccc2ccccc12</smiles>

Yield: $45-95 \%$ e.e: $33-90 \%$

Scheme 3.21 - Asymmetric biaryl coupling with ligands 35 and 36 [102].<smiles>Cc1ccc2ccccc2c1Br</smiles>
$2 \mathrm{~h}$<smiles>Cc1ccc2ccccc2c1-c1cccc2ccccc12</smiles>

Conversion: $75-100 \%$ ee: $10-37 \%$

Scheme 3.22 - Asymmetric biaryl coupling with ligands 37b-c [101].<smiles>Cc1ccc2ccccc2c1Br</smiles><smiles>Cc1ccc2ccccc2c1-c1c(C)ccc2ccccc12</smiles>

Yield: $32-65 \%$ ee: $45-54 \%$

Scheme 3.23 - Asymmetric biaryl coupling with ligand 38 [103]. 
<smiles>[R]c1[R]c2ccc([Y8])c(Br)c2c([R])c1</smiles><smiles>[R]c1ccc2ccccc2c1[GeH2]O</smiles>

Naphthyl bromide: $\mathrm{R}=\mathrm{Me}, \mathrm{OMe}, \mathrm{Ph}, \mathrm{NMe}_{2}$ $\mathrm{R}^{\prime \prime}=\mathrm{H}$

Phenyl bromide: $\mathrm{R}=\mathrm{CHO}, \mathrm{CH}\left(\mathrm{OCH}_{2} \mathrm{CH}_{2} \mathrm{CH}_{2} \mathrm{O}\right), \mathrm{NO}_{2}$ $\mathrm{R}^{\prime}=\mathrm{R}^{\prime \prime}=\mathrm{Me}$

$\mathrm{R}_{1}=\mathrm{H}, \mathrm{Me}, \mathrm{iPr}, \mathrm{OMe}$
$\mathrm{Pd}_{2}(\mathrm{dba})_{3}$

(0.05-0.25 $\mathrm{mol} \%)$ 38 (0.2-1 mol\%)

$\mathrm{K}_{3} \mathrm{PO}_{4} \cdot \mathrm{H}_{2} \mathrm{O}(3 \mathrm{eq})$ toluene $\left(50-70^{\circ} \mathrm{C}\right)$ $24 \mathrm{~h}$<smiles>[R]c1ccc2ccccc2c1-c1c([R])cc([R])c2ccccc12</smiles>

Yield: $52-99 \%$ ee: $0-36 \%$ 
Scheme 3.24 - Heterogeneous asymmetric biaryl coupling in water [106].<smiles>[R]c1ccc2ccccc2c1[X]</smiles>

$\mathrm{X}=\mathrm{Cl}, \mathrm{Br}, \mathrm{I}$

$\mathrm{R}=\mathrm{Me}, \mathrm{OMe}, \mathrm{OEt}$

$\mathrm{CO}_{2} \mathrm{Me}, \mathrm{P}(\mathrm{O})(\mathrm{OEt})_{2}$<smiles>[R]c1ccc(Br)c([R])c1</smiles>

$\mathrm{R}=\mathrm{Me}, \mathrm{NO}_{2}$

$\mathrm{R}^{\prime}=\mathrm{H}, \mathrm{CN}, \mathrm{CO}_{2} \mathrm{Me}$<smiles>[R]c1ccc2ccccc2c1[GaH]</smiles>

$\mathrm{R}^{\prime}=\mathrm{Me}, \mathrm{OMe}, \mathrm{OEt}$
$\mathrm{Pd}(\mathrm{OAc})_{2}(10 \mathrm{~mol} \%)$

$\underset{\mathrm{PS}-\mathrm{PEG}-41 \mathrm{c}(10 \mathrm{~mol} \%)}{\longrightarrow}$

$\mathrm{H}_{2} \mathrm{O}, 80^{\circ} \mathrm{C}$

$24 \mathrm{~h}$<smiles>[R]c1ccc2ccccc2c1-c1c([R])ccc2ccccc12</smiles>

Yield: $53-95 \%$ ee: $88-94 \%$<smiles>[R]c1ccc(-c2c(C)ccc3ccccc23)c([R])c1</smiles>

Yield: $89-96 \%$ ee: $92-94 \%$

Scheme 3.25 - Asymmetric biaryl coupling with high-molecular weight PQXphos (P)-(R)-43 ligands [107].<smiles></smiles>

$\mathrm{X}=\mathrm{Br}, \mathrm{R}=\mathrm{Me}$ $\mathrm{X}=\mathrm{Br}, \mathrm{R}=\mathrm{Et}$ $\mathrm{X}=\mathrm{Cl}, \mathrm{R}=\mathrm{Me}$<smiles>[R]c1cccc2ccccc12</smiles>

$\mathrm{R}^{\prime}=\mathrm{H}, \mathrm{Me}, \mathrm{OMe}, \mathrm{Cl}$

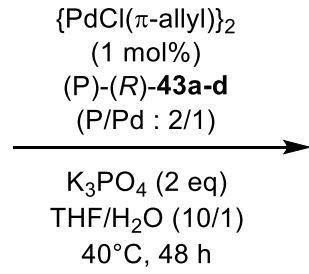

$40^{\circ} \mathrm{C}, 48 \mathrm{~h}$<smiles>[R]Oc1ccc2ccccc2c1-c1cccc2ccccc12</smiles>

(S) ee: $78-98 \%$

Scheme 3.26 - Asymmetric biaryl coupling with ligands 45a-c [109].<smiles>COc1cccc(C2OCCO2)c1Cl</smiles><smiles>Oc1cccc2ccccc12</smiles>

$\mathrm{Pd}_{2}(\mathrm{dba})_{3} \cdot \mathrm{CHCl}_{3}$ (0.05-0.25 mol \%) 45a-c (0.2-1.5 mol \%) $\mathrm{THF} / \mathrm{KF}$ or tol/CsF $75-90^{\circ} \mathrm{C}, 3-7 \mathrm{~h}$<smiles>COc1cccc(C2OCCO2)c1-c1cccc2ccccc12</smiles> 
Scheme 3.27 - Asymmetric biaryl coupling with ligands 50-51 possessing chirality at phosphorus [111,112].<smiles>[R]Oc1ccc2ccccc2c1Br</smiles>

$\mathrm{R}=\mathrm{COtBu}, \mathrm{COPh}$ $\mathrm{P}(\mathrm{O}) \mathrm{Ph}_{2}, \mathrm{P}(\mathrm{O})(\mathrm{OEt})_{2}$, BOP $\left.\mathrm{BOP}=\stackrel{\mathrm{P}}{\|}\left(\mathrm{N}^{\mathrm{O}}\right)^{\mathrm{N}}\right)_{2}$<smiles>Oc1ccccc1</smiles>

$\mathrm{Pd}(\mathrm{OAc})_{2}(1 \mathrm{~mol} \%)$ 50-51 (1.2 mol\%) $\mathrm{K}_{3} \mathrm{PO}_{4}(3$ eq) toluene/ $/ \mathrm{H}_{2} \mathrm{O}(5 / 1)$ $\mathrm{rt}, 4-12 \mathrm{~h}$<smiles>[R]Oc1ccc2ccccc2c1-c1ccccc1</smiles>

Yield: $90-98 \%$ ee: $65-99 \%$

Scheme 3.28 - Dynamic asymmetric Suzuki coupling with ligand 52 [48].

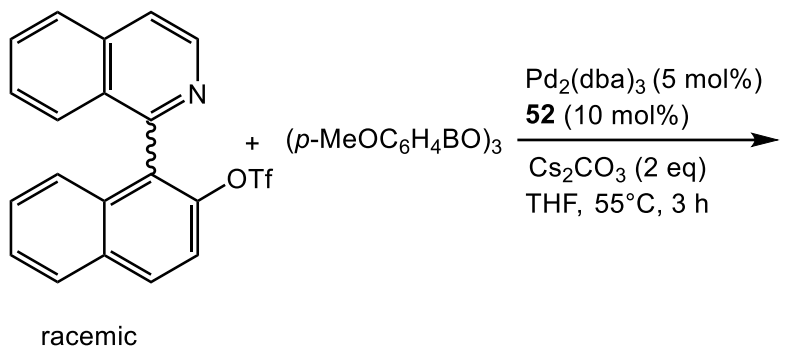<smiles>COc1ccc(-c2ccc3ccccc3c2-c2nccc3ccccc23)cc1</smiles>

Yield: $91 \%$ ee: $34 \%$

Scheme 3.29 - Asymmetric biaryl coupling with ligands 54a-h [113].<smiles>COc1ccc2ccccc2c1Br</smiles><smiles>Oc1cccc2ccccc12</smiles>
$\mathrm{PdCl}_{2}\left(\mathrm{CH}_{3} \mathrm{CN}\right)_{2}$ (5 mol \%) $\underset{\mathrm{Cs}_{2} \mathrm{CO}_{3}(2 \mathrm{eq})}{\stackrel{54 \mathrm{a}-\mathrm{h}(5 \mathrm{~mol} \%)}{\longrightarrow}}$ toluene, $\mathrm{rt}$ 15-24 h<smiles>COc1ccc2ccccc2c1-c1cccc2ccccc12</smiles>

Yield: $20-97 \%$ ee: $0-80 \%$

Scheme 3.30 - Asymmetric Suzuki-Miyaura cross-coupling reaction with ligands 63-65 [118]. 


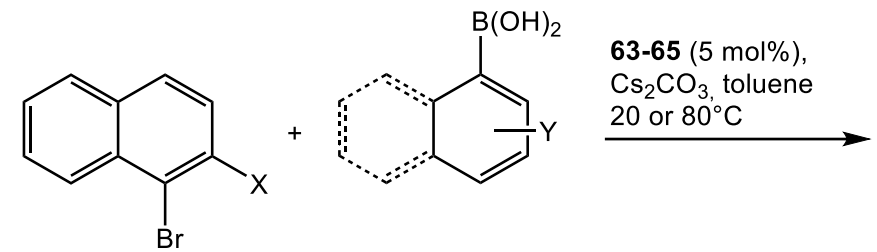

$\mathrm{X}=\mathrm{H}, \mathrm{Me}, \mathrm{OMe}$

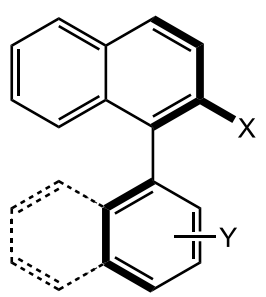

Yield: $36-99 \%$ ee: $70->98 \%$

Scheme 3.31 - Asymmetric Suzuki-Miyaura cross-coupling reaction with ligands 66a-e [119].<smiles>COc1ccc2ccccc2c1Br</smiles>
政 $80^{\circ} \mathrm{C}$

toluene/EtOH/ $\mathrm{H}_{2} \mathrm{O}$

Yield: $25-75 \%$ ee: $8-40 \%$

Scheme 3.32 - Asymmetric Suzuki-Miyaura cross-coupling reaction with ADC-Pd complexes 67-69 [123].<smiles>COc1ccc2ccccc2c1Br</smiles><smiles>COc1ccc2ccccc2c1-c1cccc2ccccc12</smiles>

Yield: $64-95 \%$ ee: $<4 \%$<smiles>CC[C+](C(F)(F)F)P(P)(Cl)(c1ccccc1)C1N2CCC[C@H]2C[C@H]2CCCN12</smiles>

67<smiles>CC[C+](Cc1ccccc1)C(F)(F)F</smiles>

68<smiles>C[C+](C)C(F)(Br)c1ccccc1</smiles>

69 
Scheme 3.33 - Selected examples of asymmetric S.-M. with chiral NHC-Pd complex 80i [129].

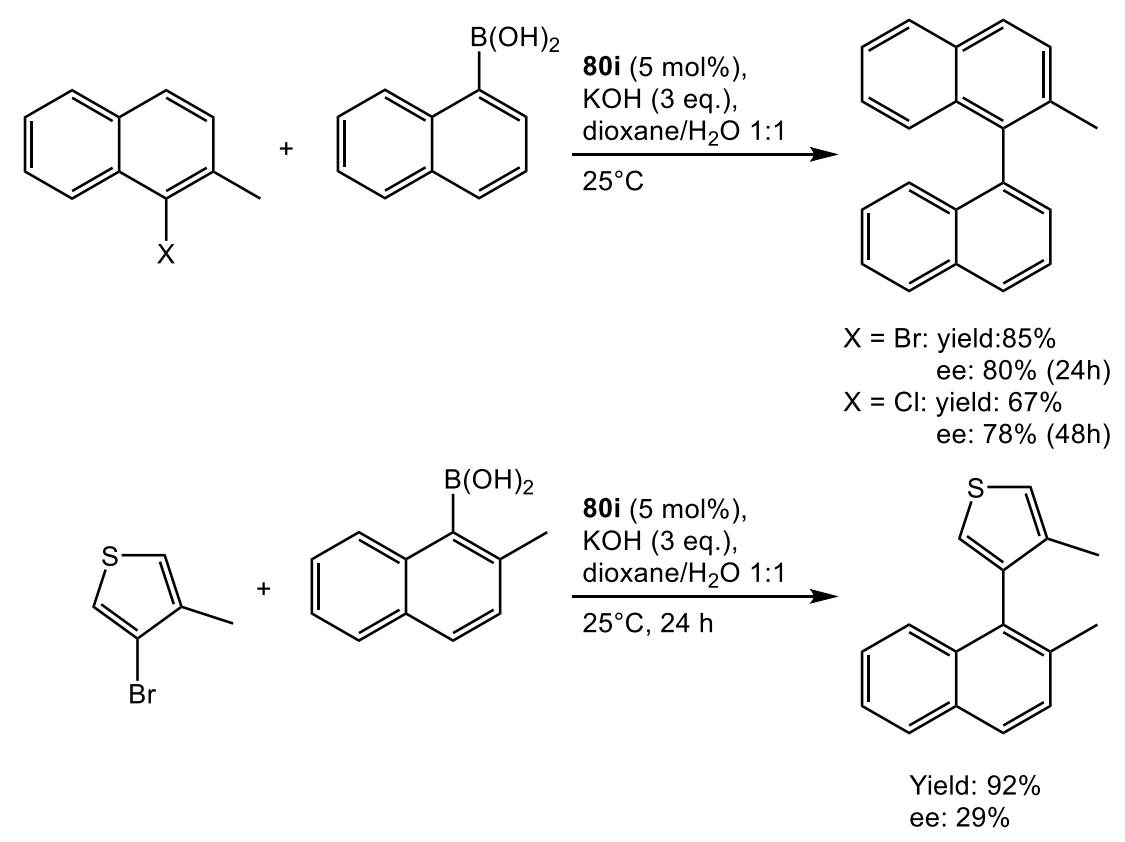

Scheme 3.34 - Selected examples of asymmetric Suzuki-Miyaura with palladium complexes 81a-h bearing chiral dienes [130]. 

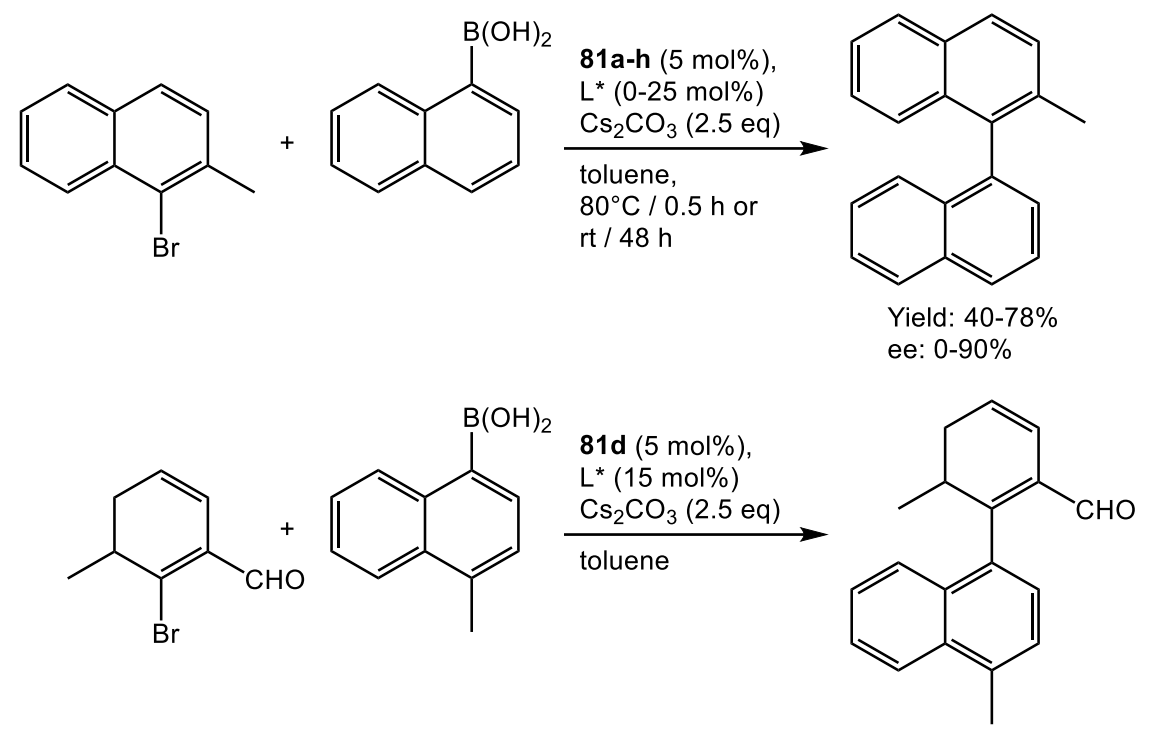

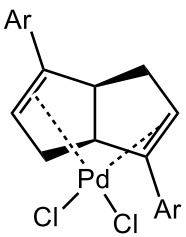

81a: $\mathrm{Ar}=\mathrm{Ph}$

81b: $\mathrm{Ar}=\mathrm{C}_{6} \mathrm{H}_{4}-4-\mathrm{F}$

81c: $\mathrm{Ar}=\mathrm{C}_{6} \mathrm{H}_{4}-4-\mathrm{OMe}$

81d: $\mathrm{Ar}=\mathrm{C}_{6} \mathrm{H}_{3}-3,5-\mathrm{Me}_{2}$

81e: $\mathrm{Ar}=\mathrm{C}_{6} \mathrm{H}_{3}-3,5-\mathrm{OMe}_{2}$

81f: $\mathrm{Ar}=\mathrm{C}_{6} \mathrm{H}_{3}-3,5-\mathrm{Bu}$

81g: $\mathrm{Ar}=1$-naphthyl

81h: $\mathrm{Ar}=2$-naphthyl

Yield: $99 \%$, ee: $70 \%\left(2 \mathrm{~h}, 25^{\circ} \mathrm{C}\right)$

Yield: $80 \%$, ee: $81 \%\left(12 \mathrm{~h}, 0^{\circ} \mathrm{C}\right)$

\section{4 - Negishi}

Scheme 4.1 - Asymmetric aryl-aryl Negishi reaction developed by Espinet et al. [97,132].

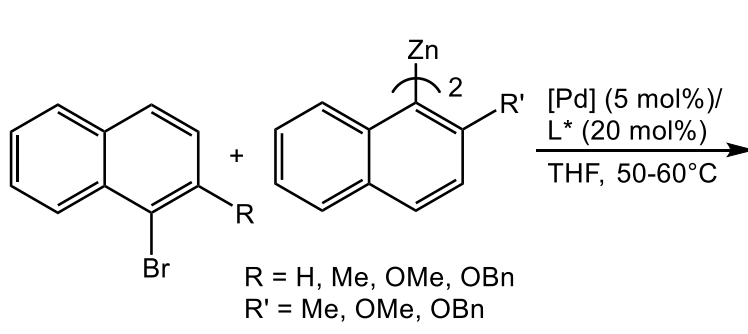<smiles>[R]c1ccc2ccccc2c1-c1c([R])ccc2ccccc12</smiles>

Yield: $55-95 \%$ ee: $49-85 \%$

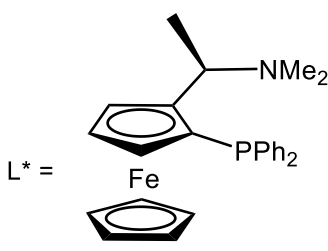

$(R)-(\mathrm{p} S)$

PPFA (2)

\section{5 - Direct C-H functionalization}

Scheme 5.1 - Atropselective alkylation of pyridine or quinoline derivatives by direct $\mathrm{C}-\mathrm{H}$ functionalization [135]. 
<smiles></smiles>

$\left[\mathrm{RhCl}(\mathrm{coe})_{2}\right]_{2}(5 \mathrm{~mol} \%)$ $4 \mathrm{a}$ or $9(30 \mathrm{~mol} \%)$

toluene, $120^{\circ} \mathrm{C}$

$20 \mathrm{~h}$

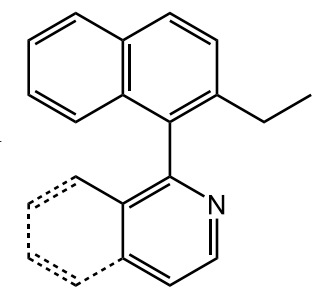

Pyridine substrate: Yield: $37-49 \%$

ee: $0-49 \%$

Quinoline substrate: Yield: $33-60 \%$

ee: $3-22 \%$

Scheme 5.2 - Direct asymmetric C-H functionalization of aryl substrates catalyzed by chiral palladium complexes [136].

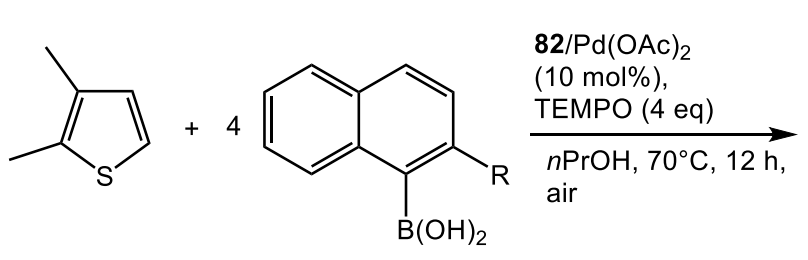<smiles>[R]c1ccc2ccccc2c1-c1csc(C)c1C</smiles><smiles>CC(C)[C@H]1COC(C2=N[C@H](C(C)C)CO2)=N1</smiles>

$$
\begin{gathered}
\mathrm{R}=\text { Me: Yield: } 63 \% \text {, ee: } 41 \%, \\
\text { 95\% C4-selectivity } \\
\mathrm{R}=i \operatorname{Pr}: \text { Yield: } 27 \% \text {, ee: } 72 \%, \\
\text { 93\% C4-selectivity }
\end{gathered}
$$
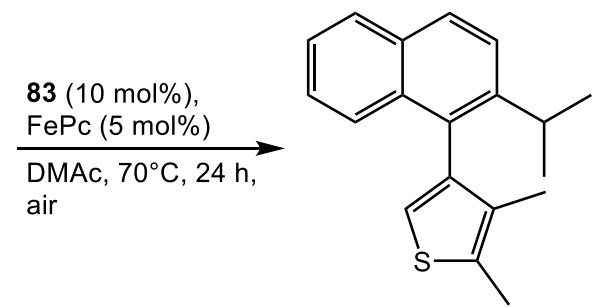

Yield: $61 \%$, ee: $61 \%$, $82 \%$ C4-selectivity

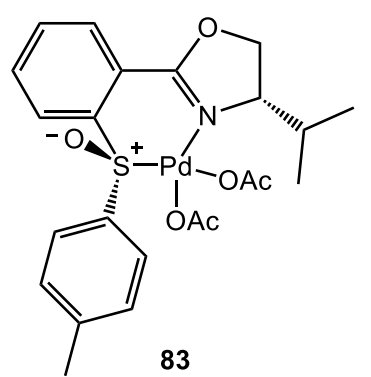


Scheme 5.3 - Atropselective alkylation of pyridine or quinoline derivatives by direct $\mathrm{C}-\mathrm{H}$ functionalization [137].<smiles>c1ccc2c(-c3nccc4ccccc34)cccc2c1</smiles><smiles>C=Cc1ccc2ccccc2c1</smiles>

84a-f (5 mol\%), $\underset{\mathrm{Cu}(\mathrm{OAc})_{2}(2 \mathrm{eq})}{\longrightarrow}$ $\mathrm{MeOH}, 80^{\circ} \mathrm{C}$<smiles>C(=C/c1ccc2ccccc2c1-c1nccc2ccc3ccccc3c12)\c1ccc2ccccc2c1</smiles><smiles></smiles>

Yield: $26-99 \%$ ee: $42-72 \%$

84a: $R=O M e$ 84b: $\mathrm{R}=\mathrm{H}$ 84c: $\mathrm{R}=\mathrm{O} i \mathrm{Pr}$ 84d: $R=P h$ 84e: $R=$ OTIPS

84f: $R$ = OTBDPS<smiles>[R]c1cc2ccc3ccccc3c2c(-c2ccc3[Z12]([H])c4cccc2c43)n1</smiles>

\section{4a $(5 \mathrm{~mol} \%)$} $(\mathrm{BzO})_{2}(5 \mathrm{~mol} \%)$ $\mathrm{Cu}(\mathrm{OAc})_{2}(20 \mathrm{~mol} \%)$ $\mathrm{Ag}_{2} \mathrm{CO}_{3}$ (1 eq) $\mathrm{MeOH}, 80^{\circ} \mathrm{C}$

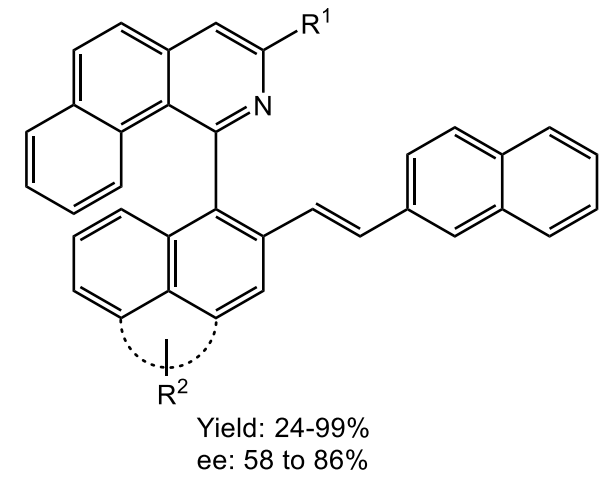

\section{6 - Oxidative coupling}

Scheme 6.1 - First stoichiometric asymmetric oxidative coupling of 2-naphthols [142].<smiles>COC(=O)c1cc2ccccc2cc1O</smiles><smiles>CC(=O)c1cc2ccccc2c(-c2c(O)c(C(C)=O)cc3ccccc23)c1O</smiles>

Yield: $21 \%$ ee: $16 \% \%$

Scheme 6.2 - First catalytic asymmetric oxidative coupling of 2-naphthols [146]. 

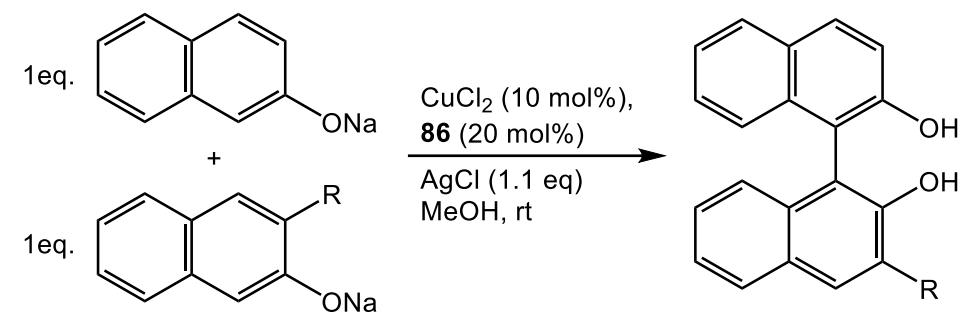

$\mathrm{R}=\mathrm{H}: 70 \%$ yield, $3 \%$ ee
$\mathrm{R}=\mathrm{CO}_{2} \mathrm{Me}: 41 \%$ yield, $32 \%$ ee

Scheme 6.3 - Catalytic, asymmetric, aerobic oxidative coupling of 2-naphthols [147,148].<smiles>[X]c1cc2ccccc2cc1O</smiles>

$\mathrm{CuCl}(10 \mathrm{~mol} \%)$, $87(11 \mathrm{~mol} \%)$

$\mathrm{O}_{2}, \mathrm{CH}_{2} \mathrm{Cl}_{2}$ reflux, $24 \mathrm{~h}$

$\mathrm{X}=\mathrm{H}, \mathrm{CO}_{2} \mathrm{Me}, \mathrm{CO}_{2} \mathrm{Et}$, $\mathrm{CO}_{2} \mathrm{Bn}, \mathrm{CO}_{2} \mathrm{tBu}$<smiles>[X]c1cc2ccccc2c(-c2c(O)c([X])cc3ccccc23)c1O</smiles>

Yield: $11-95 \%$ ee: $0-78 \%$

Scheme 6.4 - Optimized catalytic asymmetric aerobic oxidative coupling of 2-naphthols with ligands 87 [149].<smiles>O=C(O)c1cc2ccccc2cc1O</smiles>

$\mathrm{R}=\mathrm{Me}, \mathrm{Pr}, \mathrm{Bn}, t \mathrm{Bu}$

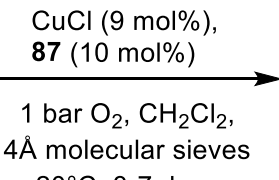

$20^{\circ} \mathrm{C}, 3-7$ days<smiles>[R]OC(=O)c1cc2ccccc2c(-c2c(O)c(C([R])=O)cc3ccccc23)c1O</smiles>

Yield: $11-95 \%$

ee: $0-57 \%$

(ee up to $87 \%$ at $0^{\circ} \mathrm{C}$ )

Scheme 6.5. - Asymmetric oxidative coupling of 2-naphthols using chiral 1,5-diaza-cisdecalin ligands 88 [150,151].<smiles>[X]c1cc2ccccc2cc1O</smiles>

Cul (2-10 mol\%), $88(2-10 \mathrm{~mol} \%)$, $\mathrm{O}_{2}, 40^{\circ} \mathrm{C}, 24 \mathrm{~h}$, $\left(\mathrm{CH}_{2} \mathrm{Cl}\right)_{2} / \mathrm{CH}_{3} \mathrm{CN}(2 / 1)$

$\mathrm{X}=\mathrm{H}, \mathrm{OBn}, \mathrm{OBz}$,

$\mathrm{CO}_{2} \mathrm{Me}, \mathrm{CO}_{2} \mathrm{Bn}$<smiles>[X]c1cc2ccccc2c(-c2c(O)c([X])cc3ccccc23)c1O</smiles>

Yield: 0-89\% ee: up to $93 \%$ 
Scheme 6.6 - Asymmetric oxidative coupling of 2-naphthols using ligand 89 [165].<smiles>[R]c1cc2ccccc2cc1O</smiles>
$\mathrm{Cu}(\mathrm{OTf})_{2} \cdot \mathrm{C}_{6} \mathrm{H}_{6} / 89(10 \mathrm{~mol} \%)$ air, $\mathrm{CH}_{2} \mathrm{Cl}_{2} / \mathrm{CH}_{3} \mathrm{CN}, 4 \AA \mathrm{MS}$, $40^{\circ} \mathrm{C}, 5-48 \mathrm{~h}$

$\mathrm{R}=\mathrm{H}, \mathrm{Me}, \mathrm{OBn}, \mathrm{COMe}$ $\mathrm{CO}_{2} \mathrm{Me}, \mathrm{CO}_{2} \mathrm{Pr}$<smiles>[R]c1cc2ccccc2c(-c2c(O)c([R])cc3ccccc23)c1O</smiles>

Yield: $48-90 \%$ ee: up to $65 \%$

Scheme 6.7 - Asymmetric oxidative coupling of 2-naphthols using dicopper complexes 90 and $91[166]$.<smiles>Oc1ccc2ccccc2c1</smiles><smiles>Oc1ccc2ccccc2c1-c1c(O)ccc2ccccc12</smiles>

Yields: $75-80 \%$; ee: $69-80 \%(90)$

Yields: $84-92 \%$; ee: $84-88 \%$ (91)

Scheme 6.8 - Asymmetric oxidative coupling of 2-naphthols using ligands 92 [167].<smiles>COC(=O)c1cc2ccccc2cc1O</smiles><smiles>CC(=O)c1cc2ccccc2c(-c2c(O)c(C(C)=O)cc3ccccc23)c1O</smiles>

Yield: $0-89 \%$

ee: up to $93 \%$

Scheme 6.9 - Asymmetric oxidative coupling of 2-naphthols using ligand 92a [168]. 


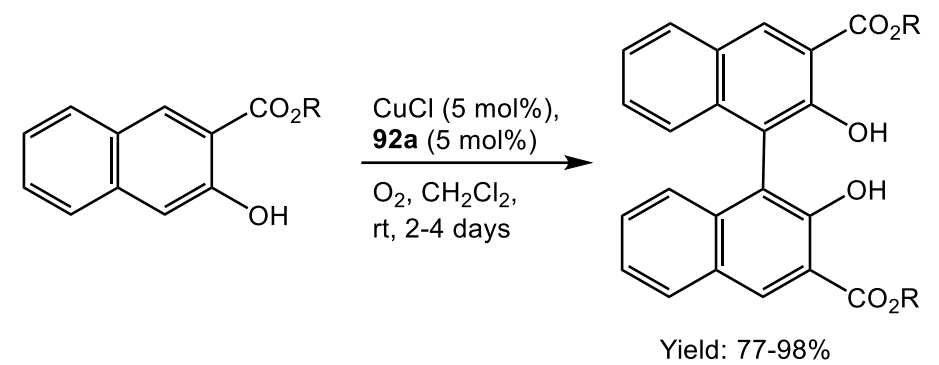

Yield: $77-98 \%$

ee: $48-97 \%$

(ee: $97 \%$ for $\mathrm{R}=\mathrm{Me}, 94 \%$ for $\mathrm{R}=\mathrm{Et}$,

$94 \%$ for $\mathrm{R}=\mathrm{Ph}, \ldots$ )

Scheme 6.10 - Asymmetric oxidative cross coupling of 2-naphthols using sparteine 86 or $(S)$ -

PhBox 93 [170,171].

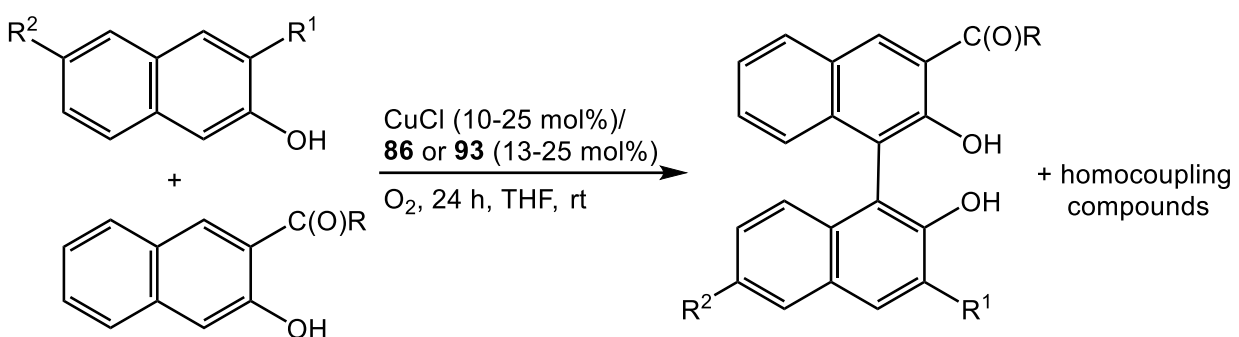

With 86, $\mathrm{R}=\mathrm{NH}(n \mathrm{Bu}), \mathrm{R}^{1}=\mathrm{H}, \mathrm{R}^{2}=\mathrm{H}$ : yield: $78 \%$, ee: $60 \%$

With 93, R=OPh, $\mathrm{R}^{1}=\mathrm{OBn}, \mathrm{R}^{2}=\mathrm{H}$ : yield: $67 \%$, ee: $73 \%$

Scheme 6.11 - Asymmetric oxidative coupling of 2-naphthols using ruthenium salen complexes 95. ${ }^{[175]}$

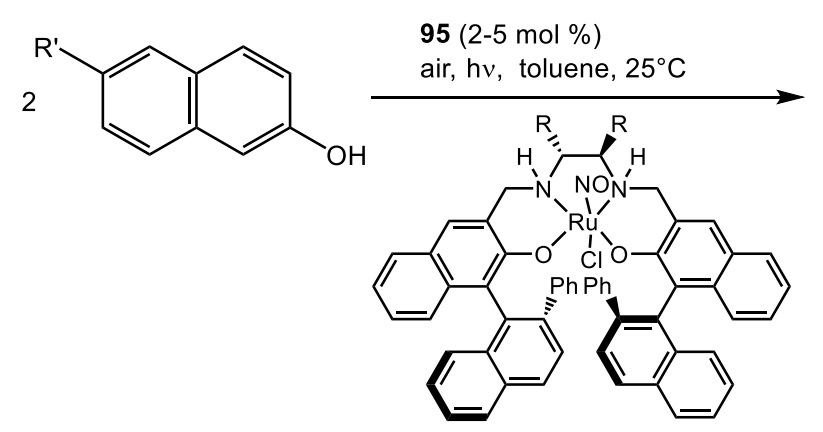

95a: $\mathrm{R}=\mathrm{Ph}$

95b: $R=M e$

95c: $\mathrm{R}, \mathrm{R}=-\left(\mathrm{CH}_{2}\right)_{4}-$<smiles>[R]c1ccc2c(-c3c(O)ccc4cc([R])ccc34)c(O)ccc2c1</smiles> 
Scheme 6.12 - Asymmetric oxidative coupling of 2-naphthols using tridentate Schiff base ligands 96-104 [176].

2<smiles>[R]c1cc2cc([R])c(O)cc2cc1[R]</smiles>
optimized complex: 103d<smiles>[R]c1cc2cc([R])c(O)c(-c3c(O)c([R])cc4cc([R])c([R])cc34)c2cc1[R]</smiles>

Scheme 6.13 - Asymmetric oxidative coupling of 2-naphthols using tridentate Schiff base ligands 105 [178].<smiles>[R]c1cc2cc([R])c(O)cc2cc1[R]</smiles>

optimized complexes: $105 a$ and $105 b$<smiles>[R]c1cc2cc([R])c(O)c(-c3c(O)c([R])cc4cc([R])c([R])cc34)c2cc1[R]</smiles>

Yield: up to $96 \%$ ee: $18-73 \%$

Scheme 6.14 - Asymmetric oxidative coupling of 2-naphthols using tridentate Schiff base ligands 107 [179].<smiles>[R]c1cc2cc([R])c(O)cc2cc1[R]</smiles>
$\underset{7-107(3-10 \mathrm{~mol} \%)}{\stackrel{\mathrm{O}}{\mathrm{CCl}_{4}, 45^{\circ} \mathrm{C},}}$<smiles>[R]c1cc2cc([R1])c(O)c(-c3c(O)c([R])cc4cc([R16])c([R])cc34)c2cc1[R5]</smiles>

Scheme 6.15 - Asymmetric oxidative coupling of 2-naphthols using vanadium dimers 108109 [180]. 

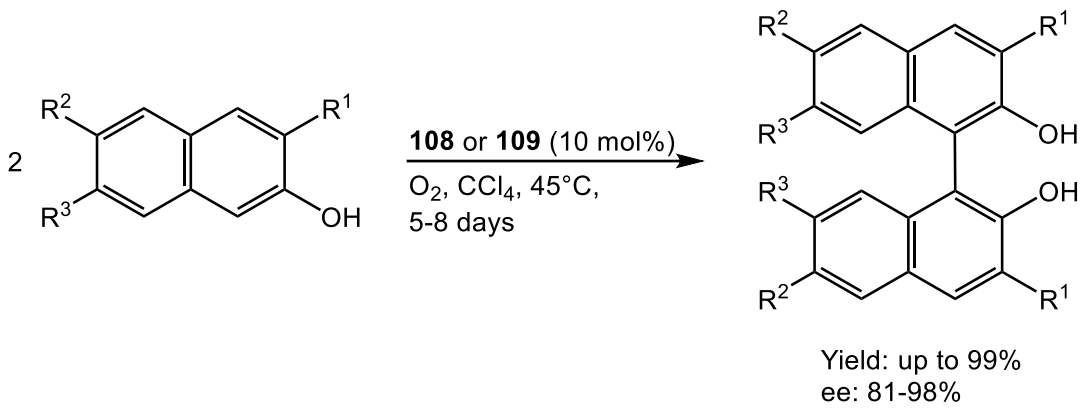

Scheme 6.16 - Optimized synthesis of some chiral binaphthols using ligand 110f [182,183].<smiles>C=CCOc1ccc2ccc(O)cc2c1</smiles><smiles>C=CCOc1ccc2ccc(O)c(-c3c(O)ccc4ccc(OCC=C)cc34)c2c1</smiles>

Yield: $95 \%$; ee: $99 \%$<smiles>CCCOc1cc2cc(O)ccc2cc1Br</smiles><smiles>CCCOc1cc2c(-c3c(O)ccc4cc(Br)c(OCCC)cc34)c(O)ccc2cc1Br</smiles>

Yield: 99\%; ee: 98\%

Scheme 6.17 - Total synthesis of (S)-2,2'-1,1'-binaphthyl-5,5',6,6'-tetraol [188].<smiles>CCCCCCCOc1ccc2c(-c3c(O)ccc4cc(OCc5ccccc5)ccc34)c(O)ccc2c1</smiles><smiles>COc1ccc2c(O)c(O)ccc2c1-c1c(OC)ccc2c(O)c(O)ccc12</smiles>

Scheme 6.18 - Grafting of complexes 117 on silica [190,191,192]. 


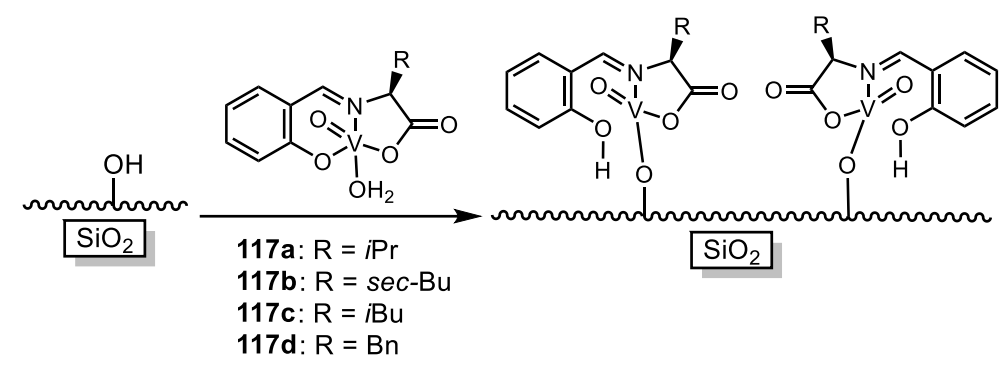

Scheme 6.19 - Asymmetric oxidative coupling of 2-naphthols using iron dimers 118 [193].

2<smiles>[R]c1cc2cc([R])c(O)cc2cc1[R]</smiles><smiles>[R]c1cc2cc([R])c(O)c(-c3c(O)c([R])cc4cc([R])c([R])cc34)c2cc1[R]</smiles>

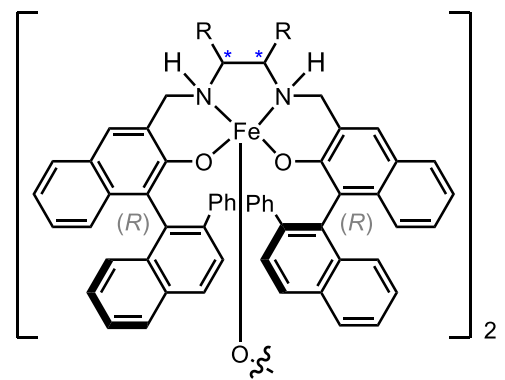

Yield: up to $93 \%$ ee: up to $97 \%$

118a: $(R, R), \mathrm{R}=-\left(\mathrm{CH}_{2}\right)_{4^{-}} \quad 118 \mathrm{c}:(S, S), \mathrm{R}=\mathrm{Ph}$

118b: $(S, S), \mathrm{R}=-\left(\mathrm{CH}_{2}\right)_{4^{-}} \quad$ 118d: $(R, R), \mathrm{R}=\mathrm{Ph}$

Scheme 6.20 - Asymmetric oxidative cross-coupling of 2-naphthols using iron dimer 118d [194]. 


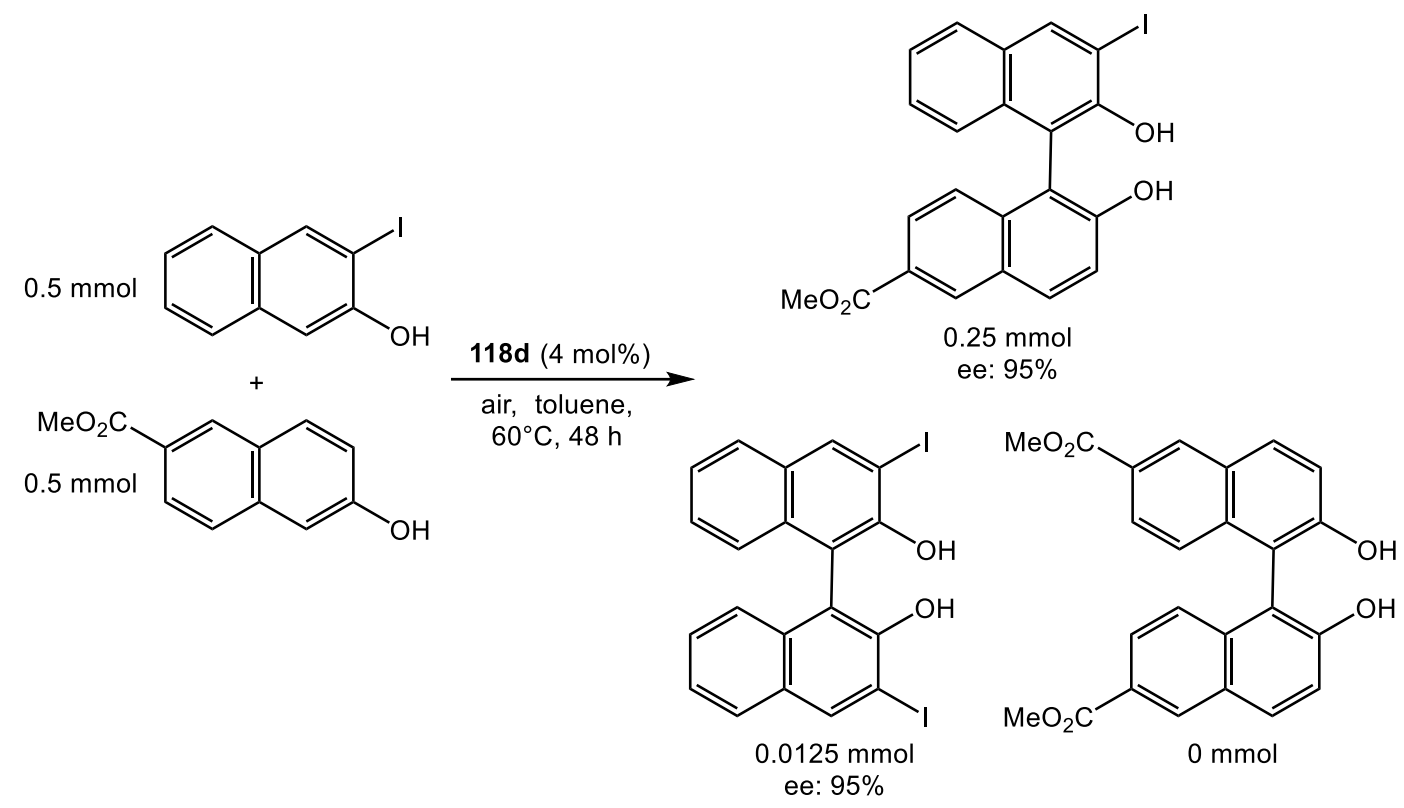

Scheme 6.21 - First catalytic asymmetric oxidative polymerization of 2-naphthols [196,197].

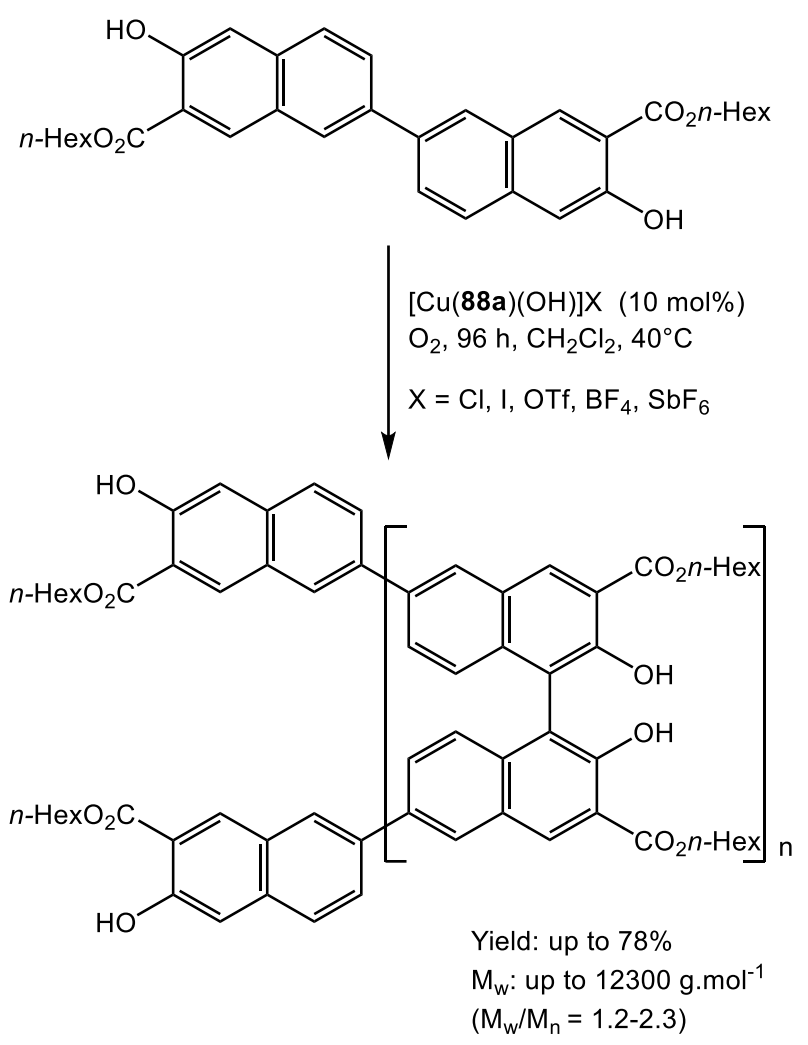

Scheme 6.22 - Asymmetric polymerization via a tandem oxidative coupling/Glaser reaction $[196,197]$ 


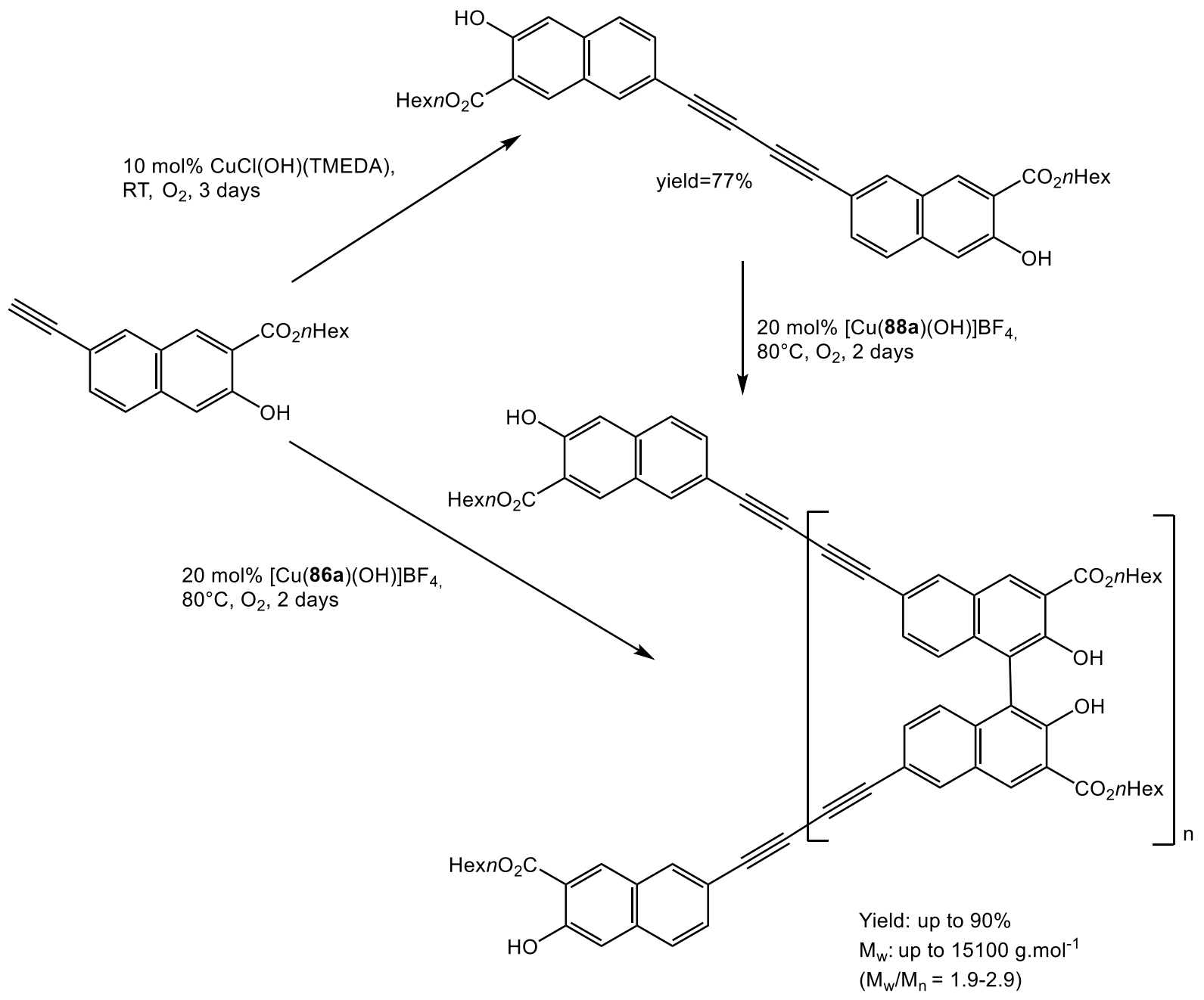

Scheme 6.23 - Asymmetric aerobic oxidative polymerization of 2,3-dihydroxynaphthalene using bis-oxazoline ligands [198].
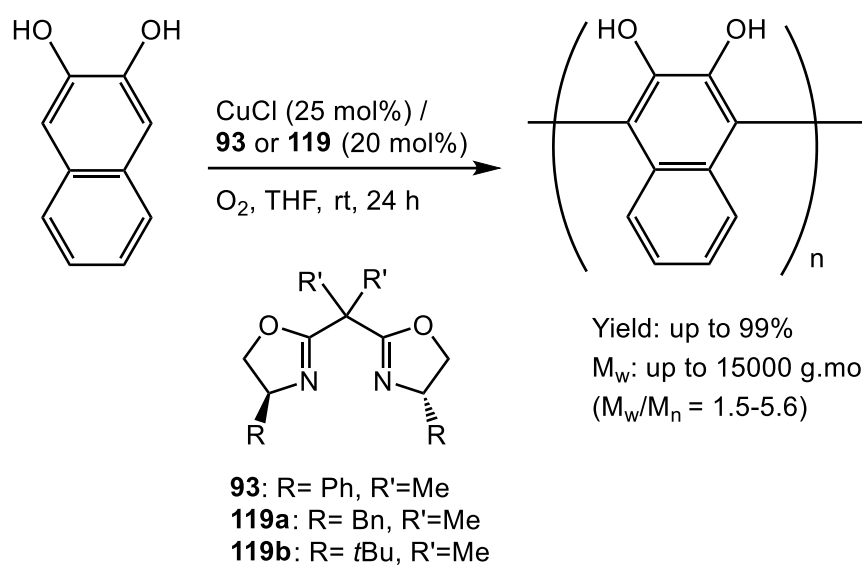

Yield: up to $99 \%$

$M_{w}$ : up to $15000 \mathrm{~g} \mathrm{~mol}^{-1}$

$\left(M_{w} / M_{n}=1.5-5.6\right)$

$119 b: R=t B u, R^{\prime}=M e$

119c: $R=P h, R^{\prime}=H$ 
Scheme 6.24 - Polymers obtained by coupling of chiral binaphthols [199-201].
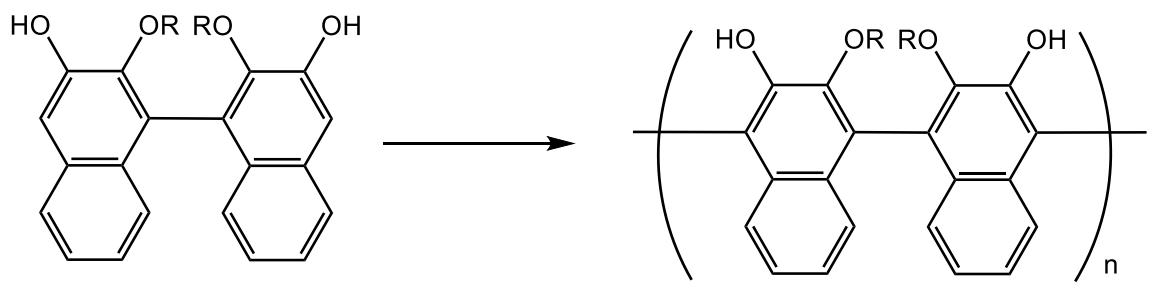

Scheme 6.25 - Asymmetric aerobic oxidative polymerization of 2-naphthols using bis(oxazoline) copper complexes [171].

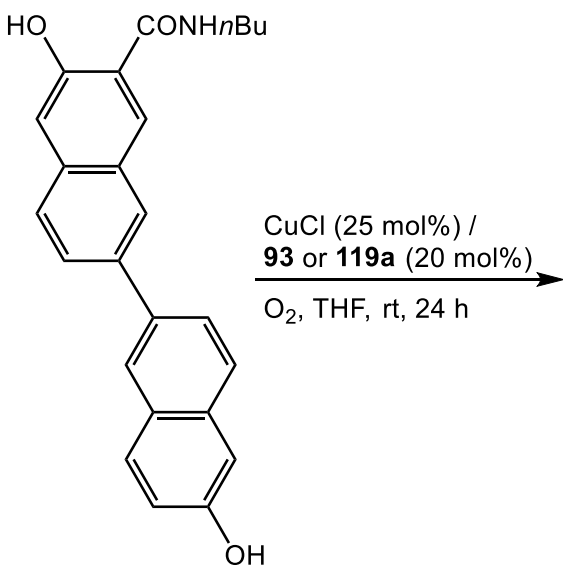<smiles>CCCCNC(=O)c1cc2cc(C(F)(F)F)ccc2c(-c2c(O)ccc3cc(C)ccc23)c1O</smiles>

Yield: $64 \%$

$\mathrm{M}_{\mathrm{w}}$ : up to $7100 \mathrm{~g} \cdot \mathrm{mol}^{-1}$ $\left(M_{w} / M_{n}=1.8-2.1\right)$

Scheme 6.26 - Asymmetric aerobic oxidative polymerization of 2,3-dihydroxynaphthalene using bis(oxazoline) vanadium complexes [202].

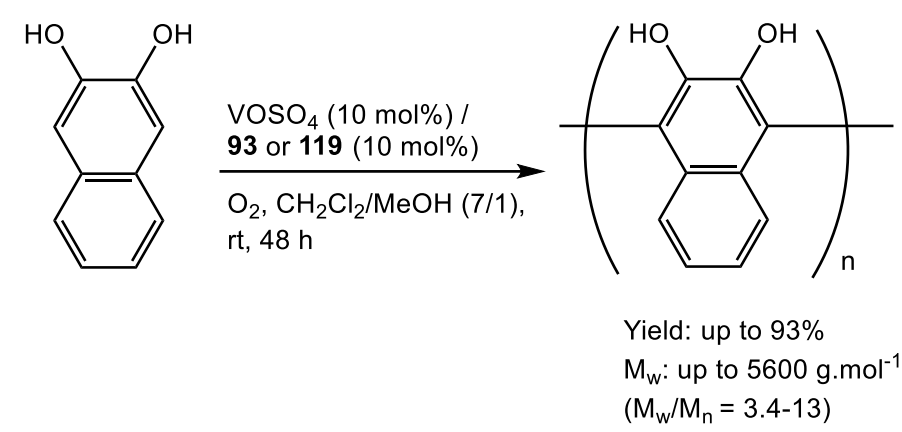

Scheme 6.27 - Asymmetric aerobic oxidative polymerization of 2,3-dihydroxynaphthalene using salen cobalt complexes [203]. 


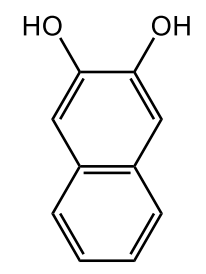

$120(10 \mathrm{~mol} \%)$

$\mathrm{O}_{2}, \mathrm{CH}_{2} \mathrm{Cl}_{2} / \mathrm{MeOH}(20 / 1)$,

rt, $30 \mathrm{~min}$
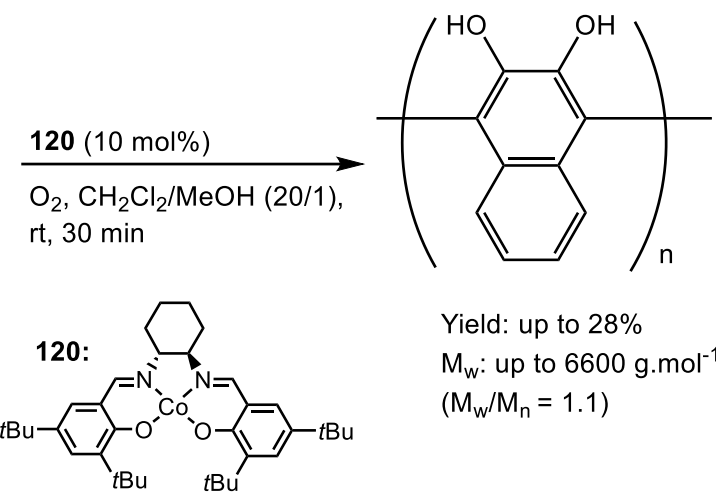

Yield: up to $28 \%$

$\mathrm{M}_{\mathrm{w}}$ : up to $6600 \mathrm{~g} \cdot \mathrm{mol}^{-1}$

$\left(\mathrm{M}_{\mathrm{w}} / \mathrm{M}_{\mathrm{n}}=1.1\right)$

Scheme 6.28 - Asymmetric aerobic oxidative polymerization of 2,3-dihydroxynaphthalene using chiral vanadium complexes obtained from tartaric acid salts [204].

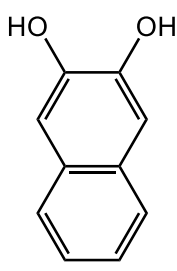

$\mathrm{VOSO}_{4}(10 \mathrm{~mol} \%) /$ $121(10 \mathrm{~mol} \%)$

$\mathrm{O}_{2}, \mathrm{THF}, \mathrm{rt}, 48 \mathrm{~h}$<smiles>COC[C@@H](O)[C@@H](O)C(=O)OC</smiles>

121a: $\mathrm{M}=\mathrm{Li}$ 121b: $\mathrm{M}=\mathrm{Na}$

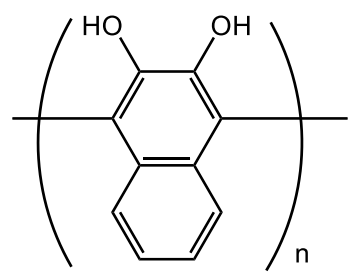

121a: Yield: $40 \%$ $\mathrm{M}_{\mathrm{w}}: 6900 \mathrm{~g} \cdot \mathrm{mol}^{-1}$ $\left(\mathrm{M}_{\mathrm{w}} / \mathrm{M}_{\mathrm{n}}=1.3\right)$

$[\alpha]_{D}=-223$

121b: Yield: $18 \%$

$\mathrm{M}_{\mathrm{w}}: 6600 \mathrm{~g} \cdot \mathrm{mol}^{-1}$

$\left(\mathrm{M}_{\mathrm{w}} / \mathrm{M}_{\mathrm{n}}=1.2\right)$

$[\alpha]_{D}=-230$

\section{7 - $[2+2+2]$ Cycloadditions}

Scheme 7.1 - Cobalt-catalyzed asymmetric cycloaddition of internal alkynes and 1naphthylonitriles [210]. 


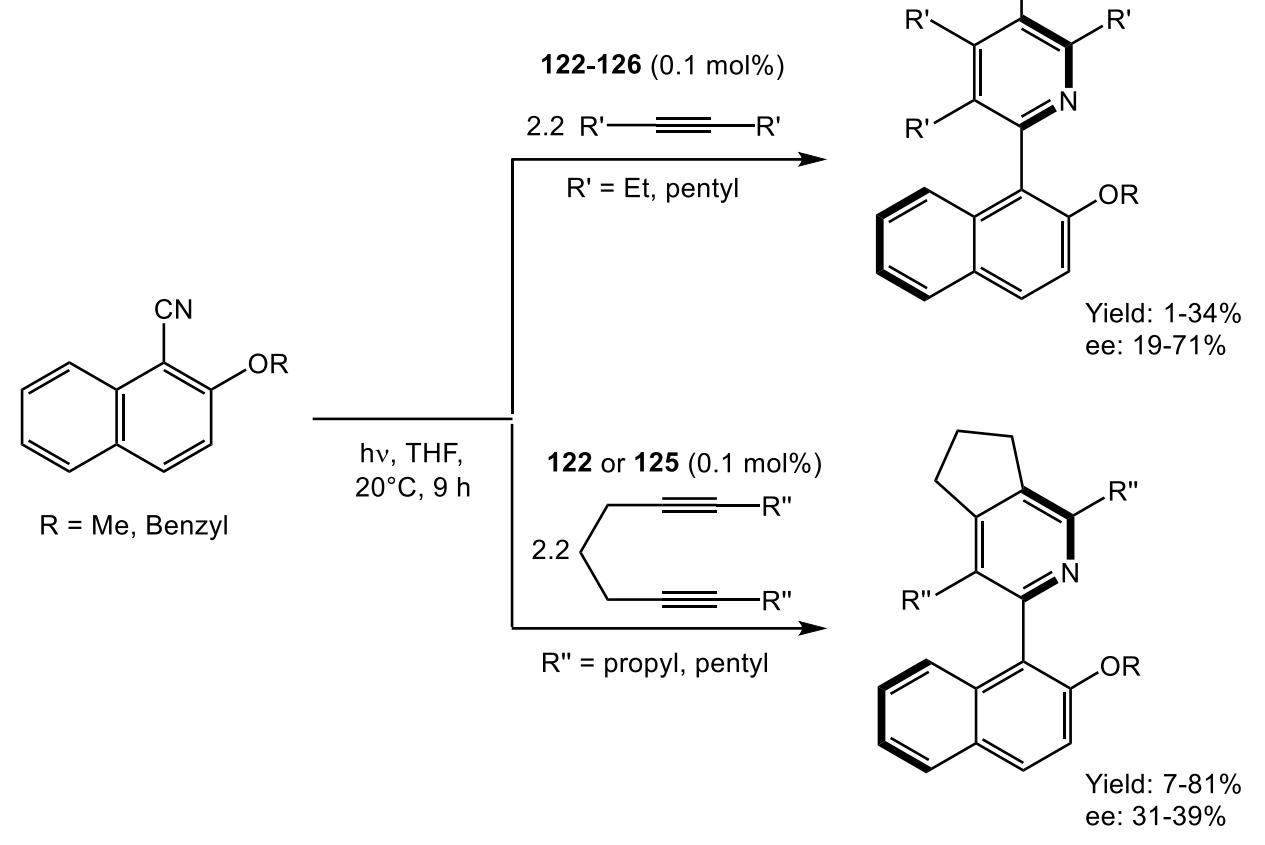

Scheme 7.2 - Cobalt-catalyzed asymmetric cycloadditions of diynes with nitriles [210].<smiles>C=CCCCC#Cc1c(OC)ccc2ccccc12</smiles>

RCN, 125b (1 mol \%)

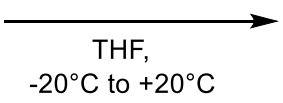
hv $(\lambda=420 \mathrm{~nm})$

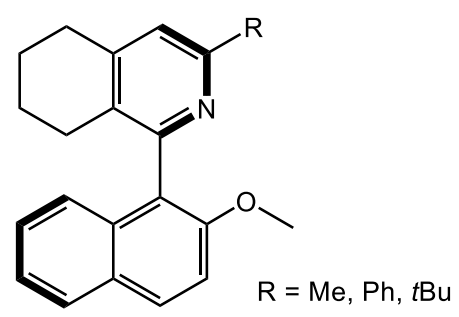

Yield: $86-98 \%$ ee: $82-93 \%$ 
Scheme 7.3 - Preparation of axially chiral biaryls bearing phosphorus functionalities [213].<smiles>[R]P([R])(=O)C#Cc1c(OC)ccc2ccccc12</smiles>

$\mathrm{R}=\mathrm{Ph}, \mathrm{p}-\mathrm{CH}_{3} \mathrm{OC}_{6} \mathrm{H}_{4}$

3.5- $\left(\mathrm{CF}_{3}\right)_{2} \mathrm{C}_{6} \mathrm{H}_{3}, \mathrm{C}_{4} \mathrm{H}_{9}$ 1-adamantyl, $\mathrm{NMe}_{2}$

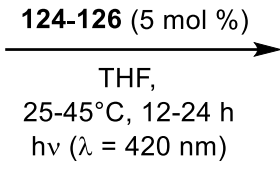

$\mathrm{h} v(\lambda=420 \mathrm{~nm})$

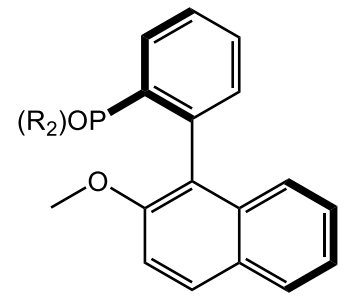

Yield: 8-80\% ee: $12-83 \%$

Scheme 7.4 - Iridium-catalyzed asymmetric [2+2+2] cycloadditions [211].

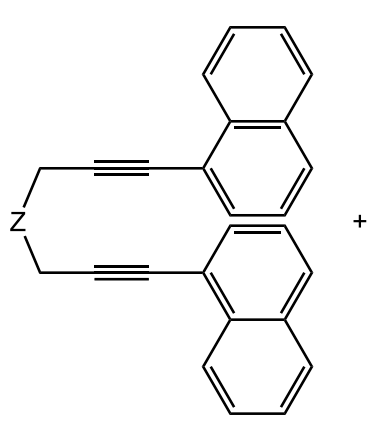

$\overbrace{\text { OR }}^{\mathrm{OR}}$

$[\mathrm{IrCl}(\mathrm{COD})]_{2}(10 \mathrm{~mol} \%)$ $128(20 \mathrm{~mol} \%)$

Xylene $100^{\circ} \mathrm{C}, 1 \mathrm{~h}$

$\mathrm{R}=\mathrm{Me}, \mathrm{TH}$,

TBS, MOM<smiles>[R]OCc1c(CO[R])c(-c2cccc3ccccc23)c2c(c1-c1cccc3ccccc13)C[Z]C2</smiles>

Yield: $74-97 \%$ ee: $>98 \%$

Scheme 7.5 - Iridium-catalyzed asymmetric [2+2+2] cycloadditions [215].

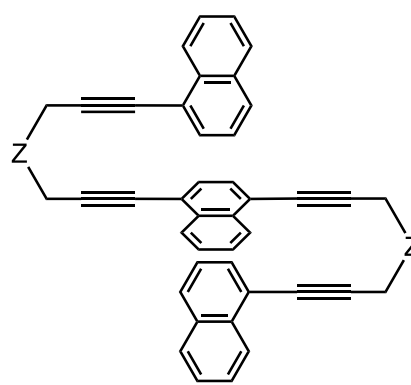

$\mathrm{Z}=\mathrm{O}, \mathrm{NTs}$, cis $-\mathrm{CH}=\mathrm{CH}$<smiles>[R]OCC#CCO[R]</smiles>

$[\mathrm{IrCl}(\mathrm{COD})]_{2}(20 \mathrm{~mol} \%)$ $(S, S)-128$ a (40 mol\%)

\section{Xylene} $100^{\circ} \mathrm{C}, 10 \mathrm{~min}$

$\mathrm{R}=\mathrm{H}, \mathrm{Me}$

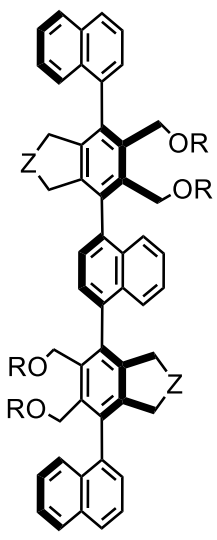

Yield: $55-89 \%$ ee: $>99 \%$ 
Scheme 7.6 - Iridium-catalyzed intramolecular [2+2+2] cycloadditions [217].

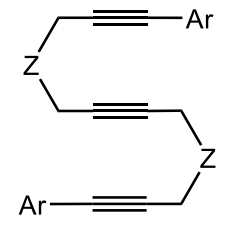

$Z=O, N T s$

$\mathrm{Ar}=$ naphthyl, anthracenyl, 9-phenanthrenyl

4-methoxy-1-naphthyl, 4-methoxy-2-tol,

2-chloro-4-nitrophenyl

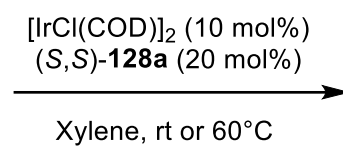

Xylene, rt or $60^{\circ} \mathrm{C}$

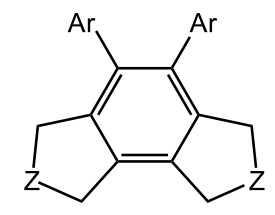

Yield: $68-99 \%$

ee: $87-95 \%$

Scheme 7.7 - Iridium-catalyzed intramolecular [2+2+2] cycloadditions [218].

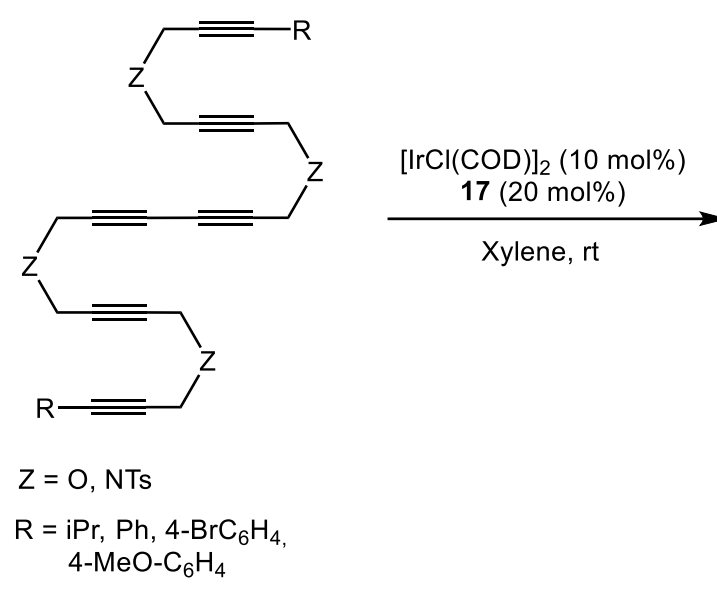

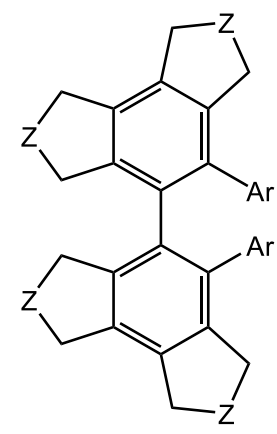

Yield: $55-69 \%$ ee: $>96 \%$

Scheme 7.8 - [4+2] cycloaddition of binaphthalene with monoalkynes [219]. 


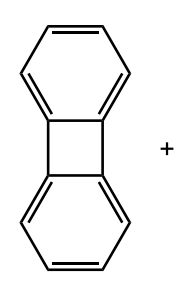<smiles>[R]C#Cc1ccccc1[R]</smiles>

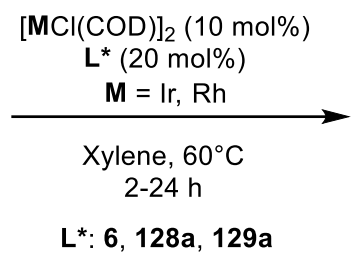

$\mathrm{R}=\mathrm{Me}, \mathrm{OMe}, \mathrm{CF}_{3}$,

$\mathrm{R}^{\prime}=\mathrm{Me}, \mathrm{CH}_{2} \mathrm{OMe}, \mathrm{CH}_{2} \mathrm{OTBS}$, 4-OMePh, 4-COOEtPh<smiles>[R]c1ccccc1-c1c([R])c2ccccc2c2ccccc12</smiles>

Yield: $68-99 \%$ ee: $87-95 \%$

C-C bond activation (oxidative addition)

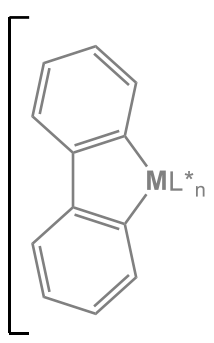

Proposed mechanism

alkyne insertion reductive elimination

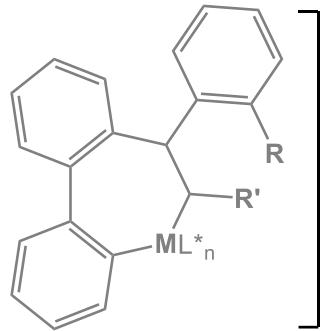

Scheme $7.9-[2+2+2]$ cycloaddition of 1,6-diynes with isocyanates [220].<smiles>CC#CCC(CC#CC)(COC)C(OC)OC</smiles><smiles>COc1ccccc1N=C=O</smiles>

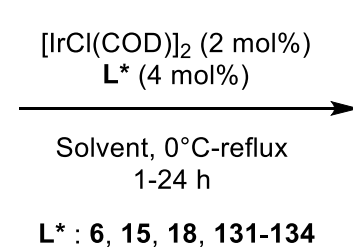

$L^{*}: 6,15,18,131-134$

Solvent: $\mathrm{ClCH}_{2} \mathrm{CH}(\mathrm{Cl}) \mathrm{CH}_{3}$ acetone, THF

1,4-dioxane, $\mathrm{MeOCH}_{2} \mathrm{CH}_{2} \mathrm{OMe}$, benzene<smiles>COc1ccccc1-n1c(C)c2c(c(C)c1=O)CC(C(C)(C)C)(C(C)(C)C)C2</smiles>

ee: $46-91 \%$

Scheme 7.10 - Rhodium-catalyzed [2+2+2] cycloadditions of 1,6-diynes [212].<smiles>[R]c1cccc2cccc(C#CC(=O)OCC#C)c12</smiles>

$\mathrm{R}=\mathrm{Me}, \mathrm{CF}_{3} \mathrm{Cl}$ or $\mathrm{Ar}=1$-naphthyl
$[\operatorname{Rh}\{(S)-135\}]\left[\mathrm{BF}_{4}\right]$ (5 mol\%)

$\mathrm{CH}_{2} \mathrm{Cl}_{2}$, rt, $3 \mathrm{~h}$

$R^{\prime}=A c, H$<smiles>[R]Cc1ccc2c(c1-c1cccc3ccccc13)C(=O)OC2</smiles>

(A)<smiles></smiles>

(B)

$$
\begin{array}{ll}
\mathrm{R}=\mathrm{Me}, \mathrm{R}^{\prime}=\mathrm{Ac}: & 79 \% \text { yield } \\
& \text { (A):(B) } 90: 10 \\
& 87 \% \text { ee }
\end{array}
$$


Scheme 7.11 - Rhodium-catalyzed [2+2+2] cycloadditions [221].
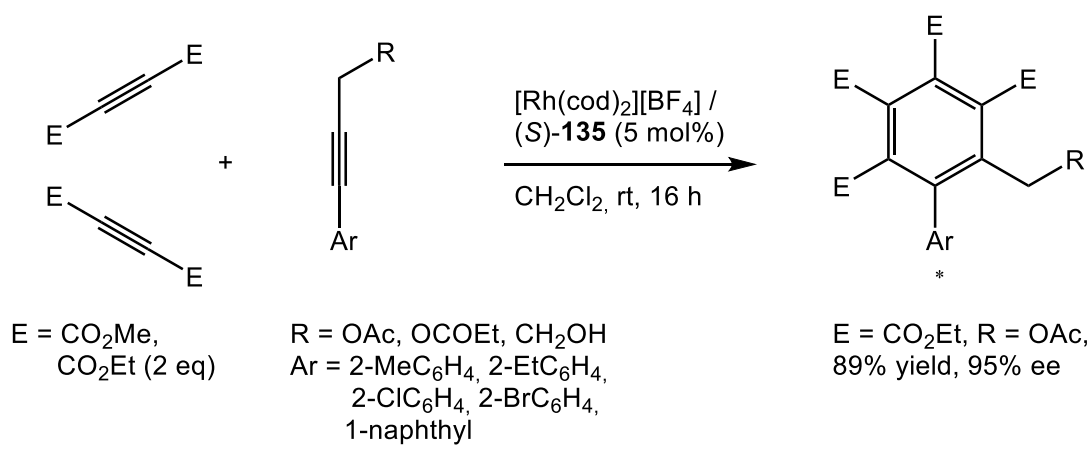

$\mathrm{E}=\mathrm{CO}_{2} \mathrm{Et}, \mathrm{R}=\mathrm{OAc}, \mathrm{Ar}=1-$ naphthyl: $89 \%$ yield, $95 \%$ ee

Scheme 7.12 - Rhodium-catalyzed [2+2+2] cycloadditions of 1,6-diynes [222].
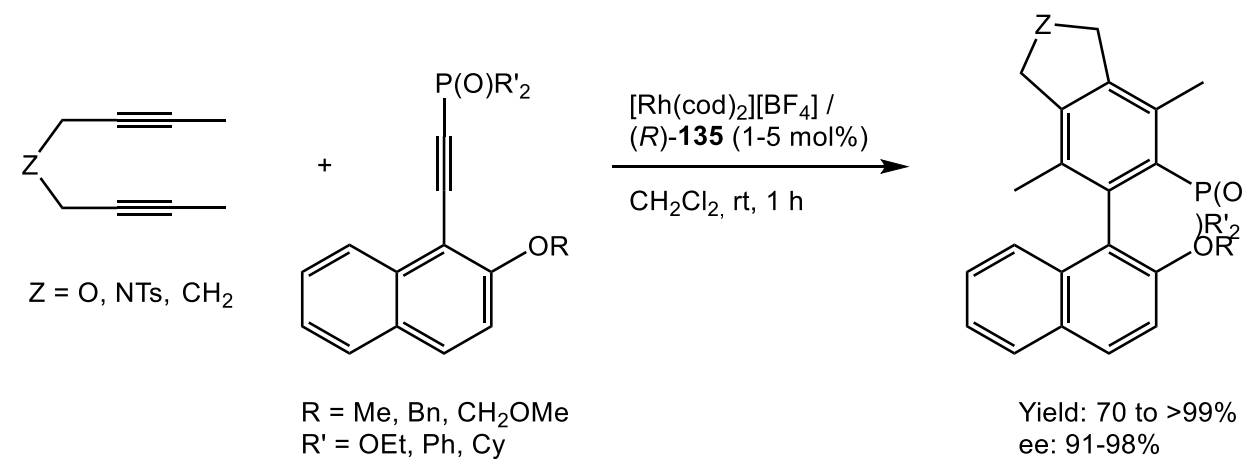

Yield: 70 to $>99 \%$ ee: $91-98 \%$

Scheme 7.13 - Rhodium-catalyzed synthesis of axially chiral biaryl diphosphonates [224].
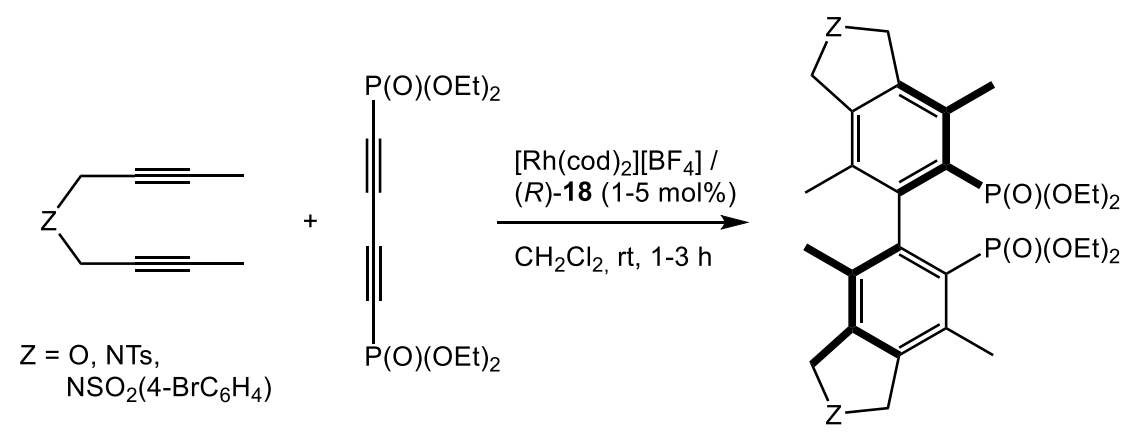

Yield: $65-81 \%$ ee: $>99 \%$

Scheme 7.14 - Rhodium-catalyzed [2+2+2] cycloadditions of 1,6-diynes [226]. 
Type 1:
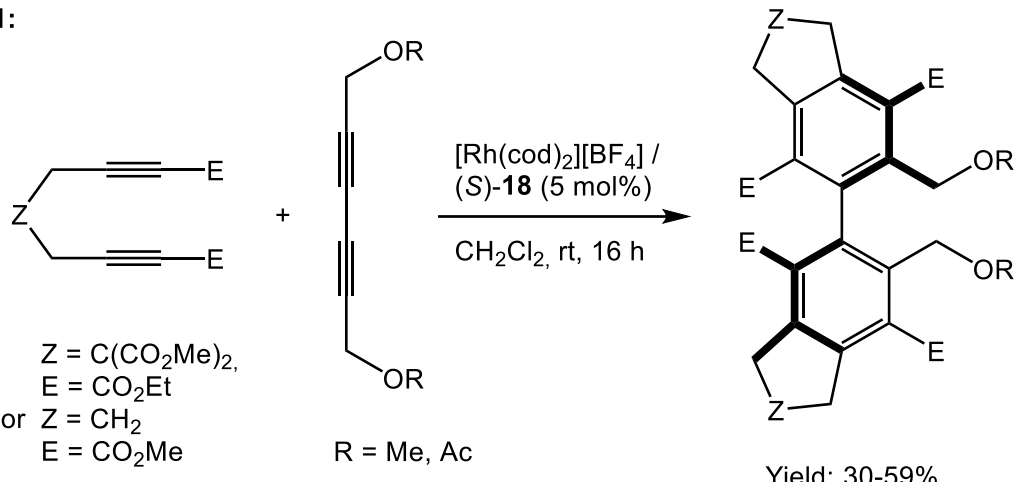

$$
\begin{aligned}
& \text { Yield: } 30-59 \% \\
& \text { ee: } 98 \text { to }>99 \%
\end{aligned}
$$

Type 2:
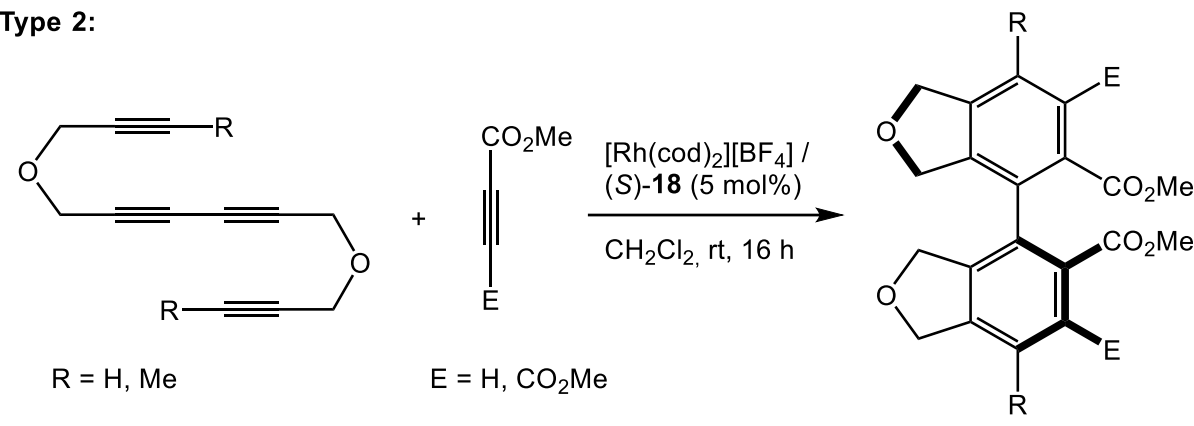

$\mathrm{R}=\mathrm{H}, \mathrm{E}=\mathrm{CO}_{2} \mathrm{Me}:$

$24 \%$ yield, $98 \%$ ee

Scheme 7.15 - Rhodium-catalyzed [2+2+2] cycloadditions of 1,6-diynes [227].

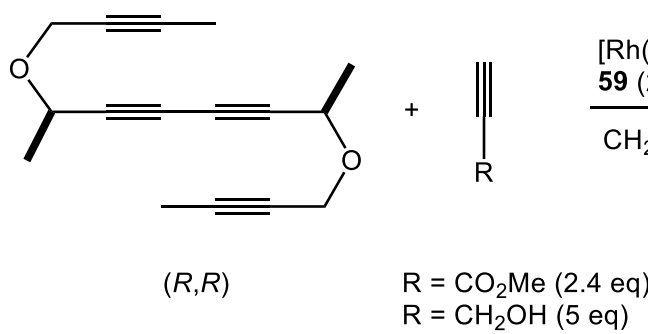

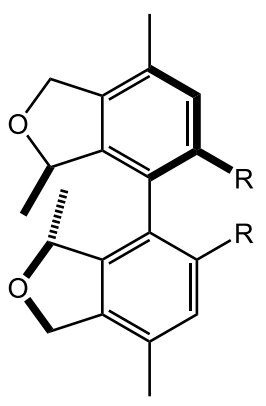

$(R, R)-(\mathrm{a} R),(\mathrm{A})$

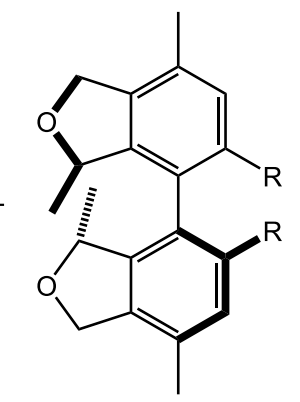

$(R, R)-(\mathrm{aS}),(\mathrm{B})$

$\mathrm{R}=\mathrm{CO}_{2} \mathrm{Me},(R, R)-59: 44 \%$ yield $,(\mathrm{A}) /(\mathrm{B})=100: 0$

$(S, S)-59: 40 \%$ yield, $(A) /(B)=100: 0$

$\mathrm{R}=\mathrm{CH}_{2} \mathrm{OH},(R, R)-59: 28 \%$ yield $,(\mathrm{A}) /(\mathrm{B})=0: 100$

$(S, S)-59: 17 \%$ yield, $(A) /(B)=0: 100$

Scheme 7.16 - Rhodium-catalyzed [2+2+2] cycloadditions of 1,6-diynes [228]. 

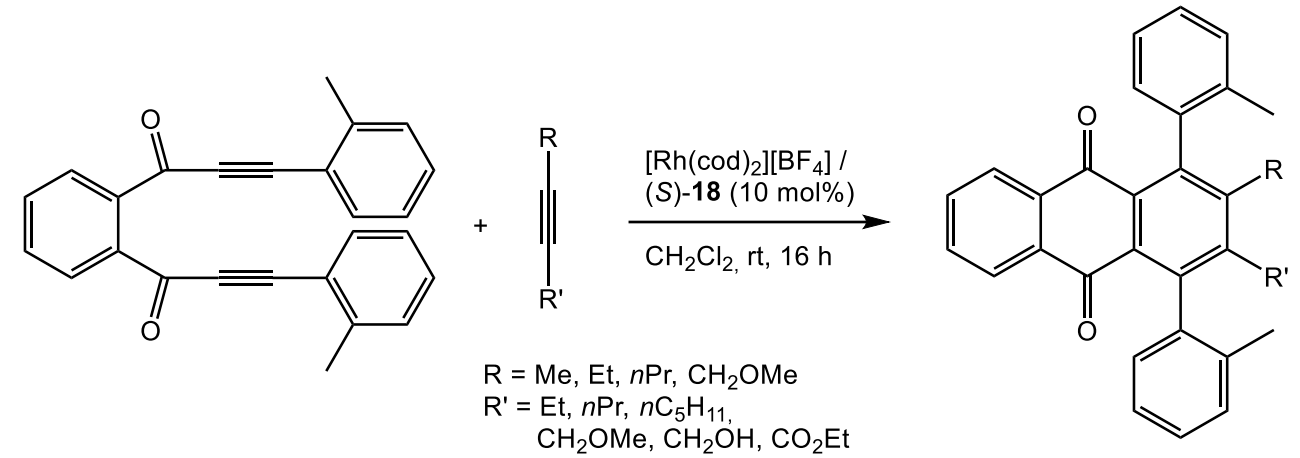

$\mathrm{R}=\mathrm{Me}, \mathrm{R}^{\prime}=n \mathrm{C}_{5} \mathrm{H}_{11}: 80 \%$ yield, $8: 1 \mathrm{dr}$ $97 \%$ ee

Scheme 7.17 - Rhodium-catalyzed [2+2+2] cycloadditions of 1,6-diynes [223].

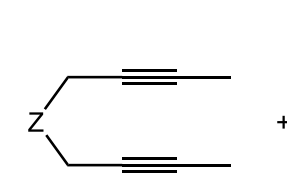

$\mathrm{Z}=\mathrm{O}, \mathrm{NTs}, \mathrm{CH}_{2}$<smiles>[R]Oc1ccc2ccccc2c1C#CC(=O)OC(C)C</smiles>

$\mathrm{R}=\mathrm{Me}, \mathrm{Bn}, \mathrm{CH}_{2} \mathrm{OMe}$
$\left[\mathrm{Rh}(\operatorname{cod})_{2}\right]\left[\mathrm{BF}_{4}\right] /$ (S)-6 (5 mol\%)

$\mathrm{CH}_{2} \mathrm{Cl}_{2}, \mathrm{rt}, 1 \mathrm{~h}$<smiles>[R]c1ccc2ccccc2c1-c1c(C)c2c(c(C)c1C(=O)OC(C)C)C[Z]C2</smiles>

Yield: $93-99 \%$ ee: $89-97 \%$

Scheme 7.18 - Rhodium-catalyzed [2+2+2] cycloadditions of 1,6-diynes [232].

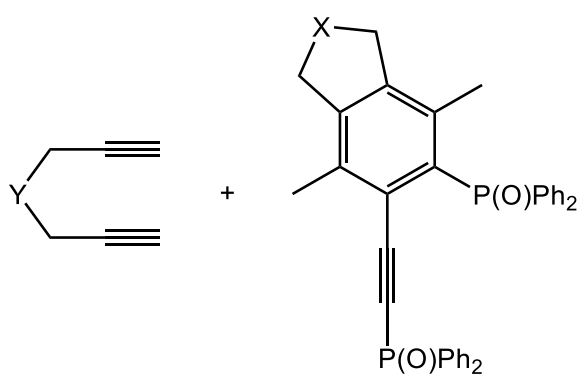

$[\operatorname{Rh}\{(R)-6\}]\left[\mathrm{SbF}_{6}\right]$ $(10 \mathrm{~mol} \%)$

1,2-dichloroethane $80^{\circ} \mathrm{C}, 16 \mathrm{~h}$

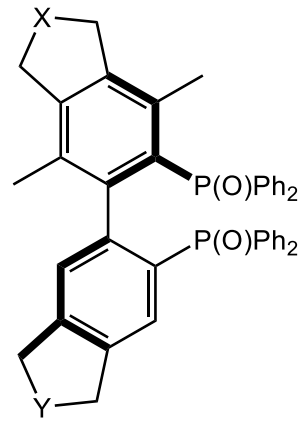

$\mathrm{X}=\mathrm{Y}=\mathrm{C}\left(\mathrm{CO}_{2} \mathrm{Me}\right)_{2}: 79 \%$ yield, $97 \%$ ee $\mathrm{CH}_{2} \mathrm{CH}_{2}: \quad 84 \%$ yield, $96 \%$ ee

Scheme 7.19 - Rhodium-catalyzed [2+2+2] cycloadditions with isocyanates [234]. 

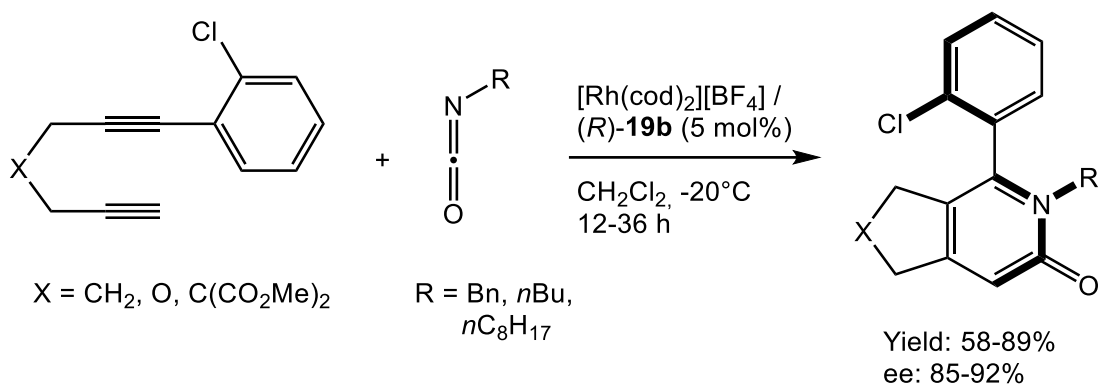

Scheme 7.20 - Rhodium-catalyzed synthesis of axially chiral 1-arylisoquinolines [236].
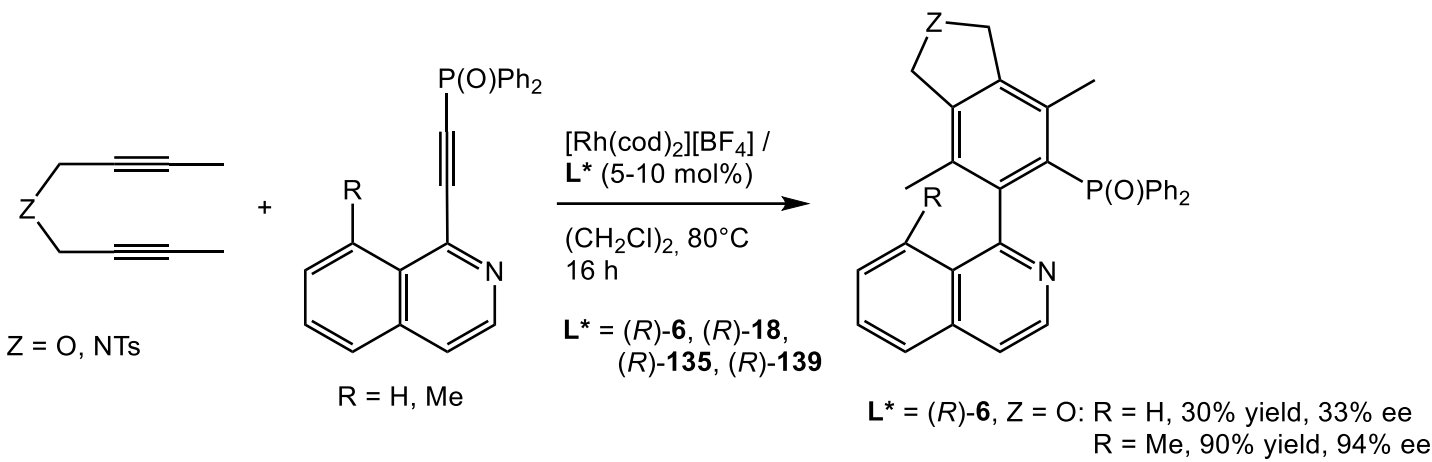

\section{References}

1 M.C. Kozlowski, B.J. Morgan, E.C. Linton, Chem. Soc. Rev. 38 (2009) 3193-3207.

2 G. Bringmann, T. Gulder, T.A.M. Gulder, M. Breuning, Chem. Rev. 111 (2011) 563-639.

3 J. Wencel-Delord, A. Panossian, F.R. Leroux, F. Colobert, Chem. Soc. Rev. 44 (2015) 3418-3430.

4 M. Tamura, J.K. Kochi, J. Am. Chem. Soc. 93 (1971) 1487-1489.

5 K. Tamao, K. Sumitani, M. Kumada, J. Am. Chem. Soc. 94 (1972) 4374-4376.

6 R.J.P. Corriu, J.P. Masse, J. Chem. Soc., Chem. Commun. (1972) 144a-144a.

7 F. Chemla, F. Ferreira, A. Perez-Luna, L. Micouin, O. Jackowski, in:, Metal-Catalyzed Cross-Coupling Reactions and More, Wiley-VCH Verlag GmbH \& Co. KGaA, 2014, pp. 365-422; K. Tamao, J. Organomet. Chem. 653 (2002) 23-26.

8 K. Tamao, A. Minato, N. Miyake, T. Matsuda, Y. Kiso, M. Kumada, Chem. Lett. 4 (1975) $133-136$.

9 T. Hayashi, K. Yamamoto, M. Kumada, Tetrahedron Lett. 15 (1974) 4405-4408.

10 K. Tamao, H. Yamamoto, H. Matsumoto, N. Miyake, T. Hayashi, M. Kumada, Tetrahedron Lett. 18 (1977) 1389-1392.

11 T. Hayashi, K. Hayashizaki, T. Kiyoi, Y. Ito, J. Am. Chem. Soc. 110 (1988) 8153-8156.

12 T. Frejd, T. Klingstedt, Acta Chem. Scand. 43 (1989) 670-675. 
13 L. Wu, A. Salvador, A. Ou, M.W. Shi, B.W. Skelton, R. Dorta, Synlett 24 (2013) 1215 1220.

14 T. Kamikawa, T. Hayashi, Tetrahedron 55 (1999) 3455-3466.

15 F.M. Piller, P. Appukkuttan, A. Gavryushin, M. Helm, P. Knochel, Angew. Chem. Int. Ed. 47 (2008) 6802-6806 ; C.E.I. Knappke, A. Jacobi von Wangelin, Chem. Soc. Rev. 40 (2011) 4948-4962.

16 E. Wenkert, T.W. Ferreira, E.L. Michelotti, J. Chem. Soc., Chem. Commun. (1979) 637638.

17 T. Shimada, Y.-H. Cho, T. Hayashi, J. Am. Chem. Soc. 124 (2002) 13396-13397; Y.-H. Cho, A. Kina, T. Shimada, T. Hayashi, J. Org. Chem. 69 (2004) 3811-3823.

18 P. Knochel, A. Gavryushin, K. Brade, in:, The Chemistry of Organomagnesium Compounds, John Wiley \& Sons, Ltd, 2008, pp. 511-593; A. Boudier, L.O. Bromm, M. Lotz, P. Knochel, Angew. Chem. Int. Ed. 39 (2000) 4414-4435; P. Knochel, W. Dohle, N. Gommermann, F.F. Kneisel, F. Kopp, T. Korn, I. Sapountzis, V.A. Vu, Angew. Chem. Int. Ed. 42 (2003) 4302-4320; F.M. Piller, P. Appukkuttan, A. Gavryushin, M. Helm, P. Knochel, Angew. Chem. Int. Ed. 47 (2008) 6802-6806; J. Adrio, J.C. Carretero, ChemCatChem 2 (2010) 1384-1386.

19 J. Hassan, M. Sevignon, C. Gozzi, E. Schulz, M. Lemaire, Chem. Rev. 102 (2002) 13591469.

20 D. Alberico, M.E. Scott, M. Lautens, Chem. Rev. 107 (2007) 174-238.

21 R.B. Bedford, C.S.J. Cazin, D. Holder, Coord. Chem. Rev. 248 (2004) 2283-2321.

22 N. Miyaura, A. Suzuki, Chem. Rev. 95 (1995) 2457-2483.

23 A. Suzuki, J. Organomet. Chem. 576 (1999) 147-168.

24 S. Kotha, K. Lahiri, D. Kashinath, Tetrahedron, 58 (2002) 9633-9695.

25 F. Bellina, A. Caprita, R. Rossi, Synthesis 15 (2004) 2419-2440.

26 J.-P. Corbet, G. Mignani, Chem. Rev. 106 (2006) 2651-2710.

27 H. Doucet, Eur. J. Org. Chem. (2008) 2013-2030.

28 N. Miyaura, A. Suzuki, J. Chem. Soc., Chem. Commun. (1979) 866-867.

29 B. Rodriguez, A. Bruckmann, T. Rantanen, C. Bolm, Adv. Synth. Catal. 349 (2007) 22132233.

30 E. Colacino, J. Martinez, F. Lamaty, L.S. Patrikeeva, L.L. Khemchyan, V.P. Ananikov, I.P. Beletskaya, Coord. Chem. Rev. 256 (2012) 2893-2920.

31 S. Chowdhury, R.S. Mohan, J.L. Scott, Tetrahedron 63 (2007) 2363-2389; T. Welton, Coord. Chem. Rev. 248 (2004) 2459-2477; J.P. Hallett, T. Welton, Chem. Rev. 111 (2011) 3508-3576.

32 K.H. Shaughnessy, in:, Metal-Catalyzed Reactions in Water, Wiley-VCH Verlag GmbH \& Co. KGaA, 2013, pp. 1-46; R. Franzen, Y. Xu, Can. J. Chem. 83 (2005) 266-272.

33 B.K. Singh, N. Kaval, S. Tomar, E. Van der Eycken, V.S. Parmar, Org. Process Res. Dev. 12 (2008) 468-474.

34 W. Shu, L. Pellegatti, M. O. Oberli, S. L. Buchwald, Angew. Chem. Int. Ed. 50 (2011) 10665-10669. 
35 D. Cantillo, C.O. Kappe, ChemCatChem 6 (2014) 3286-3305.

36 C.A. Busacca, D.R. Frandrick, J.J. Song, C.H. Senanayake, Adv. Synth. Catal. 353 (2011) 1825-1864.

37 T.E. Jacks, D.T. Belmont, C.A Briggs, N.M. Horne, G.D. K.G.L. Kanter, J.J. Krikke, R.J. McCabe, J.G. Mustakis, T.N. Nanninga, G.S. Risedorph, R.E. Seamans, R. Skeean, D.D. Winkle, T.M. Zennie, Org. Proc. Res. Dev. 8 (2004) 201-212.

38 R.J. Lundgren, M. Stradiotto, Chem. Eur. J. 18 (2012) 9758-9769.

39 N. T. S. Phan, M. Van Der Sluys, C. W. Jones, Adv. Synth. Catal. 348 (2006) 609-679.

40 M. Uemura, K. Kamikawa, J. Chem. Soc., Chem. Commun. (1994) 2697-2698.

41 K. Kamikawa, M. Uemura, Tetrahedron Lett. 37 (1996) 6359-6362.

42 S.G. Nelson, M.A. Hilfiker, Org. Lett. 1 (1999) 1379-1382.

43 B.H. Lipshutz, J.M. Keith, Angew. Chem. Int. Ed. 38 (1999) 3530-3533.

44 P.-E. Broutin, F. Colobert, Org. Lett. 5 (2003) 3281-3284.

45 K.C. Nicolaou, C.N.C. Boddy, S. Bräse, N. Winssinger, Angew. Chem. Int. Ed. 38 (1999) 2096-2152.

46 C.K. Hazra, Q. Dherbassy, J. Wencel-Delord, F. Colobert, Angew. Chem. Int. Ed. 53 (2014) 13871-13875.

47 O. Baudoin, Eur. J. Org. Chem. (2005) 4223-4229.

48 A. Ros, B. Estepa, P. Ramírez-López, E. Álvarez, R. Fernández, J.M. Lassaletta, J. Am. Chem. Soc. 135 (2013) 15730-15733.

49 V. Bhat, S. Wang, B.M. Stoltz, S.C. Virgil, J. Am. Chem. Soc. 135 (2013) 16829-16832.

50 A.N. Cammidge, K.V.L. Crépy, Chem. Commun. (2000) 1723-1724.

51 J. Yin, S.L. Buchwald, J. Am. Chem. Soc. 122 (2000) 12051-12052.

52 D. Zhang, Q. Wang, Coord. Chem. Rev. 286 (2015) 1-16.

53 A.A.C. Braga, G. Ujaque, F. Maseras, Organometallics 25 (2006) 3647-3658.

54 L.J. Goossen, D. Koley, H.L. Hermann, W. Thiel, Organometallics 25 (2006) 54-67.

55 Y.-L. Huang, C.-M. Weng, F.-E. Hong, Chem. Eur. J. 14 (2008) 4426-4433.

56 H.M. Senn, T. Ziegler, Organometallics 23 (2004) 2980-2988.

57 L.J. Goossen, D. Koley, H.L. Hermann, W. Thiel, Organometallics 24 (2005) 2398-2410.

58 F. Barrios-Landeros, J.F. Hartwig, J. Am. Chem. Soc. 127 (2005) 6944-6945.

59 F. Proutiere, F. Schoenebeck, Angew. Chem. Int. Ed. 50 (2011) 8192-8195.

60 A.A.C. Braga, N.H. Morgon, G. Ujaque, A. Lledos, F. Maseras, J. Organomet. Chem. 691 (2006) 4459-4466.

61 C. Sicre, A.A.C. Braga, F. Maseras, M.M. Cid, Tetrahedron 64 (2008) 7437-7443.

62 B.P. Carrow, J.F. Hartwig, J. Am. Chem. Soc. 133 (2011) 2116-2119.

63 A.J.J. Lennox, G.C. Lloyd-Jones, Angew. Chem. Int. Ed. 52 (2013) 7362-7370.

64 E. Zuidema, P.W.N.M. van Leeuwen, C. Bo, Organometallics 24 (2005) 3703-3710. 
65 M. Perez-Rodriguez, A.C.C.Braga, M. Garcia-Melchor, M.H. Perez-Temprano, J.A. Casares, G. Ujaque, A.R. de Lera, R. Alvarez, F. Maseras, P. Espinet, J. Am. Chem. Soc. 131 (2009) 3650-3657.

66 M. Perez-Rodriguez, A.C.C. Braga, A.R. de Lera, F. Maseras, R. Alvarez, P. Espinet, Organometallics 29 (2010) 4983-4991.

67 M.R. Mason, J.G. Verkade, Organometallics 9 (1990) 864-865.

68 P.A. McLaughin, J.G. Verkade, Organometallics 17 (1998) 5937-5940.

69 C.M. Frech, G. Leitus, D. Milstein, Organometallics 17 (1998) 5937-5940.

70 C.S. Wei, G.H.M. Davies, O. Soltani, J. Albrecht, Q. Gao, C. Pathirana, Y. Hsiao, S. Tummala, M.D. Eastgate, Angew. Chem. Int. Ed. 52 (2013) 5822-5826.

71 R. Martin, S.L. Buchwald, Acc. Chem. Res. 41 (2008) 1461-1473.

72 S. Teo, Z. Weng, T. S. A. Hor, Organometallics 25 (2006) 1199-1205.

73 Z. Weng, S. Teo, T.S.A. Hor, Acc. Chem. Res. 40 (2007) 676-684.

74 A. F. Littke, C. Dai, G. C. Fu, J. Am. Chem. Soc. 122 (2000) 4020-4028.

75 F. Schoenebeck, K. N. Houk, J. Am. Chem. Soc. 132 (2010) 2496-2497.

76 F. Proutiere, F. Schoenebeck, Angew. Chem. Int. Ed. 50 (2011) 8192-8195.

77 A.A.C. Braga, N.H. Morgon, G. Ujaque, F. Maseras, J. Am. Chem. Soc. 127 (2005) 92989307.

78 C. Amatore, A. Jutan, G. Le Duc, Chem. Eur. J. 17 (2011) 2492-2503.

79 C. Amatore, A. Jutan, G. Le Duc, Angew. Chem. Int. Ed. 51 (2012) 1371-1382.

80 C. Amatore, G. Le Duc, A. Jutan, Chem. Eur. J. 19 (2013) 10082-10093.

81 A.N. Cammidge, K.V.L. Crépy, Tetrahedron 60 (2004) 4377-4386.

82 A.-S. Castanet, F. Colobert, P.-E. Broutin, M. Obringer, Tetrahedron: Asymmetry 13 (2002) 659-665.

83 K. Mikami, T. Miyamoto, M. Hatano, Chem. Commun. (2004) 2082-2083.

84 T.J. Donohoe, C.R. Jones, A.F. Kornahrens, L.C.A. Barbosa, L.J. Walport, M.R. Tatton, M. O’Hagan, A.H. Rathi, D.B. Baker, J. Org. Chem. 78 (2013) 12338-12350.

85 K. Sawai, R. Tatumi, T. Nakahodo, H. Fujihara, Angew. Chem. Int. Ed. 47 (2008) $6917-$ 6919.

86 K. Mori, Y. Kondo, H. Yamashita, Phys. Chem. Chem. Phys. 11 (2009) 8949-8954.

87 X. Shen, G.O. Jones, D.A. Watson, B. Bhayana, S.L. Buchwald, J. Am. Chem. Soc. 132 (2010) 11278-11287.

88 A. Herrbach, A. Marinetti, O. Baudoin, D. Guénard, F. Guéritte, J. Org. Chem. 68 (2003) 4897-4905.

89 W. Wu, S. Wang, Y. Zhou, Y. He, Y. Zhuang, L. Li, P. Wan, L. Wang, Z. Zhou, L. Qiu, Adv. Synth. Catal. 354 (2012) 2395-2402.

90 L. Sun, W.-M. Dai, Tetrahedron 67 (2011) 9072-9079.

91 S. Wang, J. Li, T. Miao, W. Wu, Q. Li, Y. Zhuang, Z. Zhou, L. Qiu, Org. Lett. 14 (2012) 1966-1969. 
92 a) Y. Zhou, S. Wang, W. Wu, Q. Li, Y. He, Y. Zhuang, L. Li, J. Pang, Z. Zhou, L.Qiu, Org. Lett. 15 (2013) 5508-5511; b) Y. Zhou, X. Zhang, H. Liang, Z. Cao, X. Zhao, Y. He, S. Wang, J. Pang, Z. Zhou, Z. Ke, L. Qiu, ACS Catal. 4 (2014) 1390-1397.

93 A. Togni, C. Breutel, A. Schnyder, F. Spindler, H. Landert, A. Tijani, J. Am. Chem. Soc. 116 (1994) 4062-4066

94 H.-U. Blaser, W. Brieden, B. Pugin, F. Spindler, M. Studer, A. Togni, Top. Catal. 19 (2002) 3-16.

95 H.-U Blaser, H. P. Buser, K. Coers, R. Hanreich, H. P. Jalett, E. Jelsch, B. Pugin, H. D. Schneider, F. Spindler, A. Wegmann, Chimia 53 (1999) 275-280.

96 L.-X. Dai, X.-L. Hou in: L.-X. Dai, X.-L. Hou (Eds.), Chiral ferrocenes in asymmetric catalysis, Wiley-VCH, 2010, p 10.

97 M. Genov, A. Almorín, P. Espinet, Tetrahedron: Asymmetry 18 (2007) 625-627.

98 M. Genov, A. Almorín, P. Espinet, Chem. Eur. J. 12 (2006) 9346-9352.

99 T. Hayashi, T. Mise, M. Fukushima, M. Kagotani, N. Nagashima, Y. Hamada, A. Matsumoto, S. Kawakami, M. Konishi, K. Yamamoto, M. Kumada, Bull. Chem. Soc. Jpn. 53 (1980) 1138-1151.

100 T. Hayashi, K. Hayashizaki, T. Kiyoi, Y. Ito, J. Am. Chem. Soc. 110 (1988) 8153-8156.

101 J. F. Jensen, M. Johannsen, Org. Lett. 5 (2003) 3025-3028.

102 D. Schaarschmidt, H. Lang, Eur. J. Inorg. Chem. 2010 (2010) 4811-4821.

103 S. Bayda, A. Cassen, J.-C. Daran, C. Audin, R. Poli, E. Manoury, E. Deydier, J. Organomet. Chem. $772-773$ (2014) 258-264.

104 D. Schaarschmidt, M. Grumbt, A. Hildbrandt, H. Lang, Eur. J. Org. Chem. (2014) 66766685.

105 S.S. Zalesskiy, V. Ananikov, Organometallics 31 (2012) 2302-2309.

106 Y. Uozumi, Y. Matsuura, T. Arakawa, Y.M.A. Yamada, Angew. Chem. Int. Ed. 48 (2009) 2708-2710.

107 T. Yamamoto, Y. Akai, Y. Nagata, M. Suginome, Angew. Chem. Int. Ed. 50 (2011) 88448847.

108 V.R. Jumde, A. Iuliano, Tetrahedron: Asymmetry 22 (2011) 2151-2155.

109 T. Kamei, A.H. Sato, T. Iwasawa, Tetrahedron Lett. 52 (2011) 2638-2641.

110 A. Balanta Castillo, B.F. Perandones, E. Zangrando, S. Gladiali, C. Godard, C. Claver, J. Organomet. Chem. 743 (2013) 31-36.

111 W. Tang, N.D. Patel, G. Xu, X. Xu, J. Savoie, S. Ma, M.-H. Hao, S. Keshipeddy, A.G. Capacci, X. Wei, Y. Zhang, J.J. Gao, W. Li, S. Rodriguez, B.Z. Lu, N.K. Yee, C.H. Senanayake, Org. Lett. 14 (2012) 2258-2261.

112 G. Xu, W. Fu, G. Liu, C.H. Senanayake, W. Tang, J. Am. Chem. Soc. 136 (2014) 570573.

113 A. Ros, B. Estepa, A. Bermejo, E. Alvarez, R. Fernandez, J.M. Lassaletta, J. Org. Chem. 77 (2012) 4740-4750.

114 Y. Motoyama, H. Narusawa, H. Nishiyama, Chem. Commun. (1999) 131-132. 
115 Y. Motoyama, Y. Koga, H. Nishiyama, Tetrahedron 57 (2001) 853-860.

116 Y. Motoyama, Y. Koga, K. Kobayashi, K. Aoki, H. Nishiyama, Chem.- Eur. J. 8 (2002) 2968-2975.

117 T. Takemoto, S. Iwasa, H. Hamada, K. Shibatomi, M. Kameyama, Y. Motoyama, H. Nishiyama, Tetrahedron Lett. 48 (2007) 3397-3401.

118 A. Bermejo, A. Ros, R. Fernández, J.M. Lassaletta, J. Am. Chem. Soc. 130 (2008) 1579815799.

119 G. Grach, G. Pieters, A. Dinut, V. Terrasson, R. Medimagh, A. Bridoux, V. Razafimahaleo, A. Gaucher, S. Marque, J. Marrot, D. Prim, R. Gil, J.G. Planas, C. Viñas, I. Thomas, J.-P. Roblin, Y. Troin, Organometallics 30 (2011) 4074-4086.

120 Reviews: E.A.B. Kantchev, C.J. O’Brien, M.G. Organ, Angew. Chem. Int. Ed. 46 (2007) 2768-2813; G.C. Fortman, S.P. Nolan, Chem. Soc. Rev. 40 (2011) 5151-5169. Early examples: C.W.K. Gstöttmayr, V.P.W. Böhm, E. Herdtweck, M. Grosche, W.A. Herrmann, Angew. Chem. Int. Ed. 41 (2002) 1363-1365; G. Altenhoff, R. Goddard, C.W. Lehmann, F. Glorius, Angew. Chem. Int. Ed. 42 (2003) 3690-3693.

121 Reviews on chiral NHCs : V. César, S. Bellemin-Laponnaz, L.H. Gade, Chem. Soc. Rev. 33 (2004) 619-636 ; F. Wang, L. Liu, W. Wang, S. Li, M. Shi, Coord. Chem. Rev. 256 (2012) 804-853.

122 Review : J. Vignolle, X. Cattoën, D. Bourissou, Chem. Rev. 109 (2009) 3333-3384 ; R.W. Alder, P.R. Allen, M. Murray, A.G. Orpen, Angew. Chem. Int. Ed. Engl. 35 (1996) 1121-1123; G.D. Frey, W.A. Herrmann, J. Organomet. Chem. 690 (2005) 5876-5880; Applications in Suzuki-Miyaura: A.I. Moncada, M.A. Khan, L.M. Slaughter, Tetrahedron Lett. 46 (2005) 1399-1403; A.I. Moncada, J.M. Tanski, L.M. Slaughter, J. Organomet. Chem. 690 (2005) 6247-6251; A.I. Moncada, S. Manne, J.M. Tanski, L.M. Slaughter, Organometallics 25 (2006) 491-505; B. Dhudshia, A.N. Thadani, Chem. Commun. (2006) 668-670; D. Kremzow, G. Seidel, C.W. Lehmann, A. Fürstner, Chem.- Eur. J. 11 (2005) 1833-1853. Chiral ADCs: Y.A. Wanniarachchi, L.M. Slaughter, Chem. Commun. (2007) 3294-3296; Y.A. Wanniarachchi, Y. Kogiso, L.M. Slaughter, Organometallics 27 (2008) 21-24.

123 D.R. Snead, S. Inagaki, K.A. Abboud, S. Hong, Organometallics 29 (2010) 1729-1739.

124 N. Debono, A. Labande, E. Manoury, J.-C. Daran, R. Poli, Organometallics 29 (2010) 1879-1882; P. Loxq, N. Debono, S. Gulcemal, J.-C. Daran, E. Manoury, R. Poli, B. Cetinkaya, A. Labande, New J. Chem. 38 (2014) 338-347.

125 G. Shigeng, J. Tang, D. Zhang, Q. Wang, Z. Chen, L. Weng, J. Organomet. Chem. 700 (2012) 223-229.

126 Y. Li, J. Tang, J. Gu, Q. Wang, P. Sun, D. Zhang, Organometallics 33 (2014) 876-884.

127 L. Yang, P. Guan, P. He, Q. Chen, C. Cao, Y. Peng, Z. Shi, G. Pang, Y. Shi, Dalton Trans. 41 (2012) 5020-5025.

128 L. Wu, L. Falivene, E. Drinkel, S. Grant, A. Linden, L. Cavallo, R. Dorta, Angew. Chem. Int. Ed. 51 (2012) 2870-2873.

129 L. Benhamou, C. Besnard, E.P. Kündig, Organometallics 33 (2014) 260-266.

130 S.-S. Zhang, Z.-Q. Wang, M.-H. Xu, G.-Q. Lin, Org. Lett. 12 (2010) 5546-5549.

131 C. Fischer, G.C. Fu, J. Am. Chem. Soc. 127 (2005) 4594-4595. 
132 M. Genov, B. Fuentes, P. Espinet, B. Pelaz, Tetrahedron: Asymmetry 17 (2006) 25932595.

133 J. Yamaguchi, K. Itami, in:, Metal-Catalyzed Cross-Coupling Reactions and More, Wiley-VCH Verlag GmbH \& Co. KGaA, 2014, pp. 1315-1387.

134 O. Baudoin, Chem. Soc. Rev. 40 (2011) 4902-4911; D.A. Colby, A.S. Tsai, R.G. Bergman, J.A. Ellman, Acc. Chem. Res. 45 (2012) 814-825; G. Song, F. Wang, X. Li, Chem. Soc. Rev. 41 (2012) 3651-3678; G. Rouquet, N. Chatani, Angew. Chem. Int. Ed. 52 (2013) 11726-11743; A.R. Kapdi, Dalton Trans. 43 (2014) 3021-3034; special issue on Directed C-H Functionalization, Adv. Synth. Catal. 356 (2014) 1381-1644; review on asymmetric C-H functionalization: J. Wencel-Delord, F. Colobert, Chem.- Eur. J. 19 (2013) 14010-14017.

135 F. Kakiuchi, P. Le Gendre, A. Yamada, H. Ohtaki, S. Murai, Tetrahedron: Asymmetry 11 (2000) 2647-2651.

136 a) K. Yamaguchi, J. Yamaguchi, A. Studer, K. Itami, Chem. Sci. 3 (2012) 2165-2169; b) K. Yamaguchi, H. Kondo, J. Yamaguchi, K. Itami, Chem. Sci. 4 (2013) 3753-3757.

137 J. Zheng, S.-L. You, Angew. Chem. Int. Ed. 53 (2014) 13244-13247.

138 B. Ye, N. Cramer, J. Am. Chem. Soc. 135 (2013) 636-639.

139 S. E. Allen, R.R. Walvoord, R. Padilla-Salinas, M. Kozlowski, Chem. Rev. 113 (2013) 6234-6458.

140 For recent reviews on chiral binaphthols: (a) S. Yu, L. Pu, Tetrahedron 71 (2015) 745 772. (b) M. M. Pereira, M.J. F. Calvete, R. M. B. Carrilhoa, A. Abreu, Chem. Soc. Rev. 42 (2013) 6990-7027. (c) J.-M. Brunel, Chem. Rev. 105 (2005) 857-897. (d) M. Shibasaki, N. Yoshikawa, Chem. Rev. 102 (2002) 2187-2209.

141 For recent reviews: (a) M. C. Kozlowski, B. J. Morgan, E. C. Linton, Chem. Soc. Rev. 38 (2009) 3193-3207. (b) H. Wang, Chirality 22 (2010) 827-837.

142 B. Feringa, H; Wynberg, Bioorg. Chem. 7 (1978) 397-398.

143 J. Brussee, A. C. A. Jansen, Tetrahedron Lett. 24 (1983) 3261-3262.

144 J. Brussee, A. C. A. Jansen, Tetrahedron 41 (1985) 3313-3319.

145 M. Smrcina, M. Lorenc, V. Hanus, P. Sedmers, P. Kocovsky, J. Org. Chem. 57 (1992) 1917-1920.

146 M. Smrcina, J. Polakova, S. Vyskocyl, P. Kocovsky, J. Org. Chem. 58 (1993) 4534-4538.

147 M. Nakajima, K. Kanayama, I. Miyoshi, S. Hasimoto, Tetrahedron Lett. 36 (1995) 95199520 .

148 M. Nakajima, I. Miyoshi, K. Kanayama, S. Hasimoto, M. Noji, K. Koga, J. Org. Chem. 64 (1999) 2264-2271.

149 F. Prause, B. Arensmeyer, B. Frohlich, M. Breuning, Catal. Sci. Technol. 5 (2015) 22152226.

150 X. Li, J. Yang, M. C. Kozlowski, Org. Lett. 3 (2001) 1137-1140.

151 X. Li, J. B. Hewgley, C. A. Mulrooney, J. Yang, M. C. Kozlowski, J. Org. Chem. 68 (2003) 5500-5511.

152 C. A. Mulrooney, X. Li, E. S. Di Virgilio, M. C. Kozlowski, J. Am. Chem. Soc. 125 (2003) 6856-6857. 
153 M. C. Kozlowski, X. Li, P. J. Carroll, Z. Xu, Organometallics 21 (2002) 4513-4522.

154 J. B. Hewgley, S. S. Stahl, M. C. Kozlowski, J. Am. Chem. Soc. 130 (2008) 12232-12233.

155 E. S. Di Virgilio, E. C. Dugan, M. C. Kozlowski, Org. Lett. 9 (2007) 385-388.

156 M. C. Kozlowski, E. C. Dugan, E. S. Di Virgilio, K. Maksimenka, G. Bringmann, Adv. Synth. Catal. 349 (2007) 583-594.

157 C. A. Mulrooney, B. J. Morgan, X. Li, M. C. Kozlowski, J. Org. Chem. 75 (2010) 1629.

158 E. M. O’Brien, B. J. Morgan, M. C. Kozlowski, Angew. Chem. Int. Ed. 47 (2008) 68776880 .

159 C. A. Mulrooney, B. J. Morgan, X. Li, M. C. Kozlowski, J. Org. Chem. 75 (2010) $57-$ 68.

160 C. A. Mulrooney, B. J. Morgan, X. Li, M. C. Kozlowski, J. Org. Chem. 75 (2010) 4456.

161 B. J. Morgan, S. Dey, S. W. Johnson, M. C. Kozlowski, J. Am. Chem. Soc. 131 (2009) 9413-9425.

162 C. A. Mulrooney, B. J. Morgan, X. Li, M. C. Kozlowski, J. Org. Chem. 75 (2010) 3043.

163 E. E. Podlesny, M. C. Kozlowski, Org. Lett. 14 (2012) 1408-1411.

164 E. E. Podlesny, M. C. Kozlowski, J. Org. Chem. 78 (2013) 466-476.

165 A. Casseli, G. B. Giovenzana, G. Palmisano, M. Sisti, T. Pilati, Tetrahedron : Asymmetry 14 (2003) 1451-1454.

166 J. Gao, J. H. Reibenspies, A. E. Martell, Angew. Chem. Int. Ed. 42 (2003) 6008-6012.

167 K. H. Kim, D.-W. Lee, Y.-S. Lee, D.-H. Ko, D.-C. Ha, Tetrahedron 60 (2004) 9037-9042.

168 S.K. Alamsetti, E. Poonguzhali, D. Ganapathy, G. Sekar, Adv. Synth. Catal. 355 (2013) 2803-2808.

169 T. Temma, S. Habaue, Tetrahedron Lett. 46 (2005) 5655-5657.

170 T. Temma, B. Hatano, S. Habaue, Tetrahedron 62 (2006) 8559-8563.

171 S. Habaue, Y. Takahashi, T. Temma, Tetrahedron Lett. 48 (2007) 7301-7304.

172 P. Adao, S. Barroso, M. F. N. N. Carvalho, C. M. Teixera, M. L. Kuznetsov, J. C. Pessoa, Dalton Trans., 44 (2015) 1612-1626.

173 T. Hamada, H. Ishida, S. Usui, Y. Watanabe, K. Tsumura, K. Ohkubo, J. Chem. Soc., Chem. Commun. (1993) 909-911.

174 T. Osa, Y. Kashiwagi, Y. Yanagisawa, J. M. Bobbit, J. Chem. Soc., Chem. Commun. (1994) 2535-2537.

175 R. Irie, K. Matusani, T. Katsuki, Synlett (2000) 1433-1436.

176 S.-W. Hon, C.-H. Li, J.-H. Kuo, N. B. Barhate, Y.-H. Liu, Y. Wang, C.-T. Chen, Org. Lett. 3 (2001) 869-872.

177 C.-Y. Chu, D.-R. Hwang, S.-K. Wang, B.-J. Uang, Chem. Commun. (2001) 980-981. 
178 C.-Y. Chu, D.-R. Hwang, S.-K. Wang, B.-J. Uang, Tetrahedron : Asymmetry 14 (2003) 53-55.

179 N. B. Barhate, C.-T. Chen, Org. Lett. 4 (2002) 2529-2532.

180 Z. Luo, Q. Liu, L. Gong, X. Cui, A. Mi, Y. Jiang, Chem. Commun. (2002) 914-915.

181 Z. Luo, Q. Liu, L. Gong, X. Cui, A. Mi, Y. Jiang, Angew. Chem. Int. Ed. 41 (2002) $4532-$ 4535 .

182 Q. Liu, N. Xie, Z. Luo, X. Cui, L. Cun, A. Mi, Y. Jiang, L. Gong, J. Am. Chem. Soc. 129 (2007) 13927-13938.

183 Q. Liu, N. Xie, Z. Luo, X. Cui, L. Cun, L. Gong, A. Mi, Y. Jiang, J. Org. Chem. 68 (2003) 7921-7924.

184 H. Somei, Y. Asano, T. Yoshida, S. Takizawa, H. Yamataka, H. Sasai, Tetrahedron Lett. 45 (2004) 1841-1844.

185 S. Takizawa, T. Katayama, C. Kameyana, K. Otnisuka, T. Suzuki, T. Yanagida, T. Kawai, H. Sasai, Chem. Commun. (2008) 1810-1812.

186 S. Takizawa, T. Katayama, H. Somei, Y. Asano, T. Yoshida, C. Kameyana, D. Rajesh, K. Otnisuka, T. Suzuki, M. Mikami, H. Yamataka, D. Jayaprakash, H. Sasai, Tetrahedron 64 (2008) 3361-3371.

187 S. Takizawa, T. Katayama, H. Sasai, Chem. Commun. (2008) 4113-4122.

188 E. E. Podlesny, M. C. Kozlowski, J. Nat. Prod. 75 (2012) 1125-1129.

189 J. Dai, Y. Liu, Y.-D. Zhou, D. G. Nagle, J. Nat. Prod. 70 (2007) 1824-1826.

190 M. Tada, T. Taniike, L. M. Kantam, Y. Isawara, Chem. Commun. (2004) 2542-2543.

191 M. Tada, N. Kojima, Y. Izumi, T. Taniike, Y. Isawara, J. Phys. Chem. B. (2005) 99059916.

192 M. Tada, Y. Isawara, Chem. Commun. (2006) 2833-2844.

193 H. Egami, T. Katsuki, J. Am. Chem. Soc. 131 (2009) 6082-6083.

194 H. Egami, K. Matsumoto, T. Oguma, T. Kunisu, T. Katsuki, J. Am. Chem. Soc. 132 (2010) 13633-13635.

195 For a review about naphthyl polymers: L. Pu, Chem. Rev. 98 (1998) 2405-2494.

196 X. Xie, P.-W; Phuan, M. C. Kozlowski, Angew. Chem. Int. Ed. 42 (2003) 2168-2170.

197 B. J. Morgan, X. Xie, P.-W; Phuan, M. C. Kozlowski, J. Org. Chem. 72 (2007) 61716182.

198 S. Habaue, T. Seko, Y. Okamoto, Macromolecules 36 (2003) 2604-2608.

199 S. Habaue, T. Seko, Y. Okamoto, Macromolecules 35 (2002) 2437-2439.

200 S. Habaue, T. Seko, Y. Okamoto, Polymer 44 (2003) 7377-7381; S. Habaue, T. Seko, M; Isonaga, H. Ajiro, Y. Okamoto, Polymer J. 35 (2003) 592-597.

201 S. Habaue, H. Ajiro, Y. Yoshii, T. Hirasa, J. Polym. Sci., Part A : Polym. Chem. 42 (2004) 4528-4534.

202 S. Habaue, S. Murakami, H. Higashimura, J. Polym. Sci., Part A : Polym. Chem. 43 (2005) 5872-5878. 
203 S. Habaue, H. Aoyagi, S. Murakami, H. Higashimura, Polym. Bull. 59 (2007) 303-310.

204 S. Murakami, S. Habaue, H. Higashimura, Polymer 48 (2007) 6565-6570.

205 Selected general reviews: J.A. Varela, C. Saá, Chem. Rev. 103 (2003) 3787-3802; P.R. Chopade, J. Louie, Adv. Synth. Catal. 348 (2006) 2307-2327; B. Heller, M. Hapke, Chem. Soc. Rev. 36 (2007) 1085-1094; N. Agenet, O. Buisine, F. Slowinski, V. Gandon, C. Aubert, M. Malacria, in:, Organic Reactions, John Wiley \& Sons, Inc., 2004; B.R. Galan, T. Rovis, Angew. Chem. Int. Ed. 48 (2009) 2830-2834; G. Dominguez, J. PerezCastells, Chem. Soc. Rev. 40 (2011) 3430-3444; N. Weding, M. Hapke, Chem. Soc. Rev. 40 (2011) 4525-4538; D.L.J. Broere, E. Ruijter, Synthesis 44 (2012) 2639-2672; Y. Shibata, K. Tanaka, Synthesis 44 (2012) 323-350. Reviews on stereoselective $[2+2+2]$ cycloadditions: T. Shibata, K. Tsuchikama, Org. Biomol. Chem. 6 (2008) 1317-1323; K. Tanaka, Chem. Asian J. 4 (2009) 508-518; M. Amatore, C. Aubert, Eur. J. Org. Chem 2015 (2015) 265-286.

206 P. Garcia, Y. Evanno, P. George, M. Sevrin, G. Ricci, M. Malacria, C. Aubert, V. Gandon, Chem.- Eur. J. 18 (2012) 4337-4344.; M. Parera, A. Dachs, M. Solà, A. PlaQuintana, A. Roglans, Chem.- Eur. J. 18 (2012) 13097-13107.

207 N. Mori, S. Ikeda, K. Odashima, Chem. Commun. (2001) 181-182 ; S. Ikeda, H. Kondo, T. Arii, K. Odashima, Chem. Commun. (2002) 2422-2423 ; Y. Ura, Y. Sato, H. Tsujita, T. Kondo, M. Imachi, T. Mitsudo, J. Mol. Catal. A: Chem. 239 (2005) 166171 ; K. Tanaka, G. Nishida, M. Ogino, M. Hirano, K. Noguchi, Org. Lett. 7 (2005) 3119-3121 ; J. Hara, M. Ishida, M. Kobayashi, K. Noguchi, K. Tanaka, Angew. Chem. Int. Ed. 53 (2014) 2956-2959.

208 Y. Sato, T. Nishimata, M. Mori, J. Org. Chem. 59 (1994) 6133-6135.

209 I.G. Stará, I. Starý, A. Kollárovič, F. Teplý, Š. Vyskočil, D. Šaman, Tetrahedron Lett. 40 (1999) 1993-1996.

210 A. Gutnov, B. Heller, C. Fischer, H.-J. Drexler, A. Spannenberg, B. Sundermann, C. Sundermann, Angew. Chem. Int. Ed. 43 (2004) 3795-3797.

211 T. Shibata, T. Fujimoto, K. Yokota, K. Takagi, J. Am. Chem. Soc. 126 (2004) 83828383.

212 K. Tanaka, G. Nishida, A. Wada, K. Noguchi, Angew. Chem. Int. Ed. 43 (2004) 65106512.

213 B. Heller, A. Gutnov, C. Fischer, H.-J. Drexler, A. Spannenberg, D. Redkin, C. Sundermann, B. Sundermann, Chem. Eur. J. 13 (2007) 1117-1128.

214 M. Hapke, K. Kral, C. Fischer, A. Spannenberg, A. Gutnov, D. Redkin, B. Heller, J. Org. Chem. 75 (2010) 3993-4003.

215 T. Shibata, K. Tsuchikama, Chem. Commun. (2005) 6017-6019.

216 T. Shibata, Y. Arai, K. Takami, K. Tsuchikama, T. Fujimoto, S. Takebayashi, K. Takagi, Adv. Synth. Catal. 348 (2006) 2475-2483.

217 T. Shibata, K. Tsuchikama, M. Otsuka, Tetrahedron: Asymmetry 17 (2006) 614-619.

218 T. Shibata, S. Yoshida, Y. Arai, M. Otsuka, K. Endo, Tetrahedron 64 (2008) 821-830.

219 T. Shibata, G. Nishizawa, K. Endo, Synlett. 5 (2008) 765-768.

220 G. Onodera, M. Suto, R. Takeushi, J. Org. Chem. 77 (2012) 908-920. 
221 K. Tanaka, G. Nishida, M. Ogino, M. Hirano, K. Noguchi, Org. Lett. 7 (2005) 31193121.

222 G. Nishida, K. Noguchi, M. Hirano, K. Tanaka, Angew. Chem. Int. Ed. 46 (2007) 3951-3954.

223 S. Ogaki, Y. Shibata, K. Noguchi, K. Tanaka, J. Org. Chem. 76 (2011) 1926-1929.

224 G. Nishida, S. Ogaki, Y. Yusa, T. Yokozawa, K. Noguchi, K. Tanaka, Org. Lett. 10 (2008) 2849-2852.

225 F. Mori, N. Fukawa, K. Noguchi, K. Tanaka, Org. Lett. 13 (2011) 362-365.

226 G. Nishida, N. Suzuki, K. Noguchi, K. Tanaka, Org. Lett. 8 (2006) 3489-3492.

227 A. Mori, T. Araki, Y. Miyauchi, K. Noguchi, K. Tanaka, Eur. J. Org. Chem 2013 (2013) 6774-6778.

228 K. Tanaka, T. Suda, K. Noguchi, M. Hirano, J. Org. Chem. 72 (2007) 2243-2246.

229 T. Shibata, T. Chiba, H. Hirashima, Y. Ueno, K. Endo, Angew. Chem. Int. Ed. 48 (2009) 8066-8069; T. Shibata, T. Uchiyama, H. Hirashima, K. Endo, Pure Appl. Chem. 83 (2011) 597-605.

230 J.-F. Wen, W. Hong, K. Yuan, T.C.W. Mak, H.N.C. Wong, J. Org. Chem. 68 (2003) 8918-8931; H.-Y. Peng, C.-K. Lam, T.C.W. Mak, Z. Cai, W.-T. Ma, Y.-X. Li, H.N.C. Wong, J. Am. Chem. Soc. 127 (2005) 9603-9611; H. Huang, T. Stewart, M. Gutmann, T. Ohhara, N. Niimura, Y.-X. Li, J.-F. Wen, R. Bau, H.N.C. Wong, J. Org. Chem. 74 (2009) 359-369; H. Huang, C.-K. Hau, C.C.M. Law, H.N.C. Wong, Org. Biomol. Chem. 7 (2009) 1249-1257.

231 A. Rajca, H. Wang, P. Bolshov, S. Rajca, Tetrahedron 57 (2001) 3725-3735.

232 S. Doherty, C.H. Smyth, R.W. Harrington, W. Clegg, Organometallics 27 (2008) 48374840 .

233 L. Garcia, A. Roglans, R. Laurent, J.-P. Majoral, A. Pla-Quintana, A.-M. Caminade, Chem. Commun. 48 (2012) 9248-9250.

234 K. Tanaka, A. Wada, K. Noguchi, Org. Lett. 7 (2005) 4737-4739.

235 K. Tanaka, Y. Takahashi, T. Suda, M. Hirano, Synlett (2008) 1724-1728.

236 N. Sakiyama, D. Hojo, K. Noguchi, K. Tanaka, Chem.- Eur. J. 17 (2011) 1428-1432.

237 M. Ishii, F. Mori, K. Tanaka, Chem.- Eur. J. 20 (2014) 2169-2174.

238 J. Oppenheimer, R.P. Hsung, R. Figueroa, W.L. Johnson, Org. Lett. 9 (2007) 39693972; J. Oppenheimer, W.L. Johnson, R. Figueroa, R. Hayashi, R.P. Hsung, Tetrahedron 65 (2009) 5001-5012.

239 M. Augé, M. Barbazanges, A.T. Tran, A. Simonneau, P. Elley, H. Amouri, C. Aubert, L. Fensterbank, V. Gandon, M. Malacria, J. Moussa, C. Ollivier, Chem. Commun. 49 (2013) 7833-7835. 